\title{
Seismic Isolation of Major Advanced Reactor Systems for Economic Improvement and Safety Assurance
}

Idaho National Laboratory

University at Buffalo

TerraPower

X-Energy

Southern Nuclear Development, LLC

September 2020

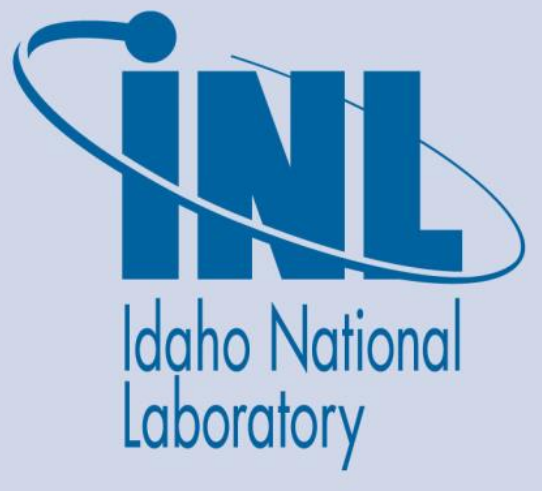

The INL is a U.S. Department of Energy National Laboratory operated by Battelle Energy Alliance 


\section{DISCLAIMER}

This information was prepared as an account of work sponsored by an agency of the U.S. Government. Neither the U.S. Government nor any agency thereof, nor any of their employees, makes any warranty, expressed or implied, or assumes any legal liability or responsibility for the accuracy, completeness, or usefulness, of any information, apparatus, product, or process disclosed, or represents that its use would not infringe privately owned rights. References herein to any specific commercial product, process, or service by trade name, trade mark, manufacturer, or otherwise, does not necessarily constitute or imply its endorsement, recommendation, or favoring by the U.S. Government or any agency thereof. The views and opinions of authors expressed herein do not necessarily state or reflect those of the U.S. Government or any agency thereof. 
INL/EXT-20-59608

\section{Seismic Isolation of Major Advanced Reactor Systems for Economic Improvement and Safety Assurance}

Chandrakanth Bolisetti, William Hoffman, and Justin Coleman, Idaho National Laboratory

Sai Sharath Parsi, Kaivalya Lal, and Andrew Whittaker, University at Buffalo Michael Cohen and Kevin Kramer, TerraPower

Paul Kirchman and Harlan Bowers, X-Energy Jason Redd, Southern Nuclear Development, LLC

September 2020

Idaho National Laboratory

Idaho Falls, Idaho 83415

www.inl.gov

Prepared for the

U.S. Department of Energy

Under DOE Idaho Operations Office

Contract DE-AC07-05ID14517 



\section{EXECUTIVE SUMMARY}

The nuclear industry is currently at a severe economic disadvantage, mainly due to the extremely large capital costs involved constructing in new nuclear power plants. Recent nuclear constructions have seen large cost overruns and schedule delays, making the nuclear sector less attractive to investors. Advanced reactor concepts currently under development in the United States are striving to improve the economics of nuclear power primarily by using passive and 'walk-away' safe technologies. The recently published report, 'Future of Nuclear Energy in a Carbon-Constrained World' (Buongiorno et al., 2018) by the Massachusetts Institute of Technology Energy Institute (MIT EI) has shown that a significant contributor to the capital cost of NPPs is the 'civil works' i.e., the construction of the balance of plant (BoP: all SSCs except those involved in power generation, e.g., reactor vessel) such as the buildings, containment dome, foundation, etc., which amount to almost half of the overnight capital cost. It also suggests that using advanced construction technologies such as seismic isolation and high-performance concrete to significantly reduce the capital costs of advanced reactors. It is therefore imperative that innovations in advanced reactors are not only in the reactor technology, but also in the design, procurement, and construction of the balance of plant and in the civil works. This report demonstrates the application of two cost-cutting solutions on generic advanced reactor designs. These solutions include, (1) seismic base isolation, and (2) risk- and cost-based seismic design optimization including seismic isolation of individual components.

To demonstrate the benefits of seismic base isolation, two different advanced reactor buildings are considered: one housing a molten chloride fast reactor (building \#1) and the other housing a high temperature gas reactor (building \#2). Three pieces of safety-class equipment (reactor vessel, steam generator, and a control rod drive mechanism housing) are included in each building and three-dimensional numerical models of the buildings coupled with the safetyclass equipment are developed. The numerical models are used to quantify the seismic 'penalty' on the equipment (i.e., the increase in the material or the cost of the equipment with an increase in the seismic capacity), as well as to develop preliminary designs for the isolation systems for the buildings. Results show that the seismic penalty on the reactor and the steam generator vessels installed in the conventional (fixed base) buildings can be significant. To increase the seismic capacity of the vessels from an input peak ground acceleration (PGA) to the building of $0.0 \mathrm{~g}$ (operational loads only) to $0.5 \mathrm{~g}$, the weights of the reactor vessel and the steam generator must be increased from 100 units to 165 units and 190 units, respectively in building $\# 1$ and to 160 units and 120 units, respectively in building \#2. If the buildings are base isolated, a 10\% increase in the vessel wall thickness from that required for operational performance would provide sufficient seismic capacity to resist earthquake shaking of up to PGA of $0.5 \mathrm{~g}$. The seismic penalty on the safety-class equipment is therefore greatly reduced if seismic isolation is implemented. If the buildings are base isolated, reactor designs certified to operate in regions of low seismicity ( $0.1 \mathrm{~g}$ PGA herein) could be deployed at regions of higher seismicity up to $0.5 \mathrm{~g}$ PGA. Thus, base isolation provides a clear pathway to Nth-of-a-Kind (NoaK) construction of advanced reactors and could result in significant reductions in capital costs.

The latter part of the report describes the development and demonstration of a risk- and costbased seismic design optimization methodology of a generic nuclear facility (GNF) that houses a safety system representative of both existing and advanced nuclear power plants. This methodology involves iteratively adjusting the seismic design of the safety system until a

minimum capital cost is reached while satisfying the necessary performance goals (see Figure 
ES-1). This framework uses the open-source seismic analysis and risk assessment software, MASTODON for the risk assessment, and a genetic algorithm in the optimization software, Dakota for the optimization. The seismic design of the GNF is characterized by the seismic fragilities of its systems, structures and components (SSCs), that represent their seismic integrity. The design iterations involve changing the seismic fragilities or using component seismic isolation to drastically reduce the seismic demands on the SSC. The seismic 'penalty' is quantified through a cost function for each SSC that relates its capital cost to its seismic fragility. Since most of the advanced reactors are still under development, a generic probabilistic risk assessment model including the event tree, fault tree, and seismic fragilities are developed for the GNF. Also, given the lack of data to relate the capital costs of SSCs to their seismic capacities, generic cost functions representing the seismic cost penalty are developed for the SSCs in the GNF.

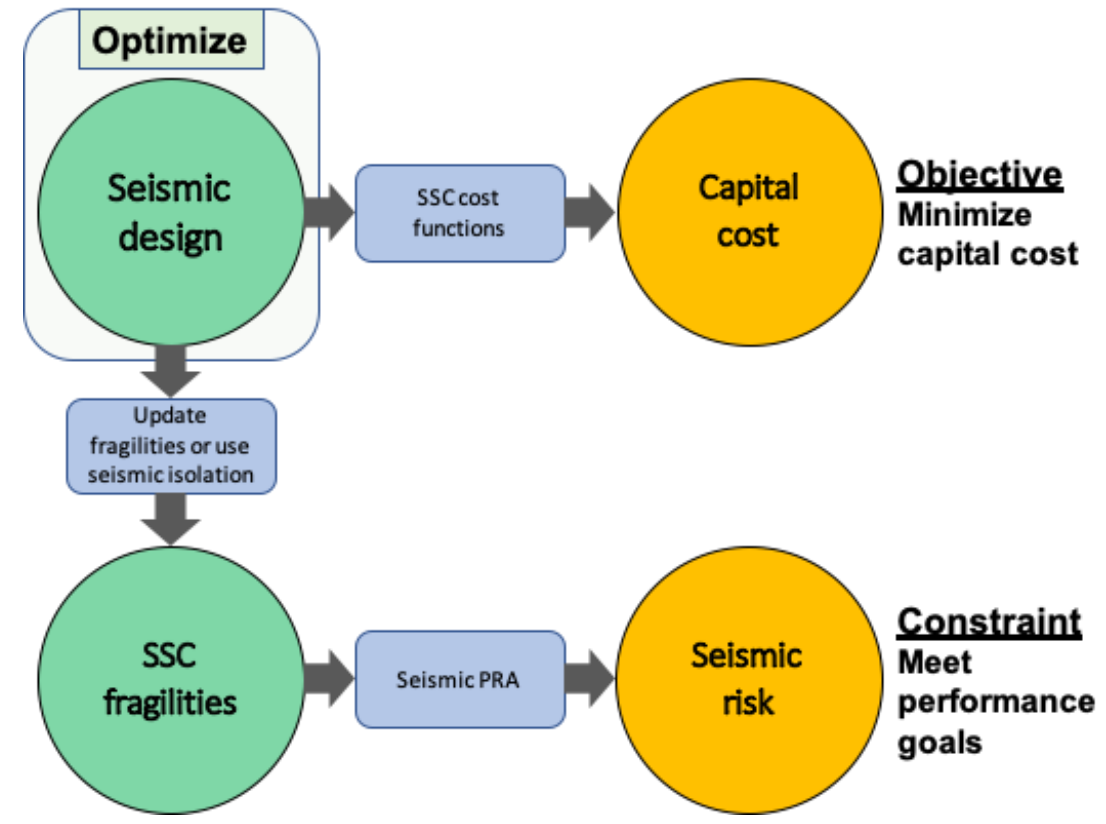

Figure ES-1: Schematic describing the seismic design optimization framework including component seismic isolation

Results show that the design optimization of the GNF without including seismic isolation resulted in a $16 \%$ capital cost reduction while meeting the safety goals (see Table ES-1). This is a significant reduction and demonstrates that intelligent 'fine-tuning' of the design can result in large capital cost savings. A comparison of the costs and risk contributions before and after optimization shows that the optimization algorithm automatically rewards redundancy in design and defense in depth and translates them into reductions in capital cost. Additionally, the algorithm ensures that the cost profile of the SSCs is in coherence with the risk profile, i.e., the cost investment is prioritized for SSCs that most contribute to the risk and provide the most benefit-to-cost ratio. Including component seismic isolation in the design optimization resulted in an additional $5 \%$ cost reduction with a total cost reduction of $21 \%$. This optimization is performed with an assumption that the seismic isolation cost is about $10 \%$ of the nominal cost of the SSC, which is likely overestimated. In practice, cost reductions due to seismic isolation can be more significant, especially since it enables the use of off-the-shelf components eliminates the SSC qualification costs and the corresponding engineering and design costs and potentially 
accelerates the regulatory process. The results of the design optimization showed that for all the SSCs, the seismic fragility is either reduced or the SSC is seismically isolated. This demonstration shows that the design optimization of complex systems like nuclear power plants is possible and can result in significant cost savings without compromising safety. The optimization framework developed here is versatile and scalable and can be extended to real facilities. This framework can also be extended to provide design guidance such as adjusting the locations of various SSCs, or seismically isolating the optimal set of SSCs to minimize capital cost.

Table ES-1: Summary of the capital cost and seismic risk results calculated using design optimization with and without component seismic isolation

\begin{tabular}{|l|c|c|}
\cline { 2 - 3 } \multicolumn{1}{c|}{} & $\begin{array}{c}\text { Capital cost } \\
\text { (USD millions) }\end{array}$ & Seismic risk \\
\hline $\begin{array}{l}\text { Initial, unoptimized, and } \\
\text { not seismically isolated }\end{array}$ & 99.20 & $5.16 \times 10^{-5}$ \\
\hline $\begin{array}{l}\text { Optimized, without including } \\
\text { component seismic isolation }\end{array}$ & 83.22 & $4.92 \times 10^{-5}$ \\
\hline $\begin{array}{l}\text { Optimized, including } \\
\text { component seismic isolation }\end{array}$ & 78.61 & $4.86 \times 10^{-5}$ \\
\hline
\end{tabular}




\section{CONTENTS}

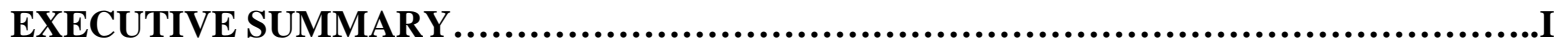

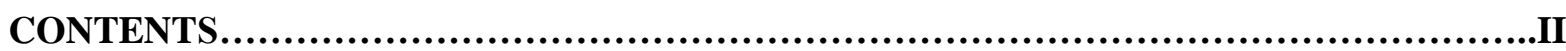

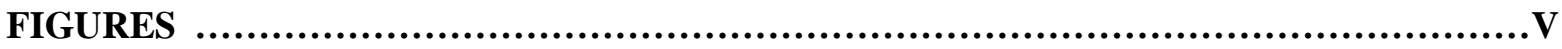

TABLES......................................................................................

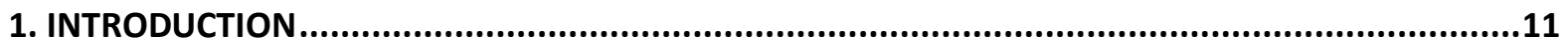

1.1. Reducing capital costs of new-build nuclear power plants ..................................................11

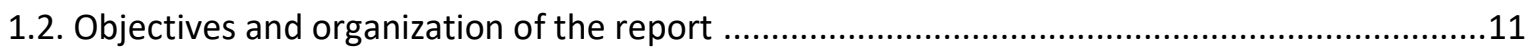

2. SEISMIC BASE ISOLATION OF TWO GENERIC ADVANCED REACTOR BUILDINGS .........................13

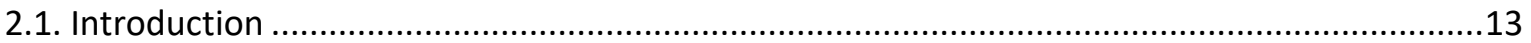

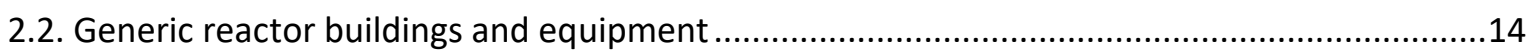

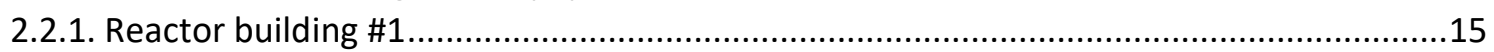

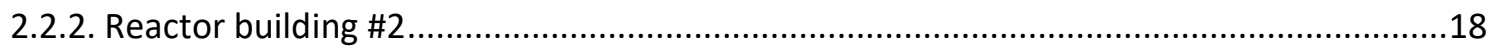

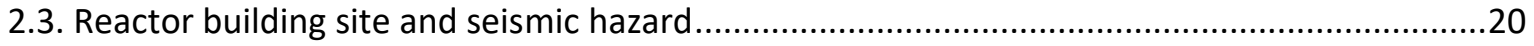

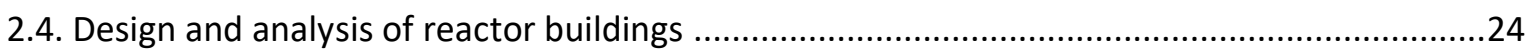

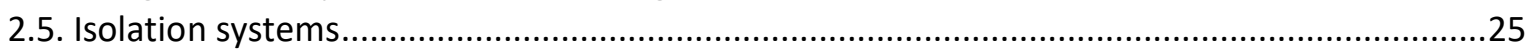

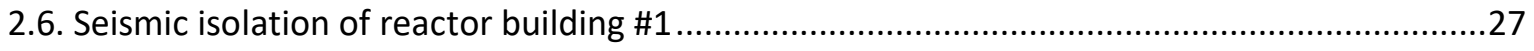

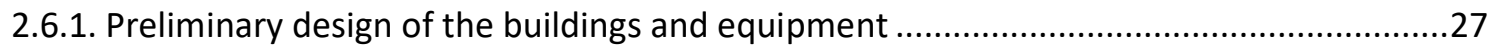

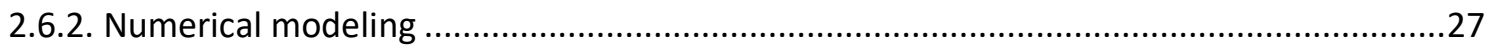

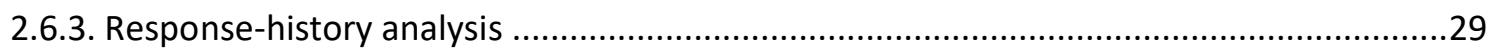

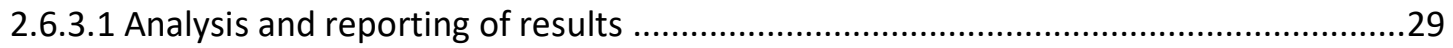

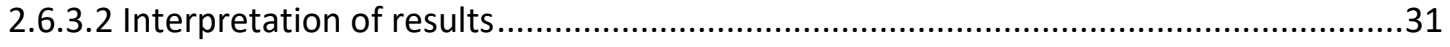

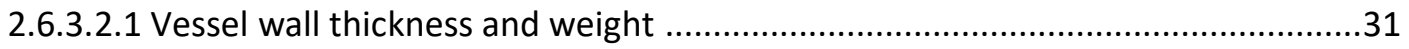

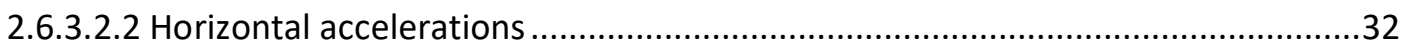

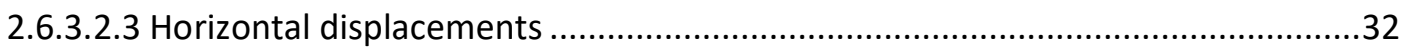

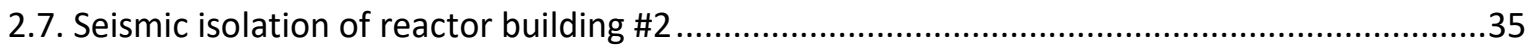

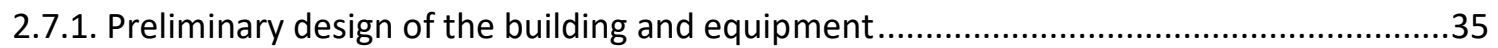

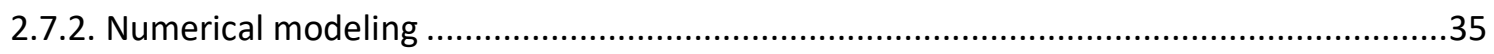

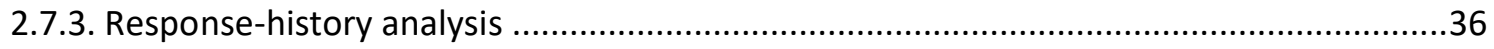

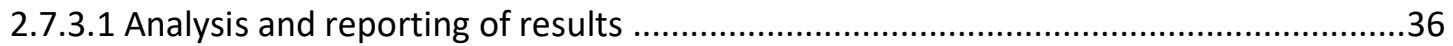

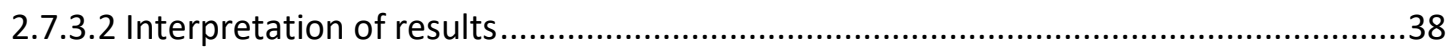

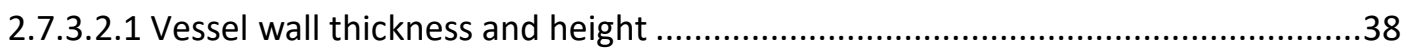

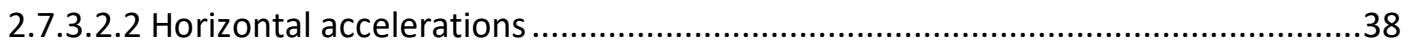

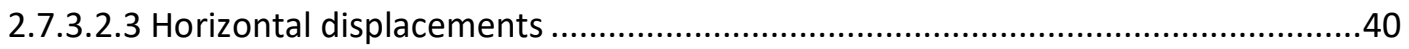

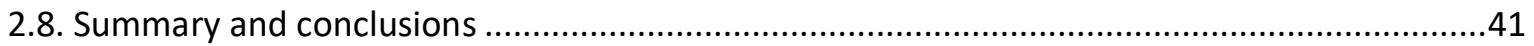

3. RISK- AND COST-BASED DESIGN OPTIMIZATION OF A GENERIC SAFETY SYSTEM .....................43

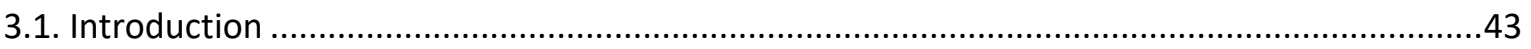

3.2. Seismic probabilistic risk assessment using MASTODON ..................................................44

3.3. Formulation of the risk- and cost-based design optimization problem ..................................47

3.4. Development of a generic PRA model for design optimization ...........................................50

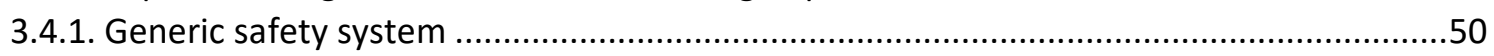


3.4.2. Development of fragility and cost functions ...............................................................52

3.4.3. Capital cost and seismic risk of the initial design of the generic safety system .................55

3.5. Design optimization of the generic safety system ..............................................................56

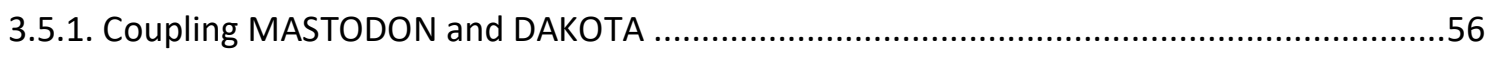

3.5.2. Sensitivity of the results to the genetic algorithm parameters .......................................56

3.5.3. Design optimization of the safety system without considering seismic isolation .............58

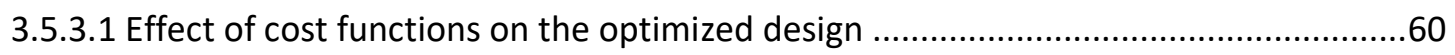

3.5.4. Design optimization with component seismic isolation ..................................................64

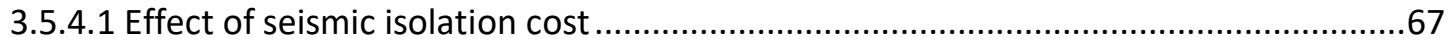

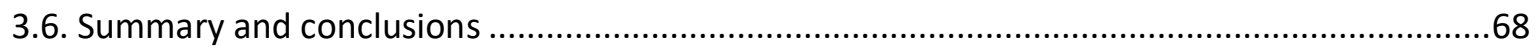

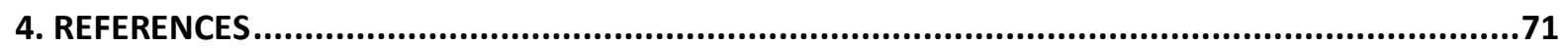

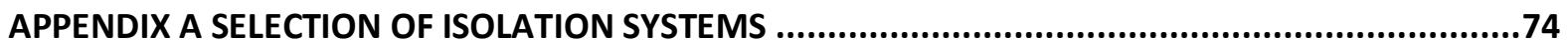




\section{FIGURES}

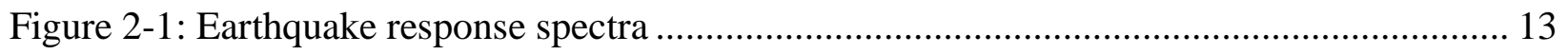

Figure 2-2: Base isolation of a reactor building (adapted from Kammerer et al. (2019)) ........... 14

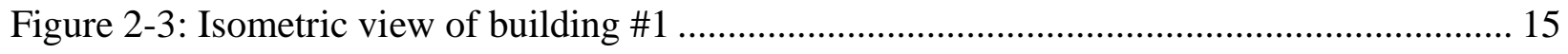

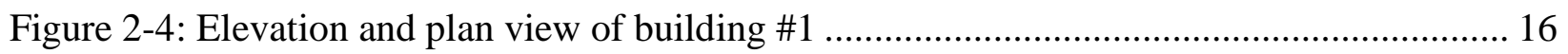

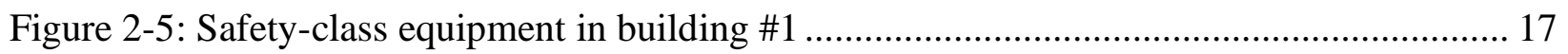

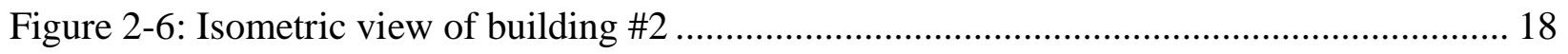

Figure 2-7: Elevation and plan view of building \#2 ........................................................ 19

Figure 2-8: Safety-class equipment in building \#2 .......................................................... 20

Figure 2-9: 5\% damped spectra of the spectrally matched motions (Yu et al., 2018)............... 21

Figure 2-10: 5\% damped spectra of the max-min motions (Yu et al., 2018) ............................ 23

Figure 2-11: 5\% damped geomean horizontal DBE spectrum at INL and RG 1.60

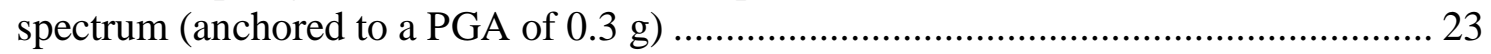

Figure 2-12: Single concave Friction Pendulum ${ }^{\mathrm{TM}}$ isolator (Kumar et al., 2019b) ................... 25

Figure 2-13: Force-displacement behavior of an FP bearing ............................................. 26

Figure 2-14: Elevation view and layout of the isolation system for building \#1 ...................... 28

Figure 2-15: Response quantities of interest reported in building \#1 ....................................... 30

Figure 2-16: $80^{\text {th }}$ percentile horizontal acceleration spectra in building \#1, input PGA =

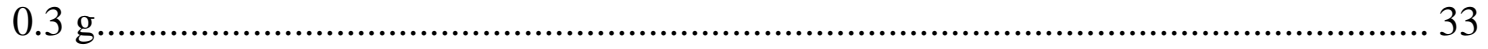

Figure 2-17: Elevation view and layout of the isolation system for building \#2 ..................... 36

Figure 2-18: Response quantities of interest reported in building \#2 ...................................... 37

Figure 2-19: $80^{\text {th }}$ percentile horizontal acceleration spectra in building \#2, input PGA =

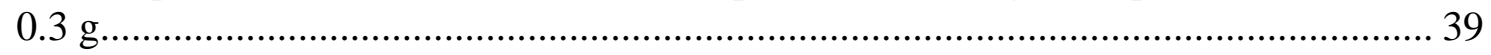

Figure 3-1: Illustration of non-iterative and iterative design processes .................................. 44

Figure 3-2: The SPRA methodology (Huang et al., 2008a; Huang et al., 2011b) .................... 46

Figure 3-3: SPRA in MASTODON (Bolisetti et al., 2019)................................................... 47

Figure 3-4: Illustration of the optimization problem of this study ......................................... 49

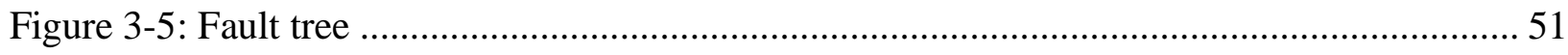

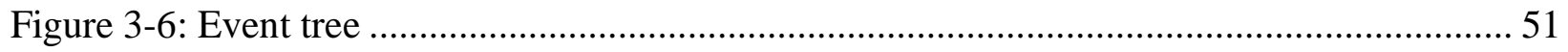

Figure 3-7: Seismic hazard curve for the peak ground acceleration at the INL site (Yu et

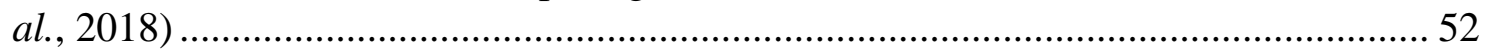

Figure 3-8: Capital costs of individual SSCs as a function of their median seismic

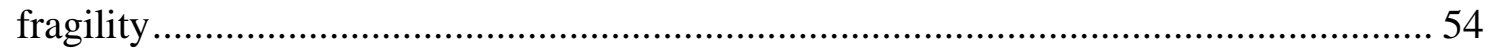

Figure 3-9: Convergence of the total capital cost with number of iterations in SOGA.............. 58 
Figure 3-10: Comparison between initial and optimized design of the GNF safety system ........ 60

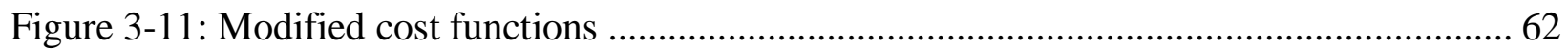

Figure 3-12: Comparison between initial and optimized designs with modified cost

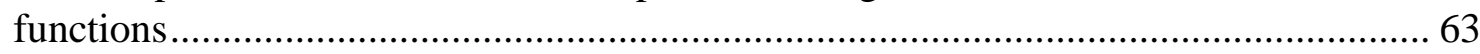

Figure 3-13: Comparison of initial and optimized designs of the GNF safety system while

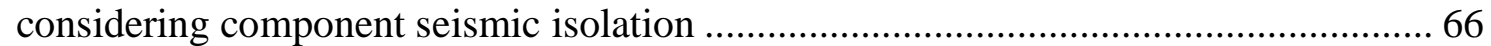

Figure 3-14: Comparison of initial and optimized designs of the GNF safety system with

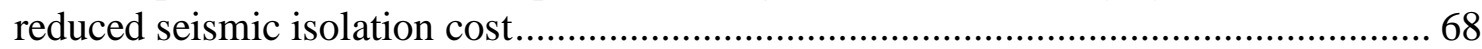




\section{TABLES}

Table 2-1: Seed motions for the INL site (Yu et al., 2018) .................................................... 22

Table 2-2: Isolation systems considered for the reactor buildings ......................................... 26

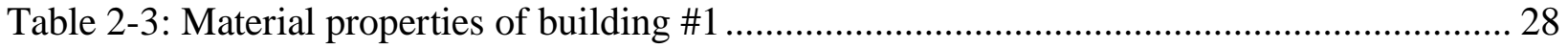

Table 2-4: Normalized vessel weights in building \#1 .................................................... 31

Table 2-5: 80th percentile geomean horizontal accelerations $(\mathrm{g})$ in building \#1 ...................... 32

Table 2-6: 80th percentile SRSS horizontal relative displacements $(\mathrm{mm})$ in building \#1 ........... 33

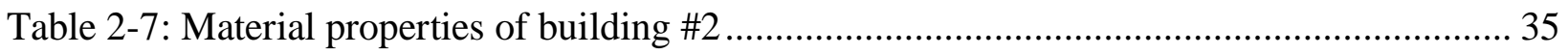

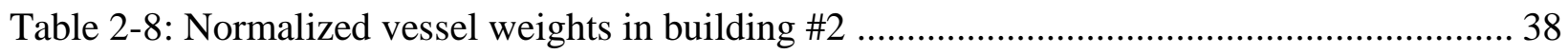

Table 2-9: 80th percentile geomean horizontal accelerations $(\mathrm{g})$ in building \#2 „..................... 38

Table 2-10: 80th percentile SRSS horizontal relative displacements ( $\mathrm{mm}$ ) in building \#2 ......... 41

Table 3-1: List of SSCs in the GNF along with their initial median fragilities, composite

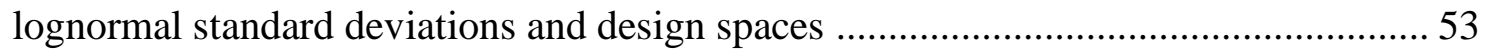

Table 3-2: Minimal cutsets of the GNF safety system and their corresponding risks and risk contributions calculated for the initial design and the seismic hazard curve

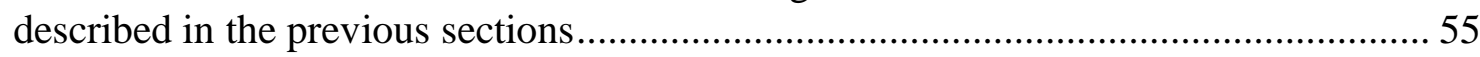

Table 3-3: Sensitivity of the optimization results to the randomization seed for SOGA ............ 57

Table 3-4: Sensitivity of the optimization results to the population size ................................... 57

Table 3-5: Capital cost and risk of the safety system before and after design optimization ........ 59

Table 3-6: Capital cost and risk of the safety system before and after optimization using

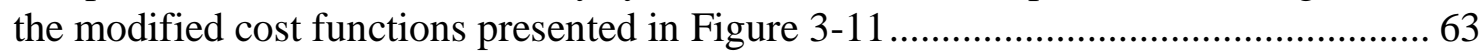

Table 3-7: Capital cost and seismic risk of the safety system before and after design optimization when component seismic isolation is included in the optimization process.

Table 3-8: Capital cost and seismic risk of the safety system of GNF before and after design optimization with reduced seismic isolation cost. 



\section{INTRODUCTION}

\subsection{Reducing capital costs of new-build nuclear power plants}

The nuclear industry is currently at a severe economic disadvantage, mainly due to the extremely large capital costs involved constructing new nuclear power plants. In addition, recent nuclear constructions have seen large cost overruns and schedule delays, making the commercial nuclear sector less attractive to investors. To minimize the effects of climate change over the coming decades, it is important to replace fossil fuels plants with nuclear power plants not only in the United States, but also in several other developing countries like India, China, and African nations, which currently rely heavily on fossil fuels. Advanced reactor concepts currently under development in the United States [e.g., the High Temperature Gas Reactor (HTGR) of X-Energy and the Molten Chloride Fast Reactor (MCFR) of TerraPower] are striving to improve the economics of nuclear power primarily by using passive and 'walk-away' safe technologies in the reactor. The recently published report, 'Future of Nuclear Energy in a Carbon-Constrained World' (Buongiorno et al., 2018) by the Massachusetts Institute of Technology Energy Institute (MIT EI) has shown that a significant contributor to the capital cost of NPPs is the 'civil works' i.e., the construction of the balance of plant (BoP: all SSCs except those involved in power generation, e.g., reactor vessel) such as the buildings, containment dome, foundation, etc., which amount to almost half of the overnight capital cost. [see Stevenson (2003) and Buongiorno et al. (2018) for a description of relative costs of various equipment classes in an NPP].

Amongst various solutions, the MIT EI report suggests technologies such as seismic isolation, and high-performance concrete as possible solutions that can significantly reduce the capital costs of advanced reactors. This report demonstrates the application of two cost-cutting solutions on advanced reactor designs that are currently under development. These solutions include, (1) seismic base isolation, and (2) risk- and cost-based seismic design optimization including component seismic isolation. Seismic base isolation is demonstrated for two different advanced reactor buildings, one housing a molten chloride fast reactor (building \#1) and the other housing a high temperature gas reactor (building \#2). The second solution is demonstrated for a generic nuclear facility (GNF) that houses a representative safety system. Since most of the advanced reactors are still currently under development, this report deals with generic designs and systems, wherever necessary. However, the solutions presented in this report can be easily extended to real designs when they become available.

\subsection{Objectives and organization of the report}

The objective of this report is to demonstrate technological solutions that improve the economics of advanced reactor designs that involve seismic isolation. Seismic isolation can be implemented as (1) base isolation, wherein the complete nuclear island sits on top of an isolation system, and (2) component isolation, where individual components are isolated at their points of attachment to the building as necessary.

Chapter 2 discusses base isolation of buildings \#1 and \#2 wherein numerical models of safety-class equipment and the reactor buildings are directly coupled for the purpose of seismic analysis. In doing so, conservatisms associated with legacy methods of decoupled analysis are avoided. Three pieces of safety-class equipment, whose design and construction are likely 
substantially affected by considerations of earthquake shaking, are included in each building: a reactor vessel (RV), a steam generator (SG) vessel, and a control rod drive mechanism (CRDM) housing. Domain experts were consulted to help the authors develop generic designs for the buildings and equipment. The buildings are assumed to be located within the boundaries of the Idaho National Laboratory (INL) because of its potential for construction of one or more advanced reactors in the coming decade. Numerical models of these buildings, including the equipment, were analyzed for incremented intensities of earthquake shaking. Using the numerical models of the generic designs, chapter 2 first quantifies the seismic penalty on the reactor buildings and their safety class equipment assuming conventional (fixed-base) construction. The numerical models are also used to then develop horizontal seismic isolation systems for the reactor buildings, and the reduction in seismic demands when compared to their fixed-base counterparts are presented to showcase the benefits of seismic base isolation.

Chapter 3 develops a cost- and risk-based design optimization process and demonstrates it by optimizing the design of a generic nuclear facility equipped with a safety system representative of those in nuclear power plants. Design optimization is typically not performed in the nuclear industry and this is a first-of-a-kind application of such a design process, to the knowledge of the authors. The design optimization aims to minimize the capital cost of the GNF while meeting its safety performance goals and uses a genetic algorithm for the optimization process. The optimization is first performed without considering component seismic isolation as an option and the results (total capital cost and seismic risk) are compared with the initial, unoptimized design. The optimization process is then repeated with component seismic isolation as an option results are again compared with the initial design. Due to the lack of data generic cost data is used to quantify the increase in the seismic design cost with seismic capacity, and also for the cost of component seismic isolation. Chapter 3 also investigates the effect of these cost functions on the result of the design optimization. 


\section{SEISMIC BASE ISOLATION OF TWO GENERIC ADVANCED REACTOR BUILDINGS}

\subsection{Introduction}

Proven analysis and design tools, hardware, standards of practice, and an experienced supply chain have enabled the application of seismic isolation to many types of civil infrastructure, including mission-critical buildings, bridges, and offshore oil and gas platforms over the past 30 years. Building isolation is achieved by the installation of horizontally flexible and vertically stiff elements, known as isolators (or bearings), immediately above the foundation. The added flexibility at the base increases the period of the superstructure, resulting in a significant reduction in horizontal acceleration (see Figure 2-1a). The trade-off to reduced acceleration is increased displacement (see Figure 2-1b) although nearly all of it is accommodated over the height of the isolators. The drift in an isolated superstructure is small and substantially less than in its conventional (fixed-base) counterpart. Figure 2-2 presents an example of base isolation, wherein seismic isolators are installed atop foundation pedestals and below the basemat of a reactor building. The gap between the basemat and the adjacent moat wall is the space available for the horizontal movement of the isolators during an earthquake. The junction (shown using dashed red lines) of the isolated superstructure and the supporting foundation is termed as the isolation interface.

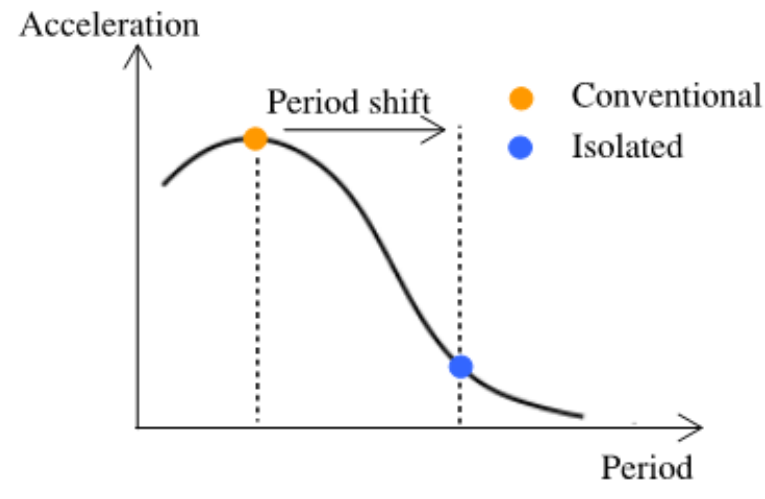

a) acceleration spectra

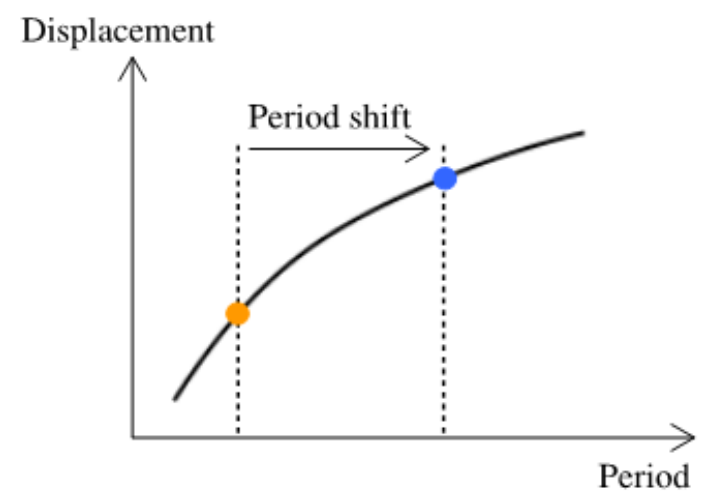

b) displacement spectra

Figure 2-1: Earthquake response spectra

Seismic isolation is yet to be applied to safety-related nuclear structures in the United States. One of the primary reasons identified a decade ago was the lack of technical guidance and standards for analysis and design of seismically isolated nuclear facilities. This issue has been addressed over the last decade through several research projects funded by the DOE and the US Nuclear Regulatory Commission (NRC). Research funded by these agencies led to the addition of chapters specific to seismic isolation in two nuclear standards: ASCE/SEI 4-16 (ASCE, 2017), and ASCE/SEI 43-19 (ASCE, 2019). Chapter 12 of ASCE 4 includes mandatory language and commentary for analysis of seismically isolated nuclear facilities. Chapter 9 of ASCE 43 provides design and testing requirements for seismic isolators and isolation systems. Research funded by the NRC contributed to three technical reports on seismic isolation of reactor buildings: 1) NUREG/CR-7253 (Kammerer et al., 2019), Technical considerations for seismic isolation of nuclear facilities, 2) NUREG/CR-7254 (Kumar et al., 2019b), Seismic isolation of 
nuclear power plants using sliding bearings, and 3) NUREG/CR-7255 (Kumar et al., 2019a), Seismic isolation of nuclear power plants using elastomeric bearings. Journal articles, conference papers, and technical reports support and complement these standards and technical reports, with most identified in Whittaker et al. (2018).

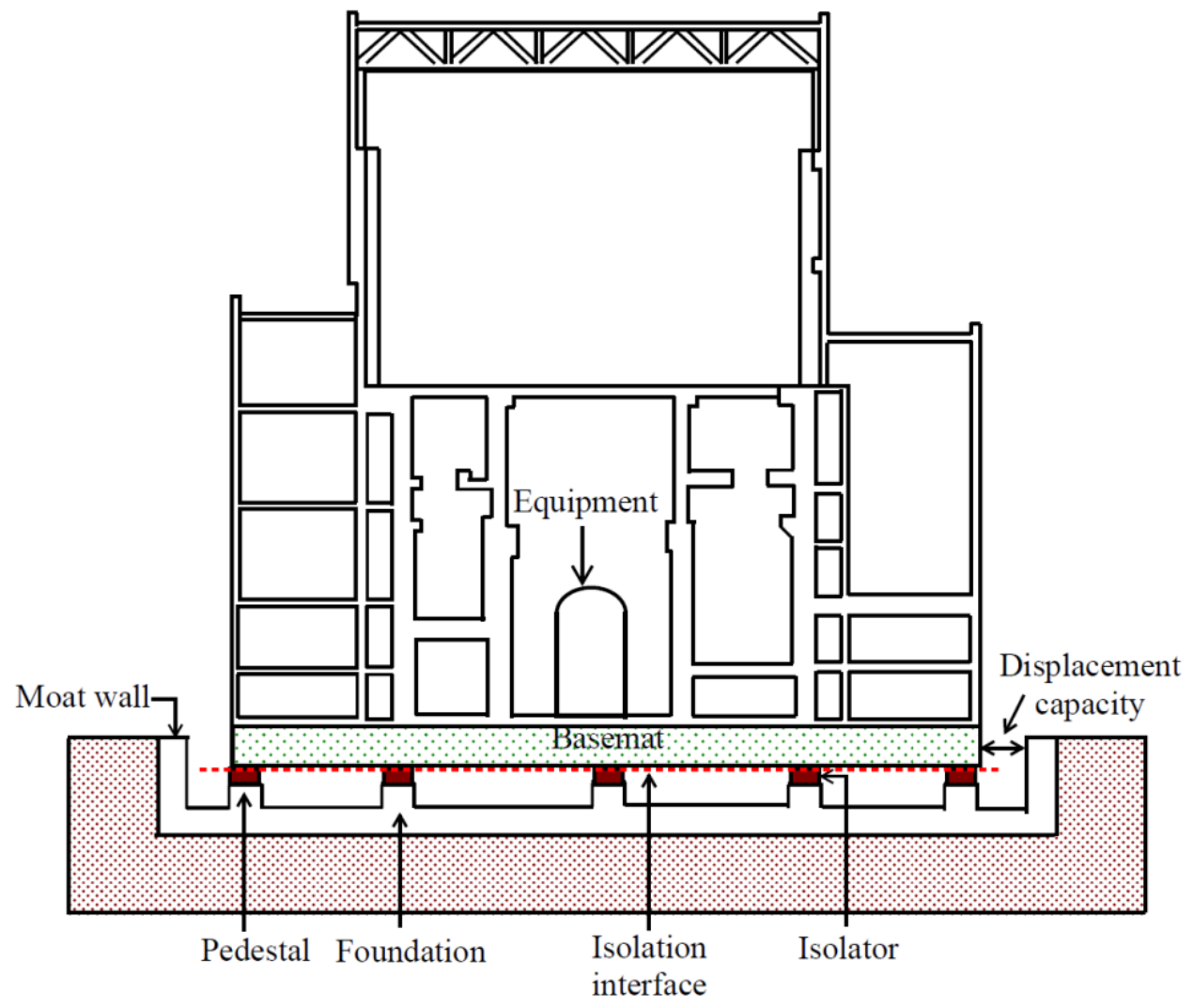

Figure 2-2: Base isolation of a reactor building (adapted from Kammerer et al. (2019))

Three primary benefits of seismically isolating NPPs are 1) reduced demands: the seismic demands (accelerations, velocities, and displacements etc.,) in the structures, systems and components (SSCs) of a facility are reduced, 2) increased safety: the mean annual frequency of unacceptable performance is significantly reduced for a given intensity of earthquake shaking, and 3) standardization of designs: enables reactor designs certified to operate in regions of low to moderate seismicity to be constructed in regions of high seismicity by optimizing isolation system properties for the seismic hazard at the new site. All three should provide a pathway to reduced capital cost. Benefits 1 and 2 have been demonstrated in the past (Bolisetti et al., 2016; Huang et al., 2008a; Huang et al., 2009; Huang et al., 2011b; 2011a; Kumar et al., 2017a; Kumar et al., 2017b; Yu et al., 2018), but benefit 3 has yet to be addressed. Herein, the application of seismic base isolation to advanced (Generation IV) reactors is addressed with a focus on benefits 1 and 3 .

\subsection{Generic reactor buildings and equipment}

To help quantify the seismic penalty on these advanced reactors if fixed-base construction is deployed, and to quantify the reductions in seismic demands made possible by base isolation, generic designs were developed for the reactor buildings and their safety-class equipment. The 
reactor buildings are discussed next. Information on the characterization of seismic hazard at the INL site is presented in Section 2.3. Section 2.4 discusses the design approach for the reactor buildings and their safety-class equipment. Details of the isolation systems are presented in Section 2.5. Sections 2.6 and 2.7 discuss analyses results for buildings \#1 and \#2, respectively.

\subsubsection{Reactor building \#1}

The generic molten chloride fast reactor considered herein is a $32 \mathrm{~m}$ high reinforced concrete building with plan dimensions of $90 \mathrm{~m} \times 60 \mathrm{~m}$. A full-height wall divides the building into two compartments: 1) a two-story compartment, $40 \mathrm{~m}$ long and $60 \mathrm{~m}$ wide, which houses the reactor vessel, and 2) a single-story compartment, $50 \mathrm{~m}$ long and $60 \mathrm{~m}$ wide, which houses four steam generators. Buttresses ( $4 \mathrm{~m}$ deep and $0.75 \mathrm{~m}$ wide) around the perimeter of the building and along the length of the central wall provide lateral stiffness to these tall walls. Figure 2-3 presents an isometric view of the building.

The suspended floor slab in the two-story compartment is $8 \mathrm{~m}$ above the basemat and is supported by a grid of reinforced concrete walls as shown in Figure 2-4a. The roof slabs of both the compartments are supported by a two-way grid of reinforced concrete beams (see Figure $2-4 b)$.

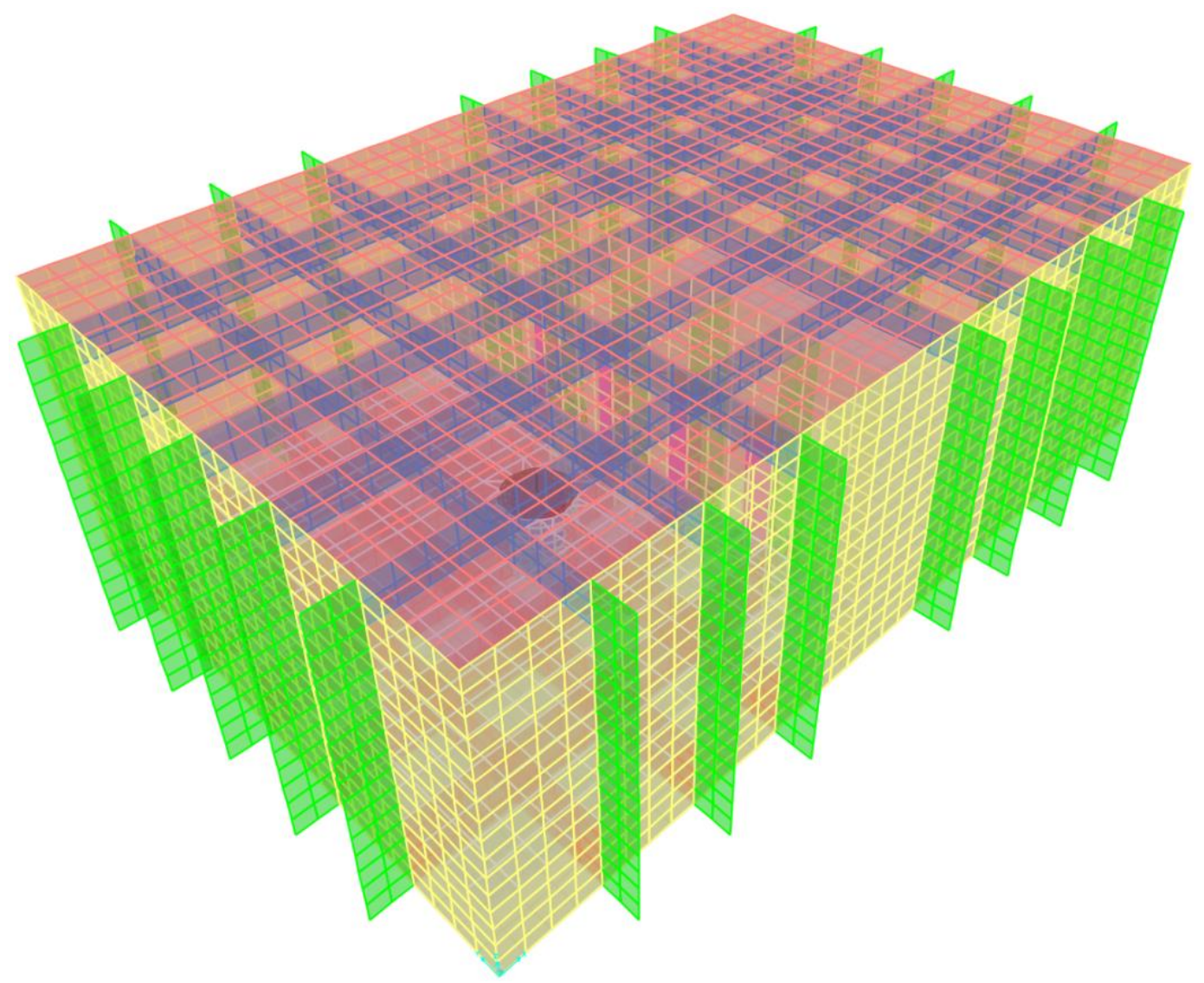

Figure 2-3: Isometric view of building \#1 


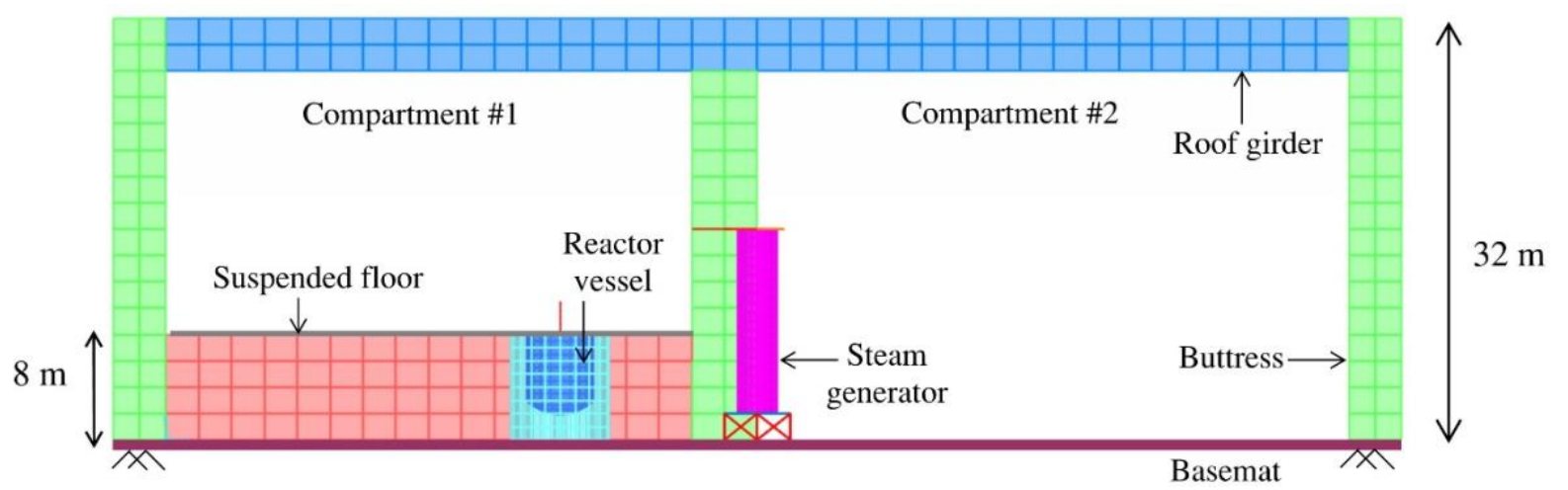

a) elevation view

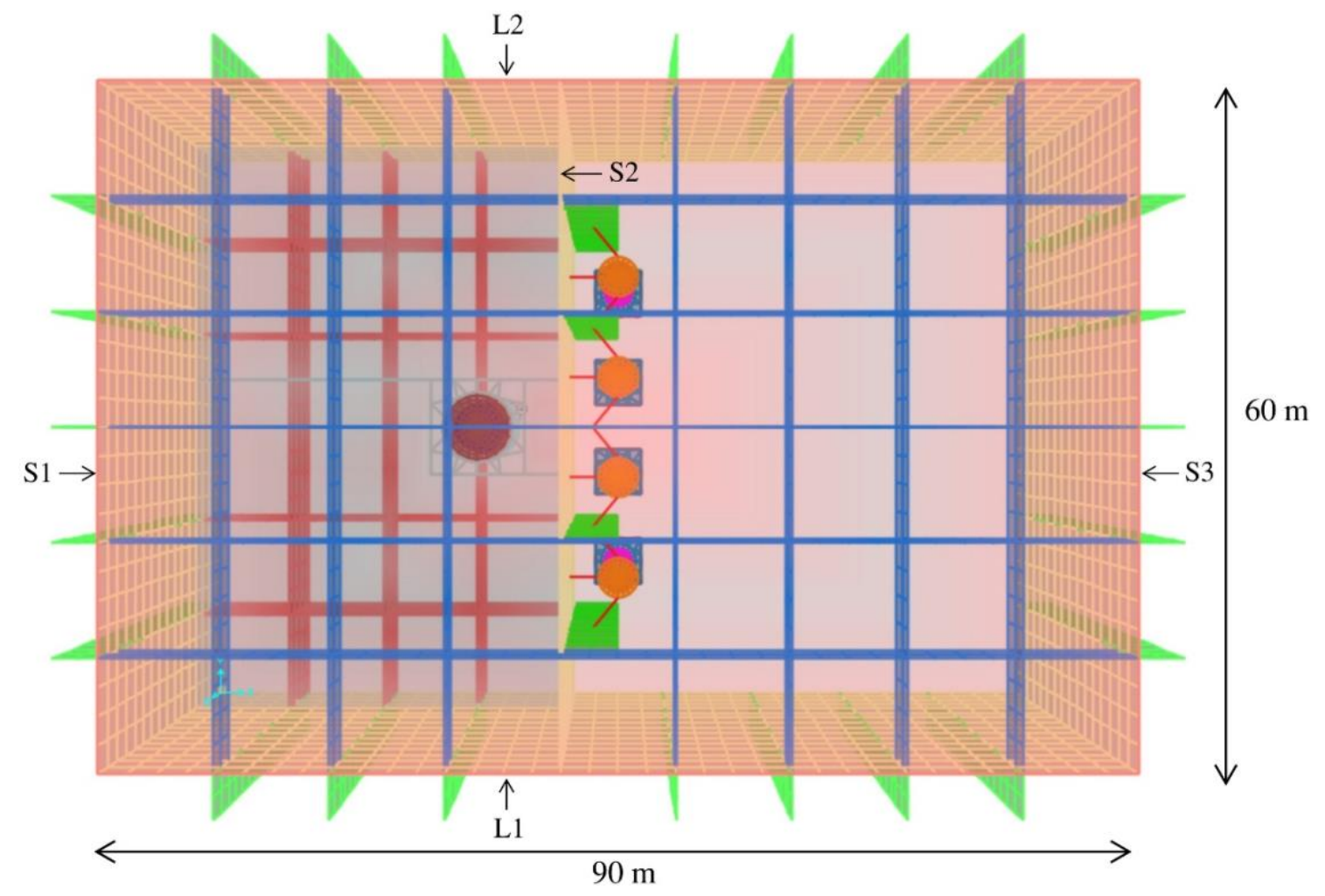

b) plan view

Figure 2-4: Elevation and plan view of building \#1

The building is populated with a reactor vessel (RV), four steam generators (SG), and a control rod drive mechanism (CRDM) housing. The vessels (i.e., RV and SG) are not connected for the purpose of this analysis. The reactor vessel is $5 \mathrm{~m}$ in diameter and $6 \mathrm{~m}$ tall, including a dome-shaped base and is supported at its head at the suspended floor level in the two-story compartment (see Figure 2-4a). The reactor vessel is enclosed by a reinforced concrete cylindrical wall for the purpose of radiation shielding. The reactor vessel has internals weighing approximately 300 tons, which includes the weight of the molten salt.

The $2.5 \mathrm{~m}$ tall CRDM housing is welded to the top of the reactor head and has an outer diameter of $150 \mathrm{~mm}$ and a wall thickness of $12.5 \mathrm{~mm}$. Although the reactor head supports many 
such housings, only one unit is considered here. A view of the RV and CRDM housing assembly is presented in Figure 2-5a.

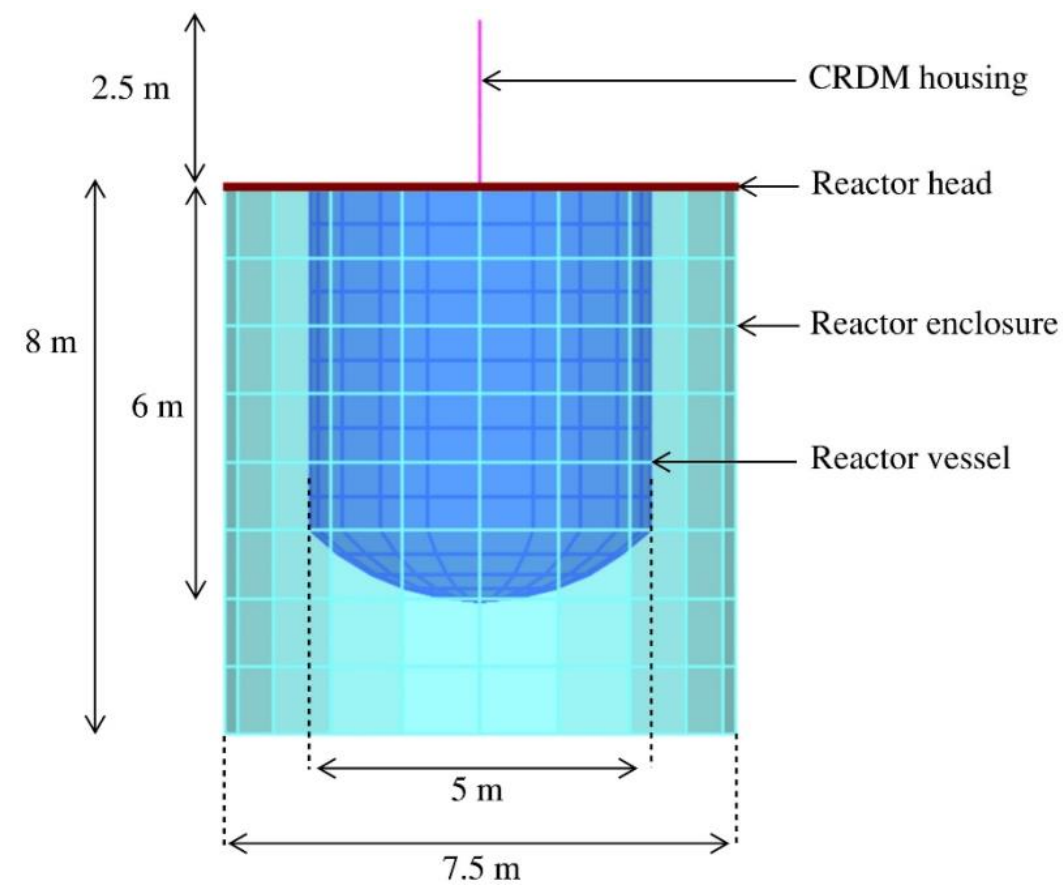

a) reactor vessel and CRDM housing assembly

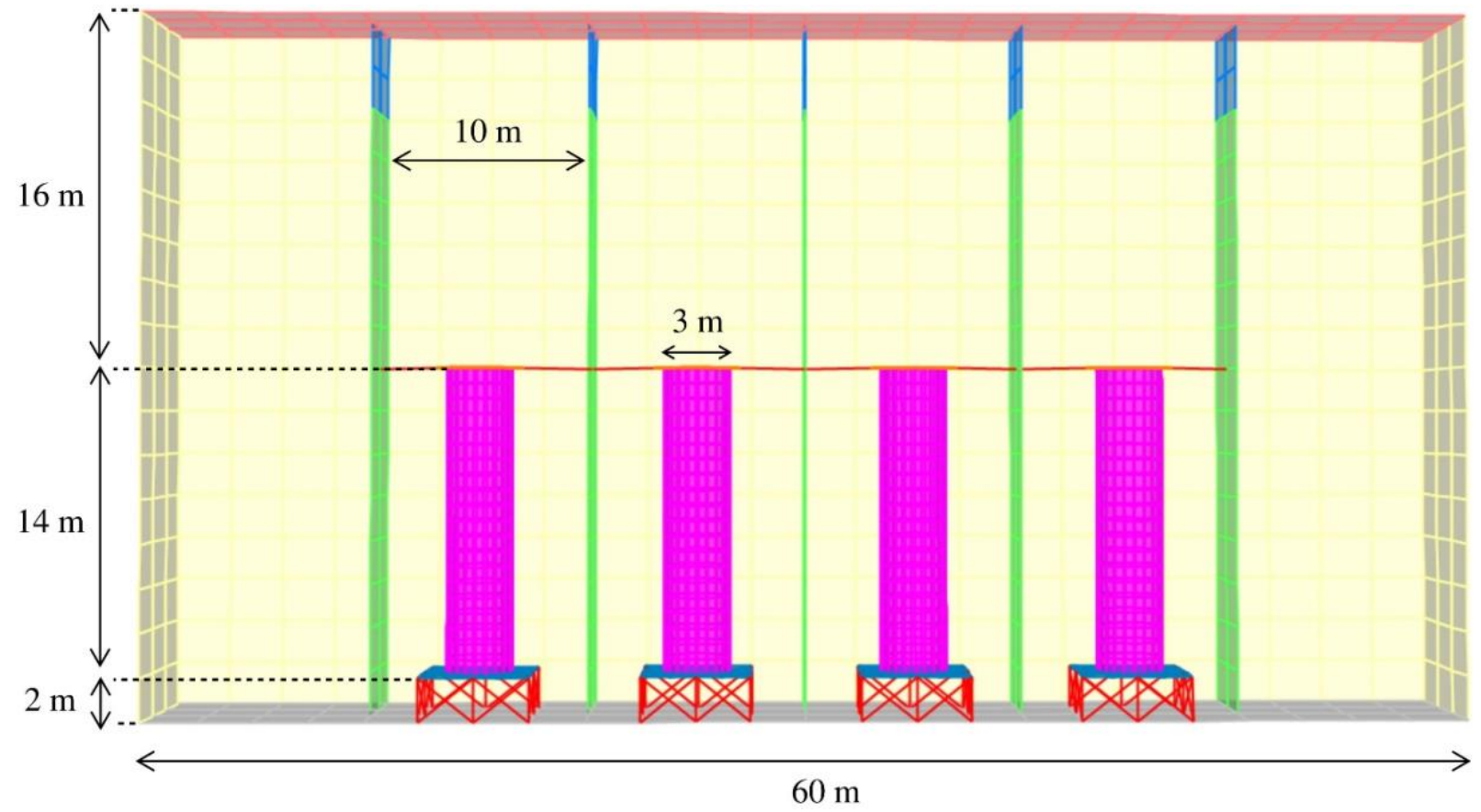

b) steam generator assembly

Figure 2-5: Safety-class equipment in building \#1

Four steam generators, each $3 \mathrm{~m}$ in diameter and $14 \mathrm{~m}$ tall, are housed inside the one-story compartment. The generators are equally spaced at $10 \mathrm{~m}$ on center and located between the 
buttresses to the central wall (see Figure 2-5b). Each generator is vertically supported by a rigid frame at its base ( $2 \mathrm{~m}$ above the basemat) and laterally braced at its top and includes internals weighing approximately 500 tons. The minimum wall thicknesses of the RV and SG required for the operational loadings only were calculated per the relevant sections of the ASME Boiler and Pressure Vessel code (ASME, 2017), as discussed in Section 2.4.

\subsubsection{Reactor building \#2}

Building \#2 is a multi-story reinforced concrete structure and houses a high temperature gas reactor. The building is $34 \mathrm{~m}$ high with plan dimensions of $24 \mathrm{~m} \times 20 \mathrm{~m}$. Figure 2-6 presents an isometric view of the building. It has two major compartments (citadels), one enclosing a reactor vessel and extending from the basemat to the roof, and the other enclosing a steam generator and extending up to floor level 5, $24 \mathrm{~m}$ above the basemat (see Figure 2-7a). The reinforced concrete citadel walls are $1 \mathrm{~m}$ thick. An elevation and a plan view of the building are presented in Figure 2-7.

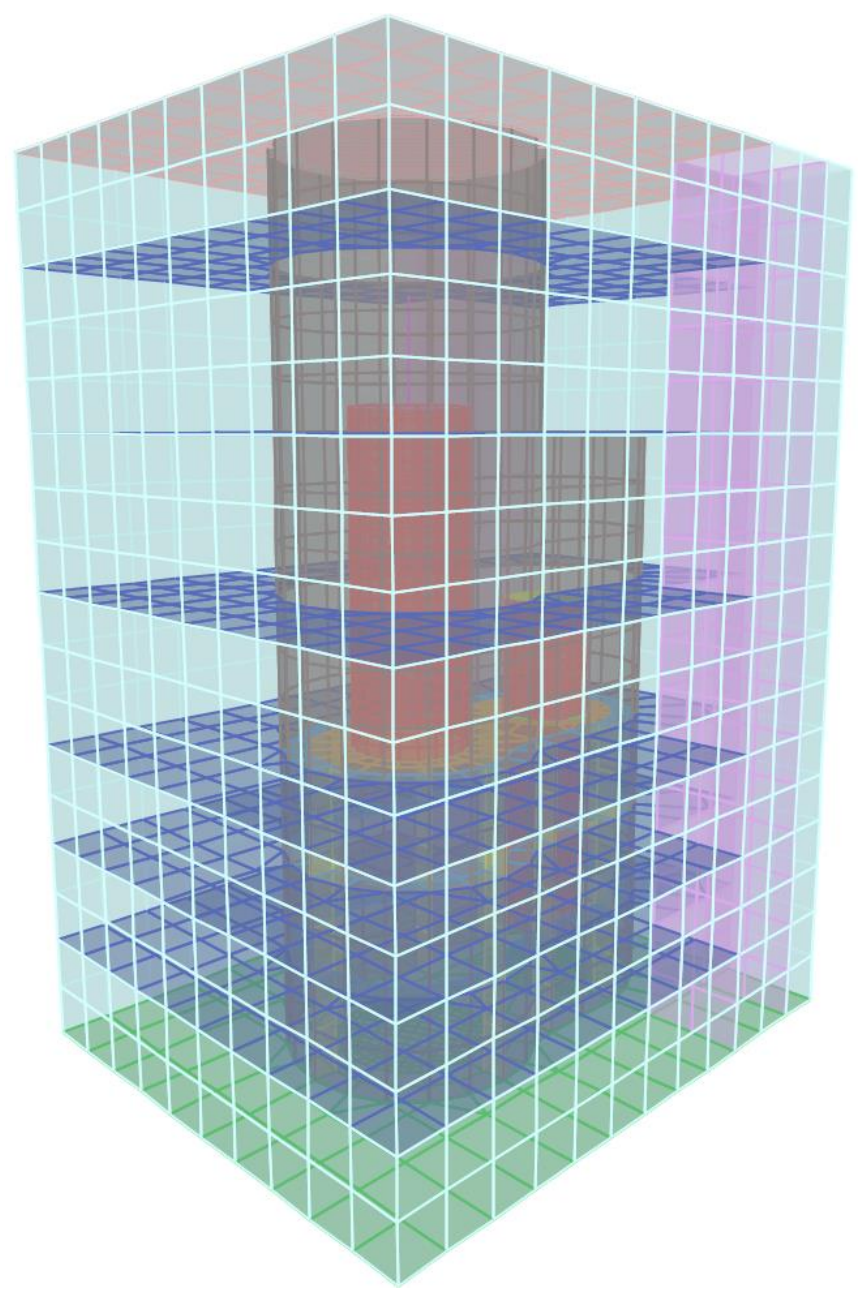

Figure 2-6: Isometric view of building \#2 


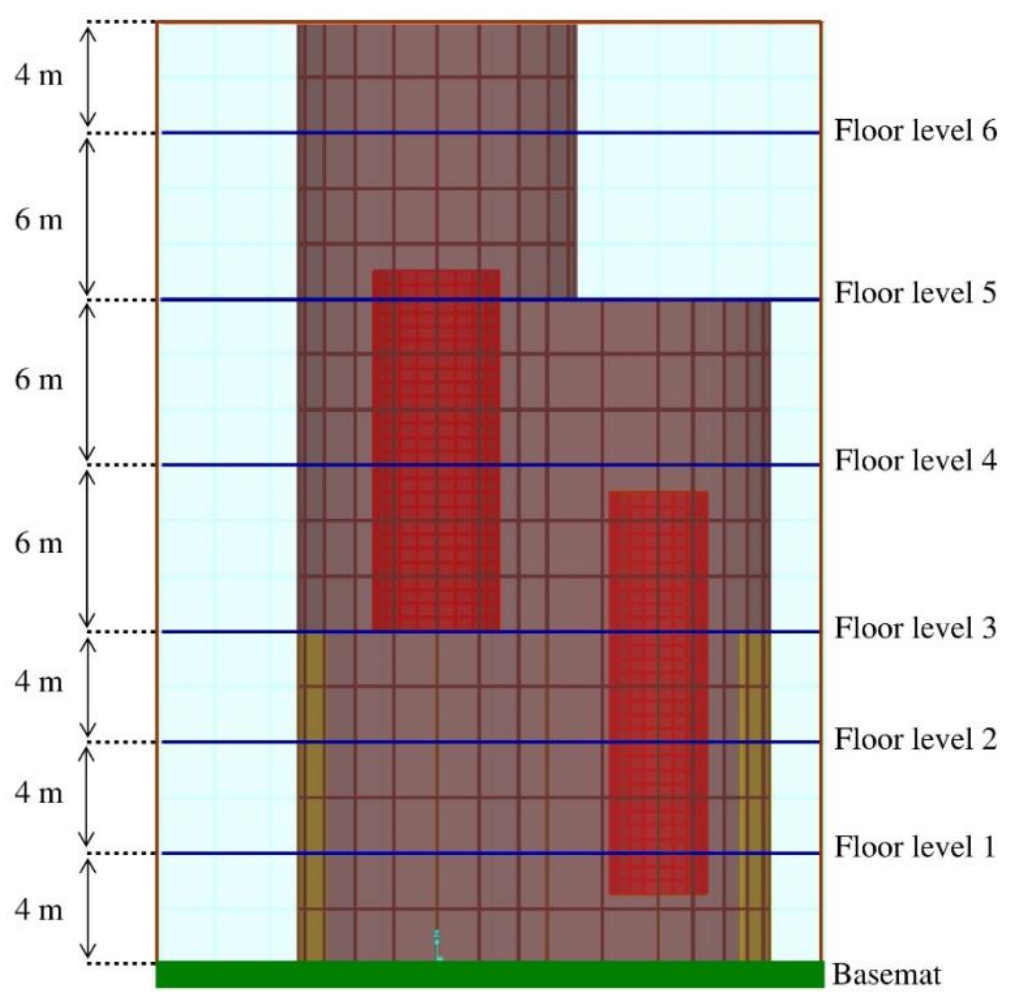

a) elevation view

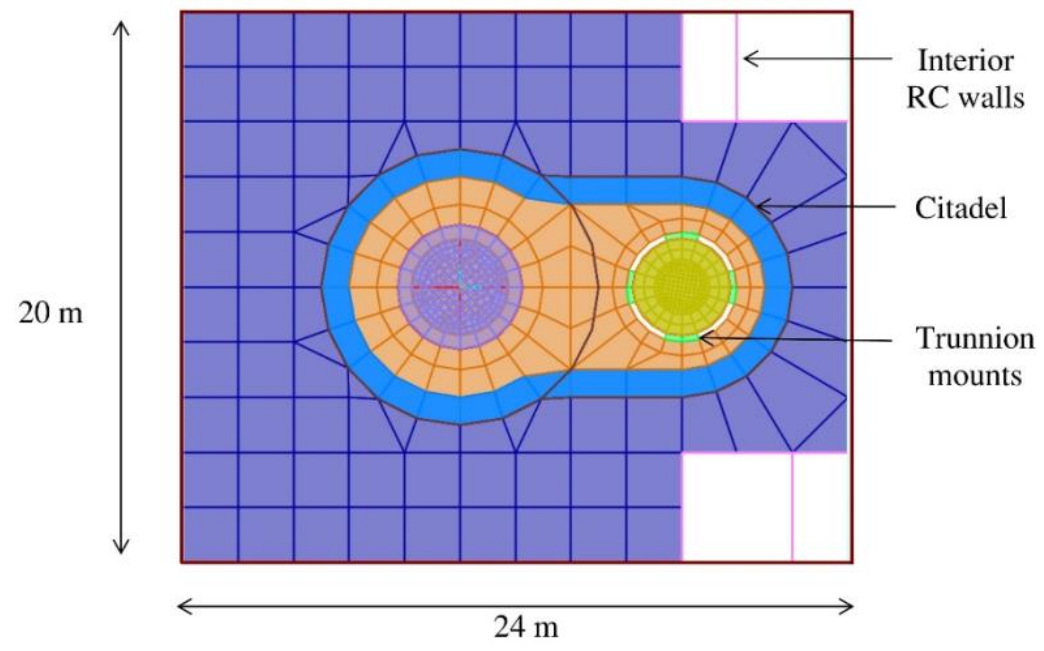

b) plan view (floor level 3)

Figure 2-7: Elevation and plan view of building \#2

Identical to building \#1, building \#2 is also populated with three pieces of safety-class equipment. The RV and SG are supported on a reinforced concrete slab at floor level 3,12 m above the basemat (see Figure 2-8). The reactor vessel is $4.5 \mathrm{~m}$ in diameter, $13 \mathrm{~m}$ tall and includes internals weighing approximately 350 tons. The $4 \mathrm{~m}$ tall tubular CRDM housing is welded to the reactor head and has an outside diameter of $260 \mathrm{~mm}$ and a wall thickness of 25 $\mathrm{mm}$. The SG is housed inside the smaller citadel and is $14.5 \mathrm{~m}$ tall and $3.5 \mathrm{~m}$ in diameter. It is supported at the same level as the RV, with projections of $5 \mathrm{~m}$ and $9.5 \mathrm{~m}$, above and below the 
point of attachment, respectively; see Figure 2-8. At this level, four trunnion mounts are extended from the SG to support the vessel on the adjacent floor slab. The steam generator includes internals weighing approximately 100 tons. The vessels (i.e., RV and SG) are not connected for the purpose of this analysis.

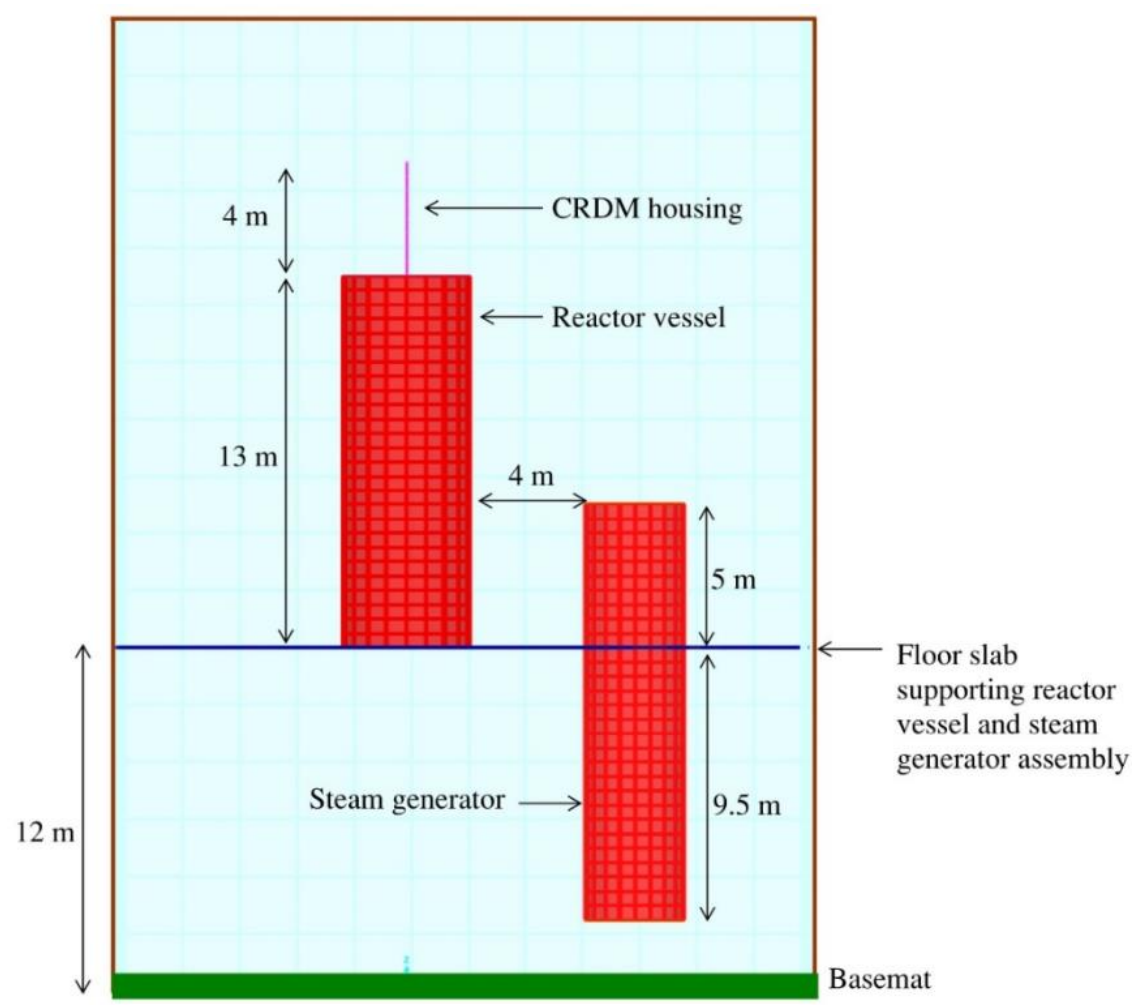

Figure 2-8: Safety-class equipment in building \#2

\subsection{Reactor building site and seismic hazard}

Buildings \#1 and \#2 were assumed to be sited within the boundaries of the Idaho National Laboratory (INL), in the northwest United States as the starting point for the seismic analysis. Yu et al. (2018) characterized the design basis earthquake (DBE) shaking at the INL site for a 10,000 -year return period and developed thirty sets of ground motions consistent with this shaking. These DBE-consistent ground motions were used herein to analyze the two reactor buildings.

The Idaho National Laboratory is located in a region of low to moderate seismicity. The local geology is composed of alluvium and basaltic rock, and is classified here by a shear wave velocity of $760 \mathrm{~m} / \mathrm{s}$ : the boundary between site classes B and C per Standard ASCE/SEI 7-10 (ASCE, 2010). The seismic hazard was characterized in terms of the geometric mean horizontal DBE shaking spectrum, which is an acceleration response spectrum corresponding to a mean annual frequency of exceedance of $10^{-4}$ (return period of 10,000 years). To select the seed motions consistent with the target horizontal DBE spectrum, seismic hazard deaggregation information for the site was obtained using the Unified Hazard Tool prepared by the United States Geological Survey (USGS, 2008) The deaggregation information was obtained at two periods: 1) at $0.1 \mathrm{sec}$ (to represent fixed-base reactor buildings), and 2) at $2 \mathrm{sec}$ which likely 
corresponds to the period of an isolated building. From the deaggregation information, the controlling magnitude-distance (M, r) pairs at $0.1 \mathrm{sec}$ and $2 \mathrm{sec}$ periods were identified as (6.2, 4.9 miles) and (6.8, and 9.1 miles), respectively. These ( $\mathrm{M}, \mathrm{r})$ pairs were used by Yu to select thirty sets of seed motions (see Table 2-1) from recorded earthquakes whose spectral shape is similar to that of the target DBE spectrum.

The frequency content of each seed motion was modified such that the modified spectral shape closely follow the target DBE spectrum in the frequency range of interest. The waveletbased procedure of RSPMatch2005 (Hancock et al., 2006) was used for spectral matching. The horizontal acceleration spectra of the spectrally matched motions are compared with the target DBE spectrum in Figure 2-9.

The downside to spectrally matched motions is they lack record-to-record variability. To rectify this, Huang et al. (2008b) proposed amplification factors, $F_{H}$ and $1 / F_{H}$, to amplitude scale the horizontal components of each set of spectrally matched motions and generate max-min pairs of ground motions that recover the geometric mean generated by probabilistic seismic hazard analysis. Yu et al. (2018) used amplification factors that were selected by a Latin Hypercube Procedure from a lognormal distribution with a mean and logarithmic standard deviation of 0.3 and 0.13 , respectively (Huang et al., 2009). The amplification factors calculated for each motion are reported in Table 2-1. Figure 2-10 enables a comparison of the generated max-min motions with the target DBE spectrum at the INL site.

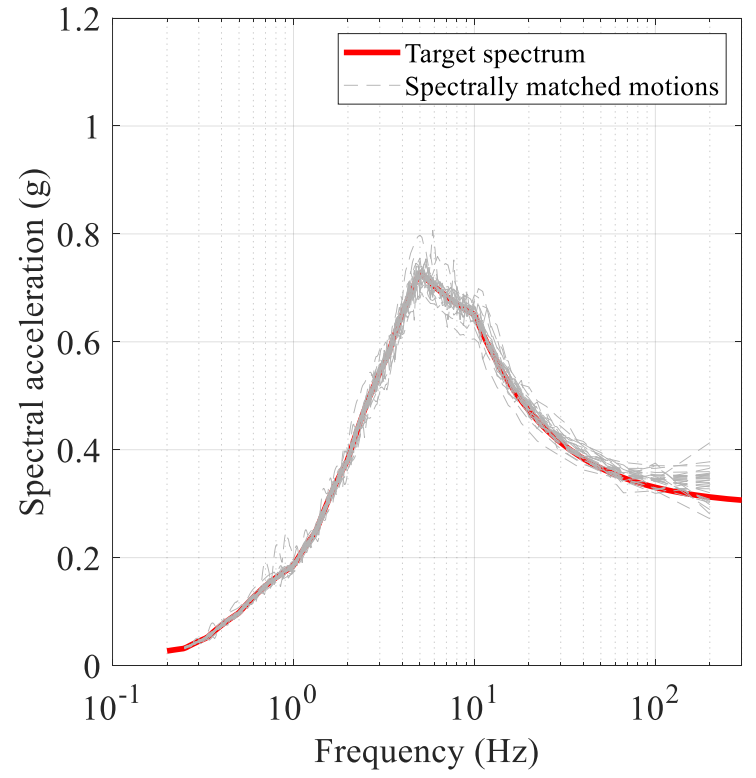

a) horizontal component 1

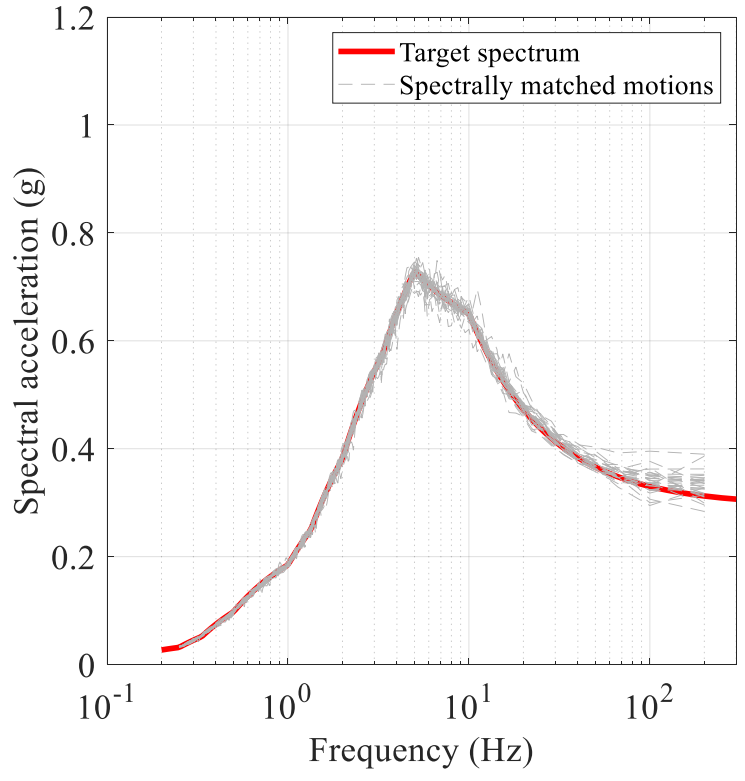

b) horizontal component 2

Figure 2-9: 5\% damped spectra of the spectrally matched motions (Yu et al., 2018) 
Table 2-1: Seed motions for the INL site (Yu et al., 2018)

\begin{tabular}{|c|c|c|c|c|c|}
\hline Earthquake (year) & Station & $\mathbf{M}^{1}$ & $\mathbf{r}^{2}(\mathbf{k m})$ & $F_{H}$ & $\frac{1}{F_{H}}$ \\
\hline Morgan Hill (1984) & Anderson Dam (Downstream) & 6.2 & 3.26 & 1.27 & 0.79 \\
\hline Loma Prieta (1989) & BRAN & 6.9 & 10.72 & 1.62 & 0.62 \\
\hline Northridge (1994) & Pacoima Kagel Canyon & 6.7 & 7.26 & 1.37 & 0.73 \\
\hline Duzce, Turkey (1999) & Lamont 1059 & 7.1 & 4.17 & 1.42 & 0.71 \\
\hline Duzce, Turkey (1999) & Lamont 375 & 7.1 & 3.93 & 1.32 & 0.76 \\
\hline Duzce, Turkey (1999) & IRIGM 496 & 7.1 & 4.21 & 1.35 & 0.74 \\
\hline Duzce, Turkey (1999) & IRIGM 498 & 7.1 & 3.58 & 1.25 & 0.80 \\
\hline Chi-Chi, Taiwan (1999) & TCU084 & 6.2 & 9.32 & 1.68 & 0.59 \\
\hline Chi-Chi, Taiwan (1999) & TCU089 & 6.2 & 9.81 & 1.09 & 0.92 \\
\hline Chi-Chi, Taiwan (1999) & CHY074 & 6.2 & 6.20 & 1.43 & 0.70 \\
\hline Chi-Chi, Taiwan (1999) & TCU078 & 6.3 & 11.52 & 1.12 & 0.89 \\
\hline Tottori, Japan (2000) & SMNH01 & 6.6 & 5.86 & 1.07 & 0.94 \\
\hline San Simeon, USA (2003) & Templeton-1 Hospital & 6.5 & 6.22 & 1.30 & 0.77 \\
\hline Parkfield, USA (2004) & Parkfield-Donnalee & 6.0 & 4.93 & 1.23 & 0.81 \\
\hline Parkfield, USA (2004) & Parkfield-Turkey Flat \#1 & 6.0 & 5.29 & 1.24 & 0.81 \\
\hline Parkfield, USA (2004) & Bear Valley Ranch & 6.0 & 4.32 & 1.38 & 0.72 \\
\hline Parkfield, USA (2004) & Parkfield-Cholame 2E & 6.0 & 4.08 & 1.47 & 0.68 \\
\hline Parkfield, USA (2004) & Parkfield-Cholame 4W & 6.0 & 4.23 & 1.19 & 0.84 \\
\hline Parkfield, USA (2004) & Parkfield-Fault Zone 11 & 6.0 & 4.00 & 1.40 & 0.72 \\
\hline Parkfield, USA (2004) & Parkfield-Gold Hill 3W & 6.0 & 5.41 & 1.20 & 0.83 \\
\hline Parkfield, USA (2004) & Parkfield-Stone Corral 2E & 6.0 & 5.80 & 1.47 & 0.68 \\
\hline Parkfield, USA (2004) & Parkfield-Vineyard Cany $2 \mathrm{E}$ & 6.0 & 4.46 & 1.31 & 0.76 \\
\hline Parkfield, USA (2004) & Parkfield-Gold Hill 4W & 6.0 & 8.27 & 1.50 & 0.66 \\
\hline Parkfield, USA (2004) & Parkfield-Stone Corral 3E & 6.0 & 8.08 & 1.14 & 0.88 \\
\hline L’Aquila, Italy (2009) & Gran Sasso (Assergi) & 6.3 & 6.40 & 1.28 & 0.78 \\
\hline Chuetsu-oki, Japan (2007) & Nagaoka & 6.8 & 16.27 & 1.55 & 0.64 \\
\hline Chuetsu-oki, Japan (2007) & Tani Kozima Nagaoka & 6.8 & 13.75 & 1.16 & 0.87 \\
\hline Iwate, Japan (2008) & WITH 24 & 6.9 & 5.18 & 1.17 & 0.86 \\
\hline Iwate, Japan (2008) & Mizusawaku Interior O Ganecho & 6.9 & 7.85 & 1.01 & 0.99 \\
\hline Big Bear, USA (1992) & Big Bear Lake Civic Center & 6.5 & 8.30 & 1.34 & 0.75 \\
\hline
\end{tabular}

1. Moment magniude

2. Shortest site-fault rupture distance 


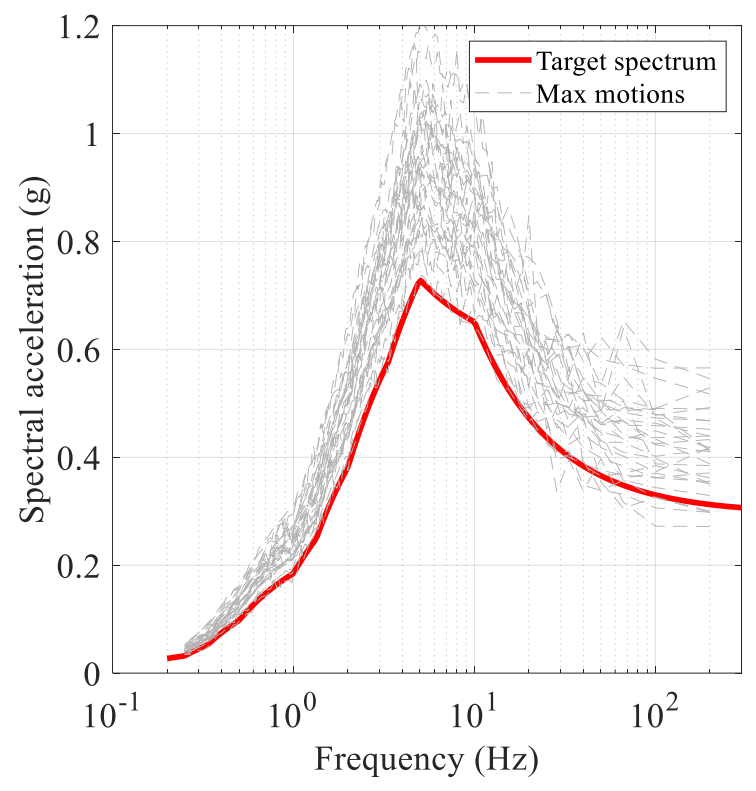

a) maximum direction

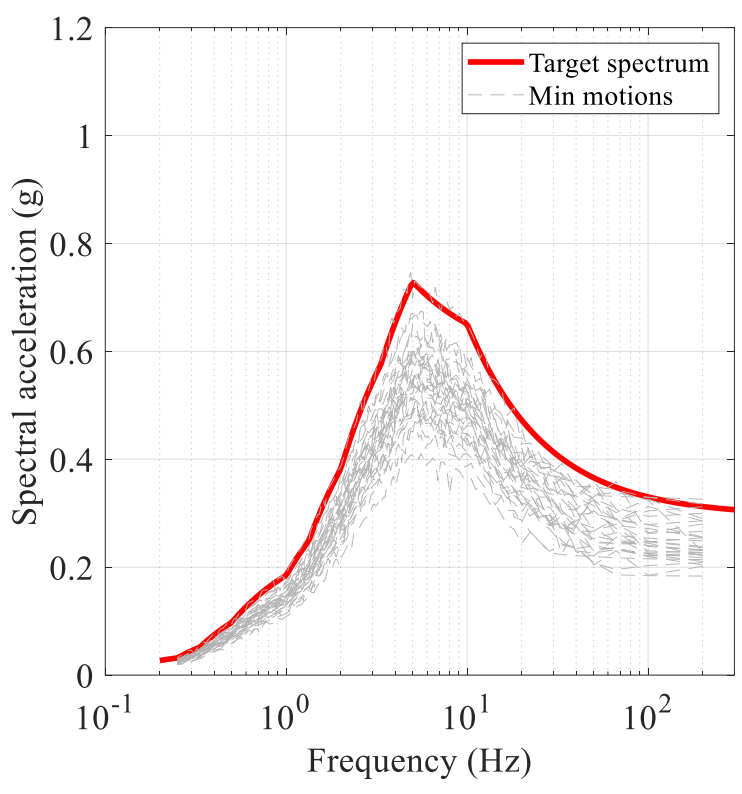

b) minimum direction

Figure 2-10: 5\% damped spectra of the max-min motions (Yu et al., 2018)

Figure 2-11 presents the geometric mean horizontal DBE spectrum at the INL site for a return-period of 10,000 years (blue solid line). A linearized Regulatory Guide (RG) 1.60 spectrum (USNRC, 2014) anchored to a horizontal zero-period acceleration ${ }^{\mathrm{a}}$ of $0.3 \mathrm{~g}$ (which corresponds to the zero-period geomean horizontal DBE acceleration at the INL site) is also shown in the figure (red solid line).

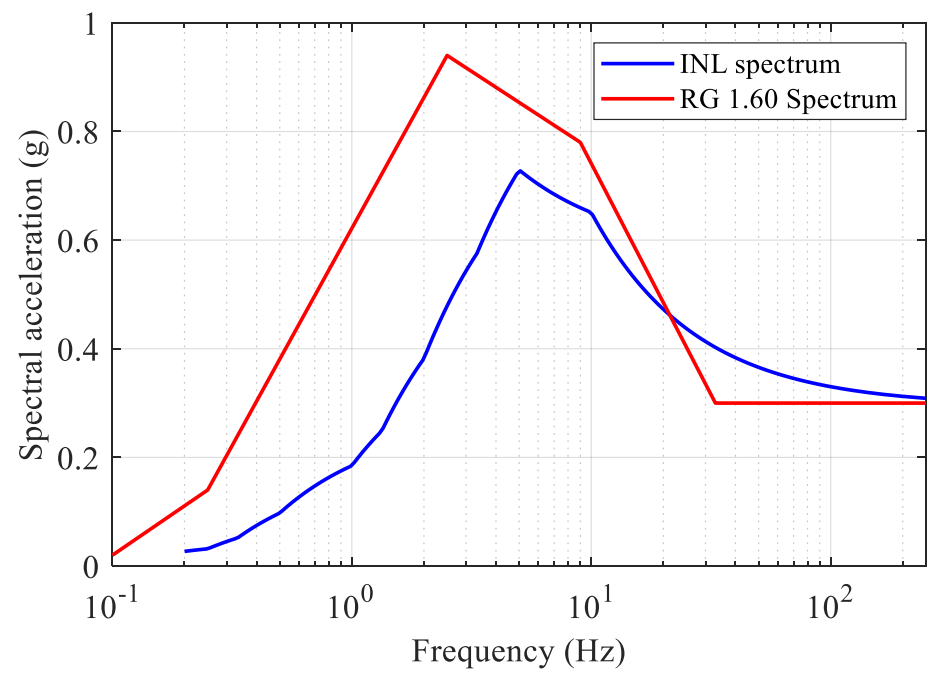

Figure 2-11: 5\% damped geomean horizontal DBE spectrum at INL and RG 1.60 spectrum (anchored to a PGA of $0.3 \mathrm{~g}$ )

\footnotetext{
${ }^{\text {a }}$ Zero-period acceleration and peak ground acceleration (PGA) are used interchangeably.
} 


\subsection{Design and analysis of reactor buildings}

Two nuclear standards ASCE/SEI 4-16 (ASCE, 2017) "Seismic analysis of safety related nuclear structures" and ASCE/SEI 43-05 (ASCE, 2005) "Seismic design criteria for structures, systems and components of nuclear facilities" were used in conjunction with other national consensus codes such as ACI 349 (ACI, 2013) "Code requirements for nuclear safety-related concrete structures and commentary", and the "ASME Boiler and pressure vessel code" (ASME, 2017) for the design of the buildings, safety-class equipment and the isolation systems for the two reactors.

Reactor buildings \#1 and \#2 have reinforced concrete (RC) structural walls as the lateral load resisting system. These $\mathrm{RC}$ walls were sized for the seismic load case to resist the linearized Regulatory Guide (RG) 1.60 spectrum of Figure 2-11. Response-spectrum analysis was performed on a preliminary design and in-plane shear stresses in the walls were calculated. The wall thicknesses were iteratively adjusted till the resulting in-plane stresses complied with the design limits of ACI-349 (ACI, 2013). Vertical shaking was not considered herein.

The geometry, material properties, weight of internals, boundary conditions and a range of possible operating conditions (e.g., temperature and internal pressure) for each piece of equipment were identified with the help of experts at TerraPower (building \#1) and X-energy (building \#2). The information was used to develop generic designs for each piece of equipment. Using the vessel (RV and SG) dimensions described in Section 2.2, the minimum required wall thicknesses of the vessels were first calculated for operational loads only (i.e., internal pressure and gravity) using Section II and Section III of Division V of the ASME Boiler and Pressure Vessel Code. The geometry (height and diameter) and the calculated minimum wall thickness were used to calculate the vessel weight required for operational performance only. These operationally designed equipment weights were used to normalize the outcomes of the seismic analysis, as described in Sections 2.6 and 2.7.

Earthquake shaking will affect the design, detailing and fabrication of safety-class equipment. For the RV and SG, increased shaking intensity will require a) an increase in the thickness of the wall of the vessel beyond a threshold intensity of shaking, and b) lateral bracing and strengthening of the vessel and internal equipment, and likely adjustments to the internal dimensions of the vessel.

To quantify this seismic penalty, numerical models for the reactor buildings (designed to resist RG 1.60 spectrum of Figure 2-11) and the equipment (designed for operational loads only) were developed in the commercial finite element program SAP2000 (CSI, 2019). Response response-history analysis (RHA) was performed per ASCE/SEI 4-16 to calculate the earthquakeinduced stresses, accelerations, and displacements in the reactor buildings and the equipment for fixed-base construction. Nonlinear RHA was performed for base-isolated variants wherein isolators are the only nonlinear components. The seismic demands were calculated at the $80^{\text {th }}$ percentile non-exceedance probability for the thirty sets of INL max-min motions. Of the 30 ground motions, 15 motions were randomly selected with their max components applied along one of the principal horizontal axes of the building while the max-min orientation was reversed for the remaining 15 motions. The vertical components of ground motion and soil-structure interaction were not considered for this analysis. 
The buildings were analyzed for increasing intensity of earthquake shaking by amplitude scaling the INL motions to recover a geomean horizontal peak ground accelerations (PGAs) of $0.1 \mathrm{~g}, 0.2 \mathrm{~g}, 0.3 \mathrm{~g}$, and $0.5 \mathrm{~g}$. For each intensity of shaking, earthquake-induced stresses in the vessels were calculated at the $80^{\text {th }}$ percentile. The combined stresses (earthquake and operational) were compared with the corresponding limits of the ASME code to determine the required increase in the wall thickness of the vessels, if any, from that required for operational performance only. For the RV and SG, the seismic penalty was quantified in terms of vessel weight (calculated from the vessel wall thickness) normalized to the benchmark values for operational loads, and horizontal acceleration at the points of attachment and representative location for the internals, as a function of the earthquake shaking. The seismic demand on the CRDM housing was quantified as the earthquake-induced horizontal acceleration and displacement at the top of the housing.

\subsection{Isolation systems}

A 2D (horizontal) isolation system was designed for each reactor building. Standard ASCE/SEI 4-16 specifies that nonlinear response-history analysis of base-isolated buildings be performed to evaluate the seismic demands in the isolation system and the SSCs at the $80^{\text {th }}$ percentile non-exceedance probability for DBE shaking. The standard identifies three types of bearings for use in US safety-related nuclear facilities: 1) low damping rubber (LDR) bearings, 2) lead-rubber (LR) bearings, and 3) Friction Pendulum (FP) bearings.

Herein, single concave Friction Pendulum ${ }^{\mathrm{TM}}(\mathrm{FP})$ bearings were used for base isolation of buildings \#1 and \#2. The single FP bearing consists of an articulated slider coated with PTFEtype composite, a sliding surface, and a housing plate. Figure 2-12 presents information on the bearing. Figure 2-13 presents a simplified force-displacement relationship for an FP bearing, where behavior is characterized by two parameters: 1$)$ coefficient of friction at the sliding interface $(\mu)$, and 2) effective radius of curvature of the sliding surface $(R)$.

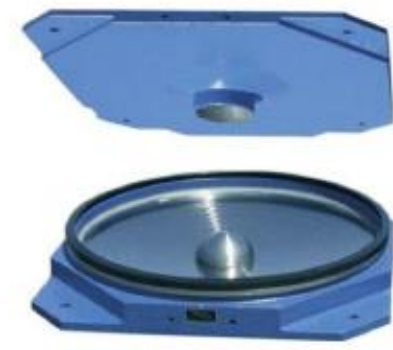

a) components

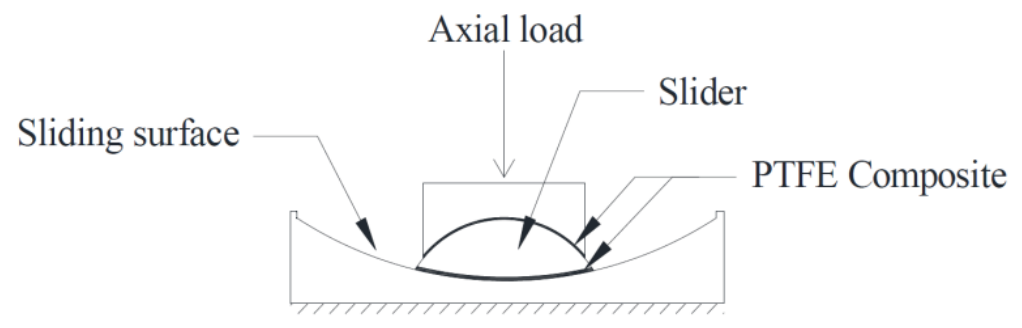

b) sectional view

Figure 2-12: Single concave Friction Pendulum ${ }^{\mathrm{TM}}$ isolator (Kumar et al., 2019b) 


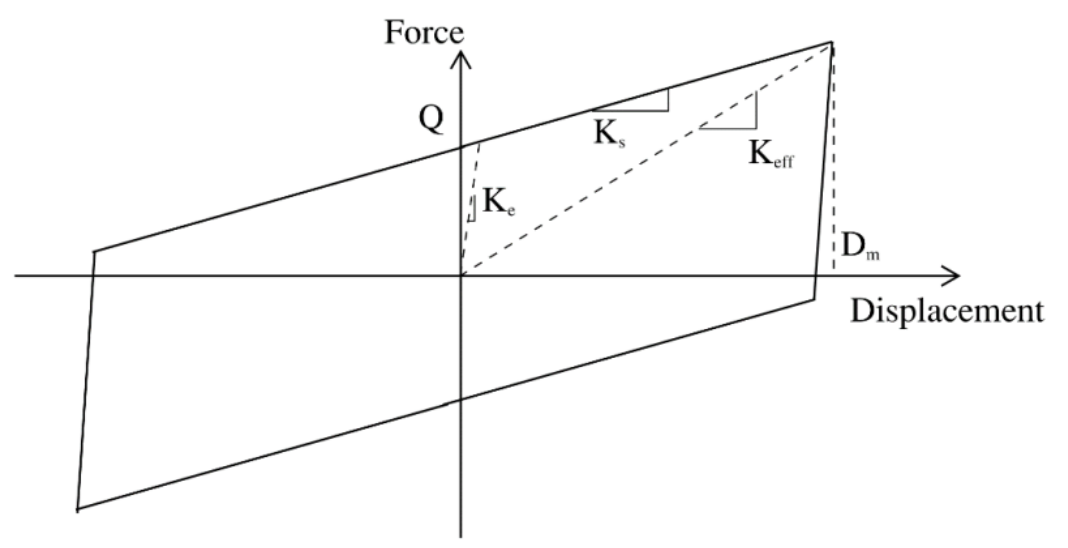

Figure 2-13: Force-displacement behavior of an FP bearing

The expressions for characteristic strength and post-elastic (sliding) stiffness of an FP bearing are:

$$
\begin{aligned}
& Q=\mu W \\
& K_{s}=\frac{W}{R}
\end{aligned}
$$

where $W$ is the instantaneous axial force on the bearing, and the other terms were defined previously. As the period of the isolation system increases, accelerations are reduced but displacements across the isolation interface increase. An optimal isolation system design will be a trade-off between the acceptable accelerations in the SSCs and displacement across the isolation interface. To help inform the choice of an optimal isolation system, the base-isolated variants of buildings \#1 and \#2 were each analyzed for a family of isolation systems for the INL ground motions $(\mathrm{PGA}=0.3 \mathrm{~g})$, as listed in Table 2-2. The combinations of coefficient of friction and radius of sliding surface were selected to achieve a wide range of responses. For each building, the responses of the four isolation systems were compared to enable selection of an isolation system with a reasonable combination of accelerations and displacement. Option 3 was considered to be the most reasonable of the four for both the buildings, as described in Appendix A. The fixed-base and the isolated (option 3) buildings were then analyzed for incremented levels of earthquake shaking (PGA $=0.1 \mathrm{~g}$ to $0.5 \mathrm{~g}$ ).

Table 2-2: Isolation systems considered for the reactor buildings

\begin{tabular}{|c|c|c|c|}
\cline { 2 - 4 } \multicolumn{1}{c|}{} & Coefficient of friction & Sliding surface radius & Sliding period \\
\hline Option 1 & 0.09 & $1000 \mathrm{~mm}$ & $2 \mathrm{sec}$ \\
\hline Option 2 & 0.07 & $2230 \mathrm{~mm}$ & $3 \mathrm{sec}$ \\
\hline Option 3 & 0.05 & $4000 \mathrm{~mm}$ & $4 \mathrm{sec}$ \\
\hline Option 4 & 0.03 & $6210 \mathrm{~mm}$ & $5 \mathrm{sec}$ \\
\hline
\end{tabular}




\subsection{Seismic isolation of reactor building \#1}

\subsubsection{Preliminary design of the buildings and equipment}

The RC walls in building \#1 were sized per ACI-349 to resist the RG 1.60 response spectrum of Figure 2-11 using response spectrum analysis. The roof slabs and the suspended floor slab (in the two-story compartment) were sized to support gravity loads only. These slabs serve as a diaphragm and are part of the seismic load path. Reinforcement in the walls and slabs is not proportioned. Vertical earthquake shaking effects would influence the final size and reinforcing of these elements, but such shaking was not imposed on either building configuration. The final thicknesses of the perimeter walls (S1, S3, L1, L3 of Figure 2-4) and interior central wall (S2) that complied with the ACI limits were $0.75 \mathrm{~m}$ and $1 \mathrm{~m}$, respectively.

All three pieces of safety-class equipment in building \#1 were assumed to be constructed of SS 316 alloy steel. The operating pressure (temperature) were assumed as 9 bar $\left(500{ }^{\circ} \mathrm{C}\right)$ for the reactor vessel and $15 \mathrm{bar}\left(500{ }^{\circ} \mathrm{C}\right)$ for the steam generator. These operating conditions do not correspond to a particular design and are considered generic. Under operating conditions, the resulting mechanical loads/stresses on the vessel were assumed to be due to gravity and internal pressure only. Section III, Division V of the ASME BPVC code was used for the calculation of minimum wall thicknesses.

\subsubsection{Numerical modeling}

The RC walls, roof slabs, suspended floor, buttresses, reactor vessel and the steam generators were modeled using four-node shell elements. The CRDM housing was modeled using a frame element with an appropriate cross-section. A sensitivity study was performed to determine an optimal mesh size for each of these components. Concrete was assumed to be uncracked with a uniaxial compressive strength of 4000 psi. The modulus of elasticity for the SS316 stainless steel was adjusted to the operating temperature of $500{ }^{\circ} \mathrm{C}$. Table $2-3$ reports the material properties used for the concrete and the steel components in building \#1.

The base nodes of the building were fixed, and modal analysis was performed to extract the building and equipment frequencies. The mass of the RV internals (300 tons) and the SG internals (500 tons) was distributed along the heights of the vessels for dynamic analysis. The translational frequencies of the building are between 6-7 Hz. The translational frequencies of the $\mathrm{RV}$ and the CRDM housing are approximately $14 \mathrm{~Hz}$ and $25 \mathrm{~Hz}$, respectively. The SG is laterally braced to the central wall at its top and its dominant modes are coupled with the translational modes of the building.

The total seismic weight of building \#1 is approximately 75,000 tons. The building is isolated with 70 FP bearings per the layout shown in Figure 2-14. The FP bearings were modelled using two-node link elements with six degrees of freedom (three translational and three rotational) defined at each node. The computer program SAP2000 has a built-in material 'Friction isolator' to simulate the nonlinear hysteretic behavior of an FP bearing and it was assigned to these twonode link elements. 
Table 2-3: Material properties of building \#1

\begin{tabular}{|c|c|c|c|}
\hline Material & Density $\left(\mathbf{k g} / \mathbf{m}^{\mathbf{3}}\right)$ & Young's modulus (GPa) & Poisson's ratio \\
\hline Concrete & 2400 & 24.8 & 0.2 \\
\hline SS 316 for the RV and SG & 7850 & 170 & 0.3 \\
\hline SS 316 for the CDRM housings & 7850 & 200 & 0.3 \\
\hline
\end{tabular}

1. Modulus of elasticity at the specified operating temperature.

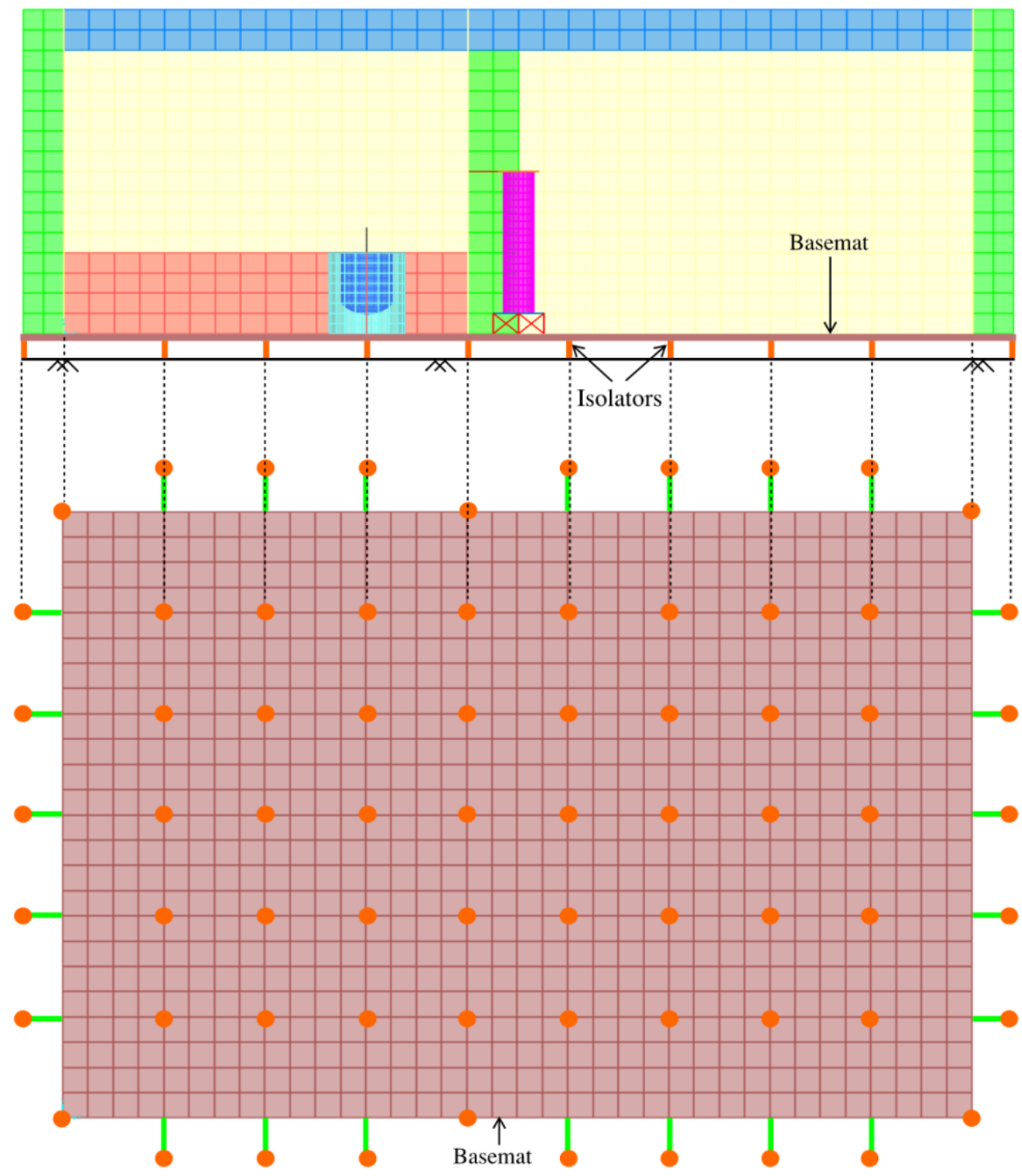

Figure 2-14: Elevation view and layout of the isolation system for building \#1 


\subsubsection{Response-history analysis}

\subsubsection{Analysis and reporting of results}

The fixed-base and base-isolated variants of building \#1 were analyzed for incremented levels of earthquake shaking as described in Section 2.4. Option 3 isolation system per Table 2-2 was chosen for analyses, as noted previously. The fast-nonlinear analysis (FNA) algorithm in SAP2000 was employed for response-history analyses. This algorithm uses Ritz modes for modal decomposition and the first 200 modes recovered $99 \%$ and $90 \%$ of the mass in the horizontal and the vertical directions, respectively, for the fixed-base building. A modal damping ratio of $4 \%$ was assigned to the first 200 modes of the fixed-base building. For the isolated building, the isolators provide hysteretic damping and to avoid overdamping in the isolation system, $0.5 \%$ damping was assigned to the isolated modes and $4 \%$ damping was assigned to all other modes. The products of the RHA for incremented intensities of earthquake shaking, were:

1. Stresses in the walls of the vessels (RV and SG).

2. Horizontal accelerations at points marked using solid green circles in Figure 2-15a. Points \#a2, and $\# \mathrm{a} 5$ are the representative locations for the vessel internals.

- \#a1 - point of attachment of the reactor vessel

- $\quad \#$ a 2 - bottom of the reactor vessel

- $\quad \#$ a3 - top of the CRDM housing

- $\quad \#$ a4 - point of attachment of the steam generator

- $\quad \#$ a5 - top of the steam generator

3. Relative horizontal displacements between points of interest, as identified in Figure 2-15b.

- \#d1 - displacement at the bottom of the RV with respect to its point of attachment

- \#d2 - displacement at the top of the CRDM housing with respect to its point of attachment

- $\quad \# \mathrm{~d} 3$ - displacement at the top of the SG with respect to its points of attachment

4. Displacement across the isolation interface (\#id1), as shown in Figure 2-15c.

Quantities \#a1 through \#a5, and \#d1 through \#d3 are reported for both the fixed-base and the isolated variants. Quantity \#id1 is reported only for the isolated building.

The earthquake-induced stresses in the walls of the vessels were used to calculate the required wall thickness for different intensities of earthquake shaking. Stresses in the immediate vicinity of the supports and elsewhere in the vessel were monitored to avoid secondary effects. The stresses were calculated at the $80^{\text {th }}$ percentile and then increased by $25 \%$ because the assumption of $4 \%$ modal damping is too high for the safety-class equipment (constructed of steel), for which $2 \%$ (or less) would be appropriate. (The modes involving significant response of the equipment are coupled with the building response and it was not possible to separately assign damping to the reinforced concrete and the steel equipment.) The combined stress intensities from the operational loadings and the earthquake loading (as adjusted above) were compared with the limiting stress intensities of the ASME code to determine the required wall thickness for each intensity of shaking (PGA of $0.1 \mathrm{~g}, 0.2 \mathrm{~g}, 0.3 \mathrm{~g}$, and $0.5 \mathrm{~g}$ ). The horizontal accelerations at points \#a1 through \#a5 were calculated at the $80^{\text {th }}$ percentile. The accelerations at representative locations for the internals (\#a2, \#a5) and at the upper end of the CRDM housing (\#a3) were increased by $25 \%$ to account for their $2 \%$ (or less) damping. The relative horizontal displacements \#d1 through \#d3 were also increased by $25 \%$ to account for their $2 \%$ (or less) damping. 

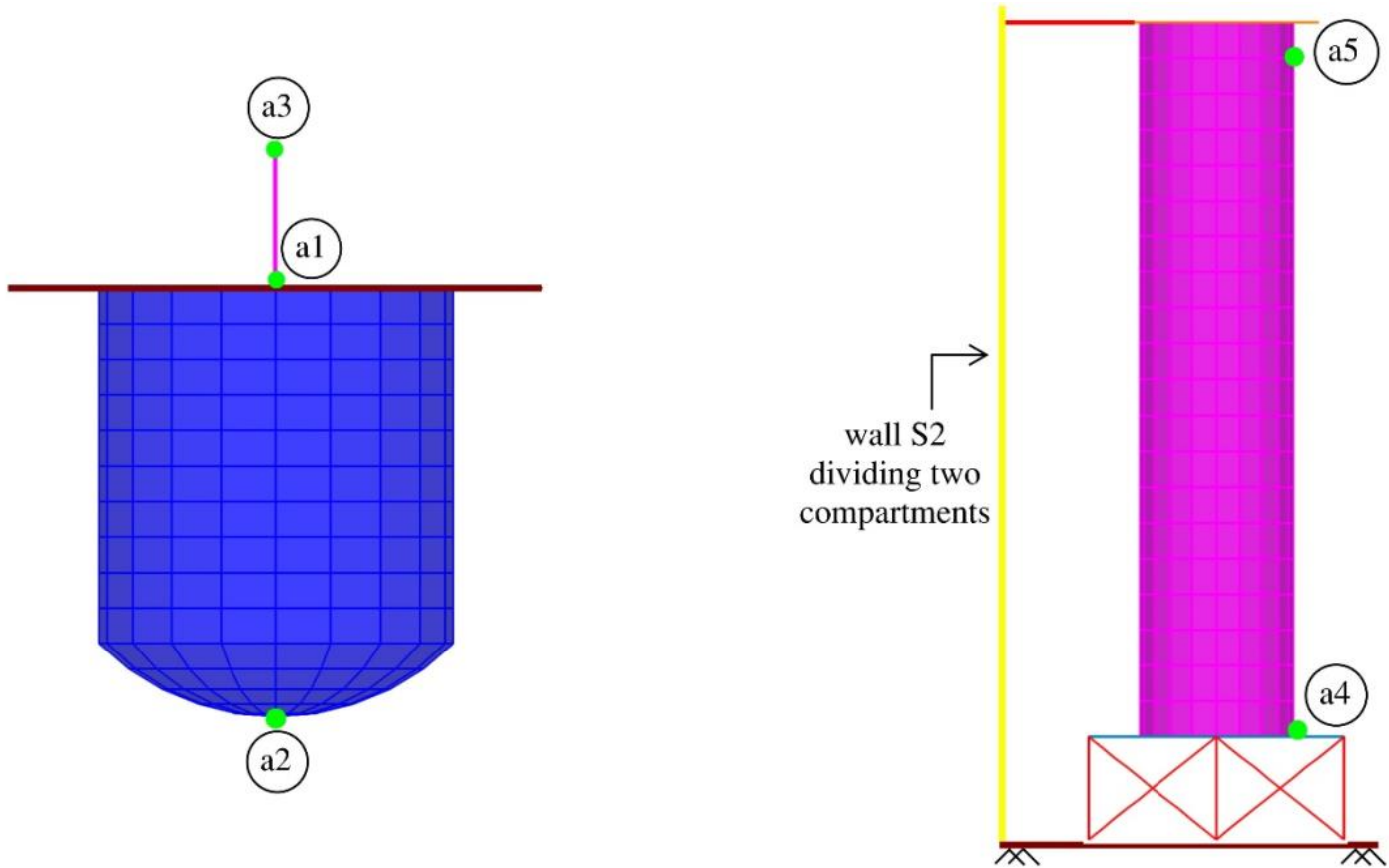

a) horizontal accelerations
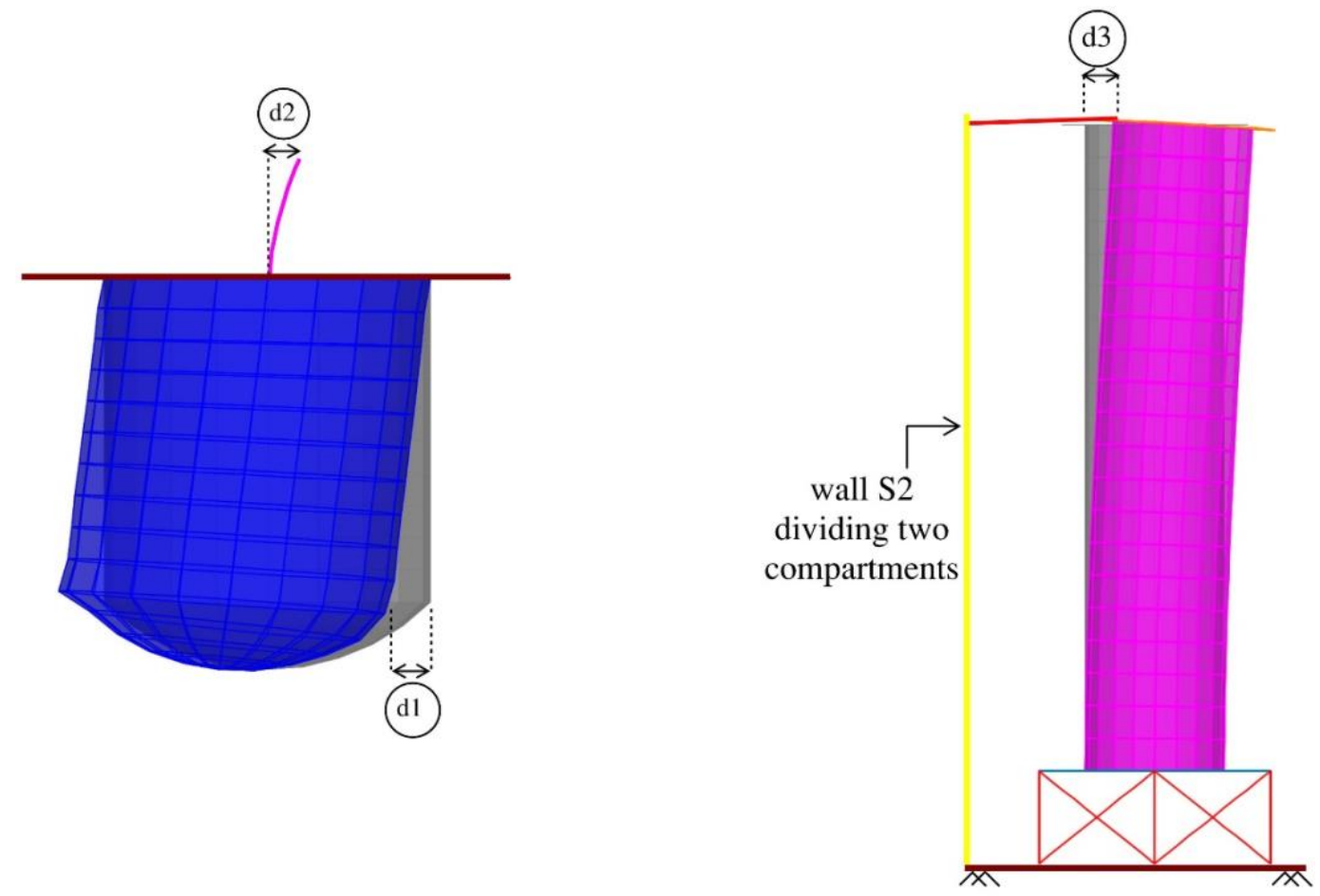

b) horizontal displacements

Figure 2-15: Response quantities of interest reported in building \#1 


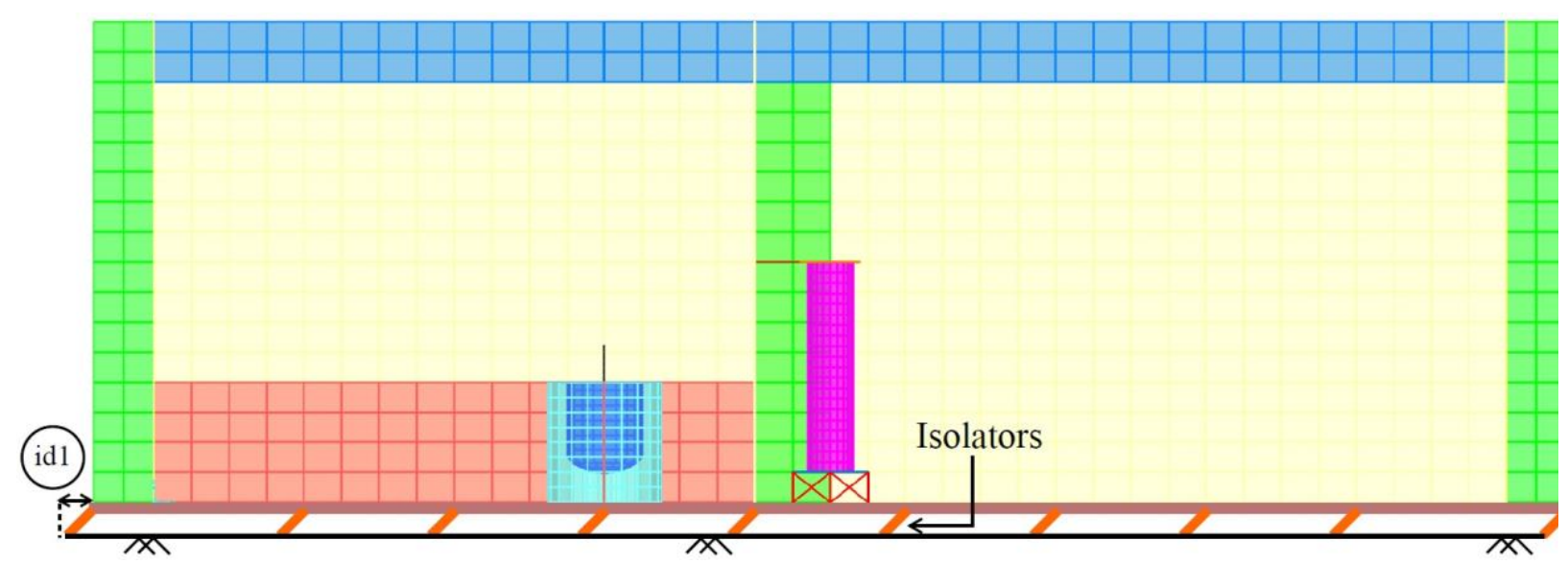

c) isolator displacement

Figure 2-15: Response quantities of interest reported in building \#1 (cont'd)

\subsubsection{Interpretation of results}

\subsection{Vessel wall thickness and weight}

The weight of each pressure vessel, designed for operational loadings only (i.e., no seismic load case), was set equal to 100 unit to normalize results. The effects of earthquake shaking on the weights of the vessels are characterized in Table 2-4. For the fixed-base (FB) building, earthquake shaking at the base of the building with a PGA of $0.1(0.5) \mathrm{g}$ results in a $15 \%(65 \%)$ and $20 \%(90 \%)$ increase in the weights of the reactor vessel and the steam generator, respectively, from that required for operational performance only. These weights are likely lower bound estimates to the required increase because additional wall thickness would be required for bracing of components, internal and external to the vessel. For the base-isolated (BI) building, the weights of both the reactor vessel and the steam generator increase by $5 \%(10 \%)$, for ground motion input of PGA $=0.1(0.5) \mathrm{g}$ to the building.

The seismic penalties for the equipment in the isolated buildings are small, smaller than those for any of the fixed-base buildings, and identical for a given piece of equipment across a wide range of earthquake hazard. Not considered here are the effects of vertical earthquake shaking on stresses in the walls of the vessels, which are expected to be similar for the isolated and fixedbase configurations, and additive to gravity induced stresses.

Table 2-4: Normalized vessel weights in building \#1

\begin{tabular}{|c|c|c|c|c|}
\hline \multirow{2}{*}{ PGA } & \multicolumn{2}{|c|}{ Reactor vessel } & \multicolumn{2}{c|}{ Steam generator } \\
\cline { 2 - 5 } & FB & BI & FB & BI \\
\hline $0.0 \mathrm{~g}$ & 100 & 100 & 100 & 100 \\
\hline $0.1 \mathrm{~g}$ & 115 & 105 & 120 & 105 \\
\hline $0.2 \mathrm{~g}$ & 125 & 105 & 130 & 105 \\
\hline $0.3 \mathrm{~g}$ & 140 & 105 & 150 & 110 \\
\hline $0.5 \mathrm{~g}$ & 165 & 110 & 190 & 110 \\
\hline
\end{tabular}




\subsection{Horizontal accelerations}

The $80^{\text {th }}$ percentile geomean horizontal accelerations at points \#a1 through \#a5 are reported in Table 2-5 for both the FB and BI variants. The horizontal accelerations, in $\mathrm{g}$, at these points, for operational loadings only, is $0 \mathrm{~g}$. For the fixed-base building with an input PGA of $0.5 \mathrm{~g}$, the ground motion is amplified from the basemat to the bottom of the reactor vessel by a factor of 4 $(0.5 \mathrm{~g}$ to $2.14 \mathrm{~g})$; from the basemat to the top of the CRDM housings by a factor of 6 ( $0.5 \mathrm{~g}$ to $3.05 \mathrm{~g})$; and from the basemat to the top of the steam generator by a factor of $5(0.5 \mathrm{~g}$ to $2.52 \mathrm{~g})$. These amplifications may pose a significant challenge for the seismic design and qualification of the equipment and their internals. For the isolated building, the accelerations at all the points are less than the input PGA of $0.5 \mathrm{~g}$ (see Table 2-5).

Figure 2-16a through 2.16j present acceleration response spectra at points \#a1 through \#a5 for an input PGA of $0.3 \mathrm{~g}$ to the building. The figures enable a comparison of the spectral accelerations in the fixed-base building and in its isolated counterpart. Herein, the $x$ - and $y$ directions correspond to the $90 \mathrm{~m}$ and the $60 \mathrm{~m}$ dimensions of the building shown in Figure 2-4, respectively.

Table 2-5: 80th percentile geomean horizontal accelerations (g) in building \#1

\begin{tabular}{|c|c|c|c|c|c|c|c|c|}
\hline \multirow{3}{*}{$\begin{array}{l}\text { Response } \\
\text { parameter }\end{array}$} & \multicolumn{8}{|c|}{ Input horizontal ground acceleration } \\
\hline & \multicolumn{2}{|c|}{$0.1 \mathrm{~g}$} & \multicolumn{2}{|c|}{$0.2 \mathrm{~g}$} & \multicolumn{2}{|c|}{$0.3 \mathrm{~g}$} & \multicolumn{2}{|c|}{$0.5 \mathrm{~g}$} \\
\hline & FB & BI & FB & BI & FB & BI & FB & BI \\
\hline$\# \mathrm{a} 1$ & 0.15 & 0.05 & 0.31 & 0.06 & 0.46 & 0.07 & 0.77 & 0.09 \\
\hline$\# \mathrm{a} 2$ & 0.43 & 0.14 & 0.85 & 0.18 & 1.28 & 0.20 & 2.14 & 0.25 \\
\hline \#a3 & 0.61 & 0.07 & 1.22 & 0.09 & $1.83^{1}$ & 0.10 & 3.05 & 0.13 \\
\hline$\# \mathrm{a} 4$ & 0.14 & 0.06 & 0.27 & 0.07 & 0.41 & 0.08 & 0.69 & 0.10 \\
\hline$\#$ a5 & 0.50 & 0.15 & 1.00 & 0.19 & 1.51 & 0.21 & 2.52 & 0.25 \\
\hline
\end{tabular}

1. Geomean horizontal accelerations are reported in this table. See Figure 2-16e and f for example. For the fixedbase building, the peak horizontal accelerations at the top of the CRDM housing (\#a3) in the $\mathrm{x}$ and $\mathrm{y}$ directions are $1.80 \mathrm{~g}$ and $1.85 \mathrm{~g}$, respectively. The geomean horizontal acceleration is $\sqrt{1.8 \times 1.85}=1.83 \mathrm{~g}$.

\subsection{Horizontal displacements}

The $80^{\text {th }}$ percentile relative horizontal displacements in building $\# 1$ are presented in Table 2-6. The horizontal frequencies of the reactor vessel and the CRDM housing are $14 \mathrm{~Hz}$ and 25 $\mathrm{Hz}$, respectively, and hence the spectral displacements \#d1 and \#d2 are expected to be small. Displacement \#d3, at the top of the steam generator relative to its point of attachment, is approximately $18 \mathrm{~mm}$ in the fixed-base building and $2 \mathrm{~mm}$ in the isolated building, for an input PGA of $0.5 \mathrm{~g}$ to the building.

Table 2-5 and 2-6 show the reductions in equipment weights and horizontal accelerations possible by base isolation. Of importance in an isolated structure is the displacement across the isolation interface. The $80^{\text {th }}$ percentile SRSS isolator displacements in building \#2 are: $12 \mathrm{~mm}$ at $0.1 \mathrm{~g}$ site; $41 \mathrm{~mm}$ at $0.2 \mathrm{~g}$ site; $72 \mathrm{~mm}$ at $0.3 \mathrm{~g}$ site; and $165 \mathrm{~mm}$ at $0.5 \mathrm{~g}$ site. The clearance between the basemat and the surrounding reinforced concrete moat wall must be sufficient to 
accommodate this displacement and more, namely, the $90^{\text {th }}$ percentile displacements for beyond design-basis earthquake shaking.

Table 2-6: 80th percentile SRSS horizontal relative displacements $(\mathrm{mm})$ in building \#1

\begin{tabular}{|c|c|c|c|c|c|c|c|c|}
\hline \multirow{2}{*}{$\begin{array}{c}\text { Response } \\
\text { parameter }\end{array}$} & \multicolumn{9}{|c|}{ Input horizontal ground acceleration } \\
\cline { 2 - 9 } & $\mathbf{0 . 1}$ & \multicolumn{2}{|c|}{$\mathbf{0 . 2} \mathbf{g}$} & \multicolumn{2}{|c|}{$\mathbf{0 . 3} \mathbf{g}$} & \multicolumn{2}{|c|}{$\mathbf{0 . 5} \mathbf{~ g}$} \\
\hline & FB & BI & FB & BI & FB & BI & FB & BI \\
\hline$\# \mathrm{~d} 1$ & 1 & 1 & 2 & 1 & 3 & 1 & 5 & 1 \\
\hline$\# \mathrm{~d} 2$ & 1 & 1 & 1 & 1 & 2 & 1 & 3 & 1 \\
\hline$\# \mathrm{~d} 3$ & 4 & 1 & 7 & 2 & 11 & 2 & 18 & 2 \\
\hline
\end{tabular}

Fixed-base --- Base-isolated Option 3

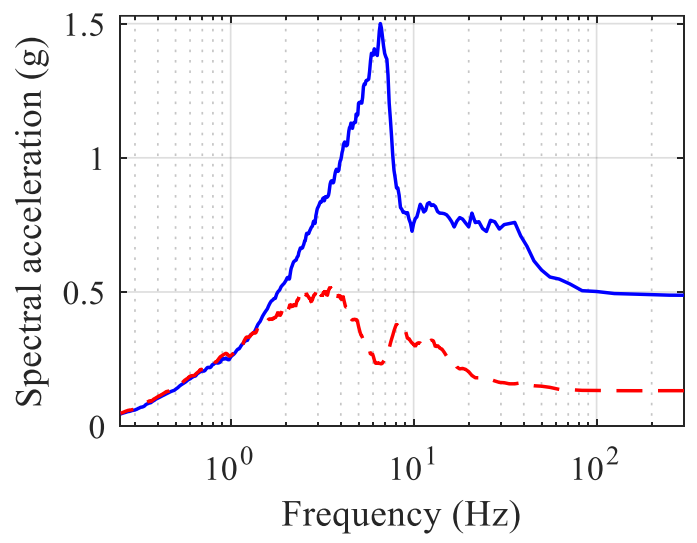

a) $x$-direction, \#a 1

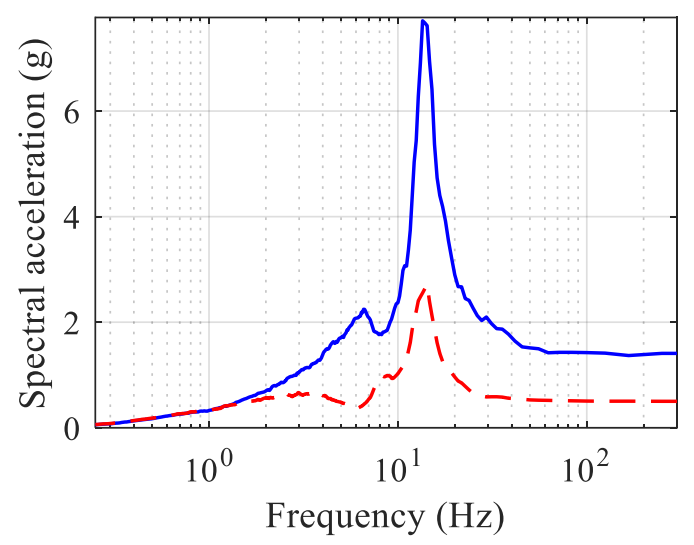

c) $x$-direction, \#a2

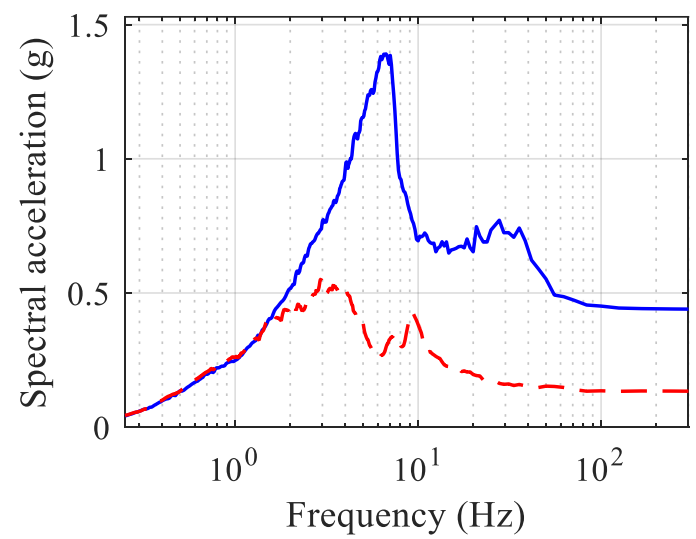

b) $y$-direction, \#a1

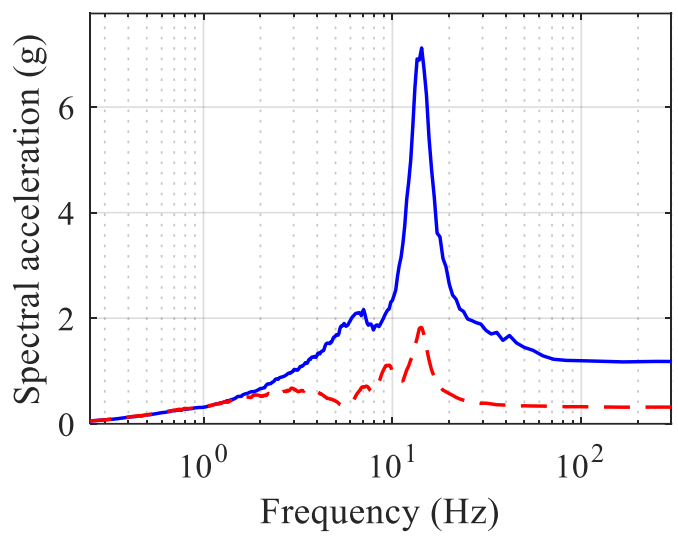

d) $y$-direction, \#a2

Figure 2-16: $80^{\text {th }}$ percentile horizontal acceleration spectra in building \#1, input PGA $=0.3 \mathrm{~g}$ 


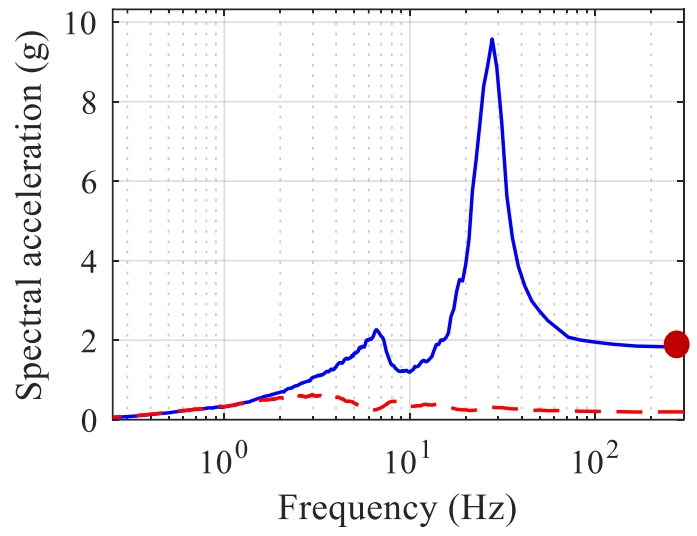

e) $x$-direction, \#a3

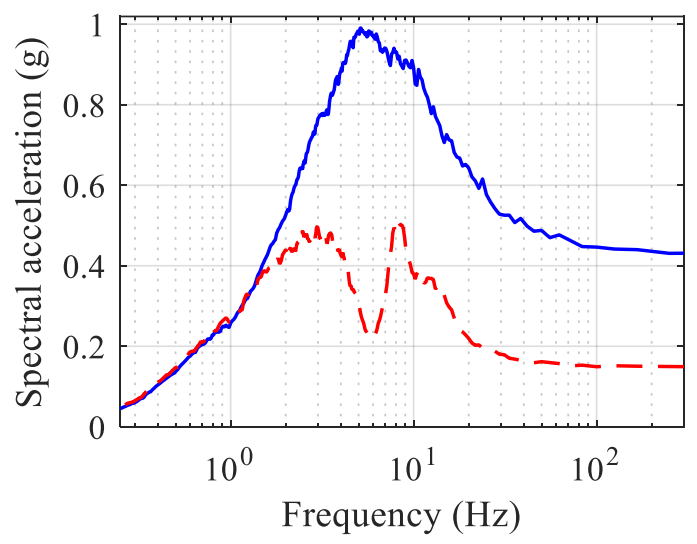

g) $x$-direction, \#a4

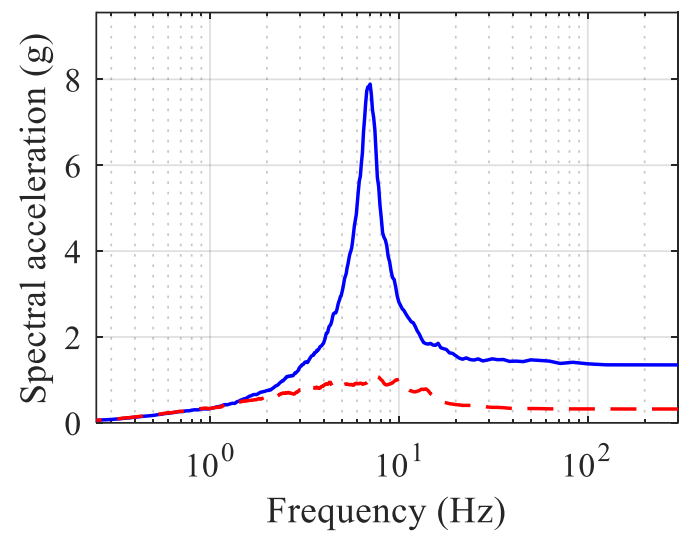

i) $x$-direction, \#a5

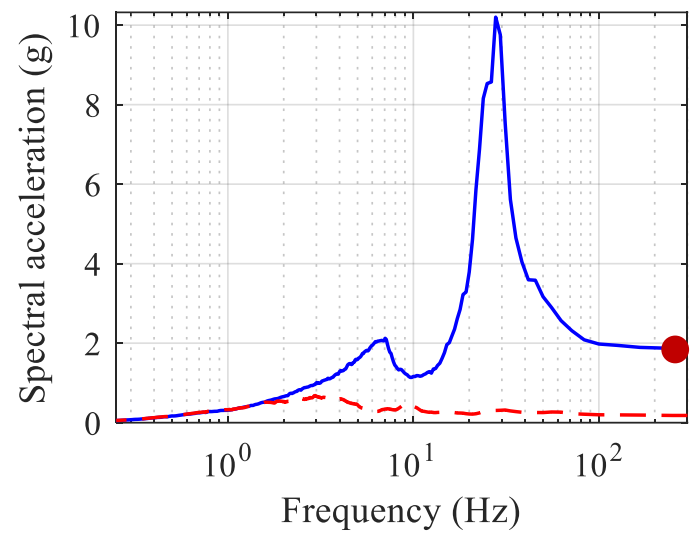

f) $y$-direction, \#a3

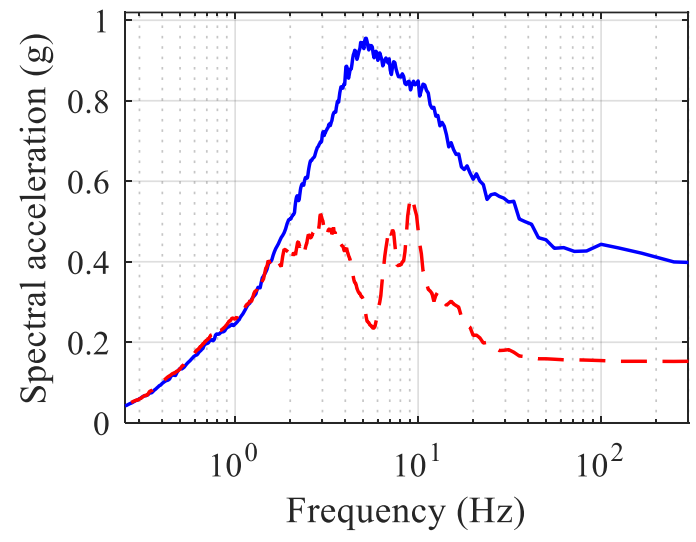

h) $y$-direction, \#a4

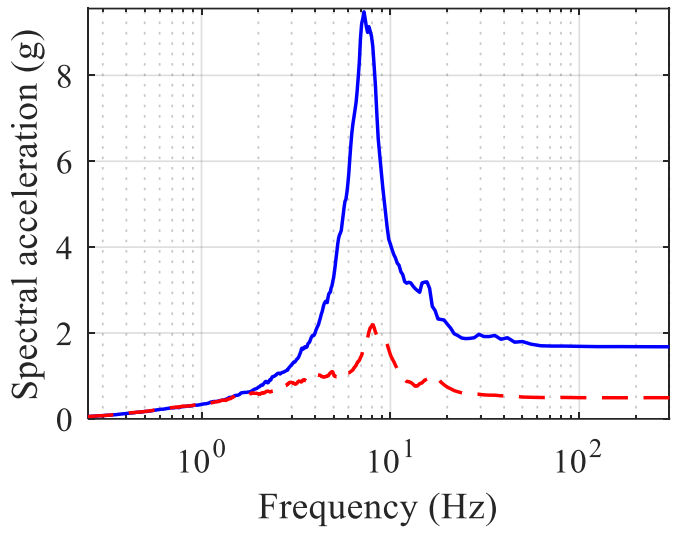

j) $y$-direction, \#a5

Figure 2-16: $80^{\text {th }}$ percentile horizontal acceleration spectra in building \#1, input PGA $=0.3 \mathrm{~g}$ (cont'd) 


\subsection{Seismic isolation of reactor building \#2}

\subsubsection{Preliminary design of the building and equipment}

The floor and roof slabs in building \#2 were sized to support gravity loads and are part of the seismic load path. The ACI complied thicknesses of the perimeter RC walls in the $24 \mathrm{~m}$ and 20 $\mathrm{m}$ direction (see Figure 2-7) were $0.4 \mathrm{~m}$ and $0.6 \mathrm{~m}$, respectively.

In building \#2, SA508 alloy steel was assumed for the construction of the reactor vessel and CRDM housing and SA 516 alloy steel for the steam generator. Experts at X-energy provided a range of values for the operating pressure and temperature inside these vessels. Identical values of pressure (temperature) were selected as 70 bar $\left(285^{\circ} \mathrm{C}\right)$ for both the RV and SG. These operating conditions does not correspond to any particular design and are considered generic. The stress intensities in the vessels due to the operational loads (gravity and internal pressure) were compared with the design limits of the ASME code and the minimum wall thicknesses of the RV and SG were calculated to be $85 \mathrm{~mm}$ and $104 \mathrm{~mm}$, respectively.

\subsubsection{Numerical modeling}

The RC walls, citadels, floor and roof slabs, basemat, and the interior walls in building \#2 were all modeled using four-node shell elements. The CRDM housing unit was modeled using a frame element with an appropriate cross-section. Concrete was assumed to be uncracked with a uniaxial compressive strength of $4000 \mathrm{psi}$ identical to building \#1. The modulus of elasticity for the SA 508 and SA 516 alloy steel was adjusted to their operating temperature. The material properties for the concrete and steel components in building \#2 are reported in Table 2-7.

Table 2-7: Material properties of building \#2

\begin{tabular}{|c|c|c|c|}
\hline Material & Density $\left(\mathbf{k g} / \mathbf{m}^{\mathbf{3}}\right)$ & Young's modulus (GPa) & Poisson's ratio \\
\hline Concrete & 2400 & 24.8 & 0.2 \\
\hline SA 508 for the RV & 7850 & $175^{1}$ & 0.3 \\
\hline SA 508 for the CRDM housing & 7850 & 200 & 0.3 \\
\hline SA 516 alloy steel & 7850 & $185^{1}$ & 0.3 \\
\hline
\end{tabular}

1. Modulus of elasticity at the specified operating temperature

The base nodes of the building were fixed and the mass of RV internals (350 tons) and SG internals (100 tons) was distributed along the height of the vessels for dynamic analyses. The translational frequencies were extracted as: 6-7 Hz for the reactor building; $8 \mathrm{~Hz}$ for the RV; 14 $\mathrm{Hz}$ for the CRDM housing; and $12-13 \mathrm{~Hz}$ for the SG. The total seismic weight of building \#2 is approximately 15,700 tons. The building is isolated with $20 \mathrm{FP}$ bearings per the layout shown in Figure 2-17. The FP bearings were modelled using two-node link elements and assigned 'Friction isolator' material in SAP2000 similar to building \#1. 


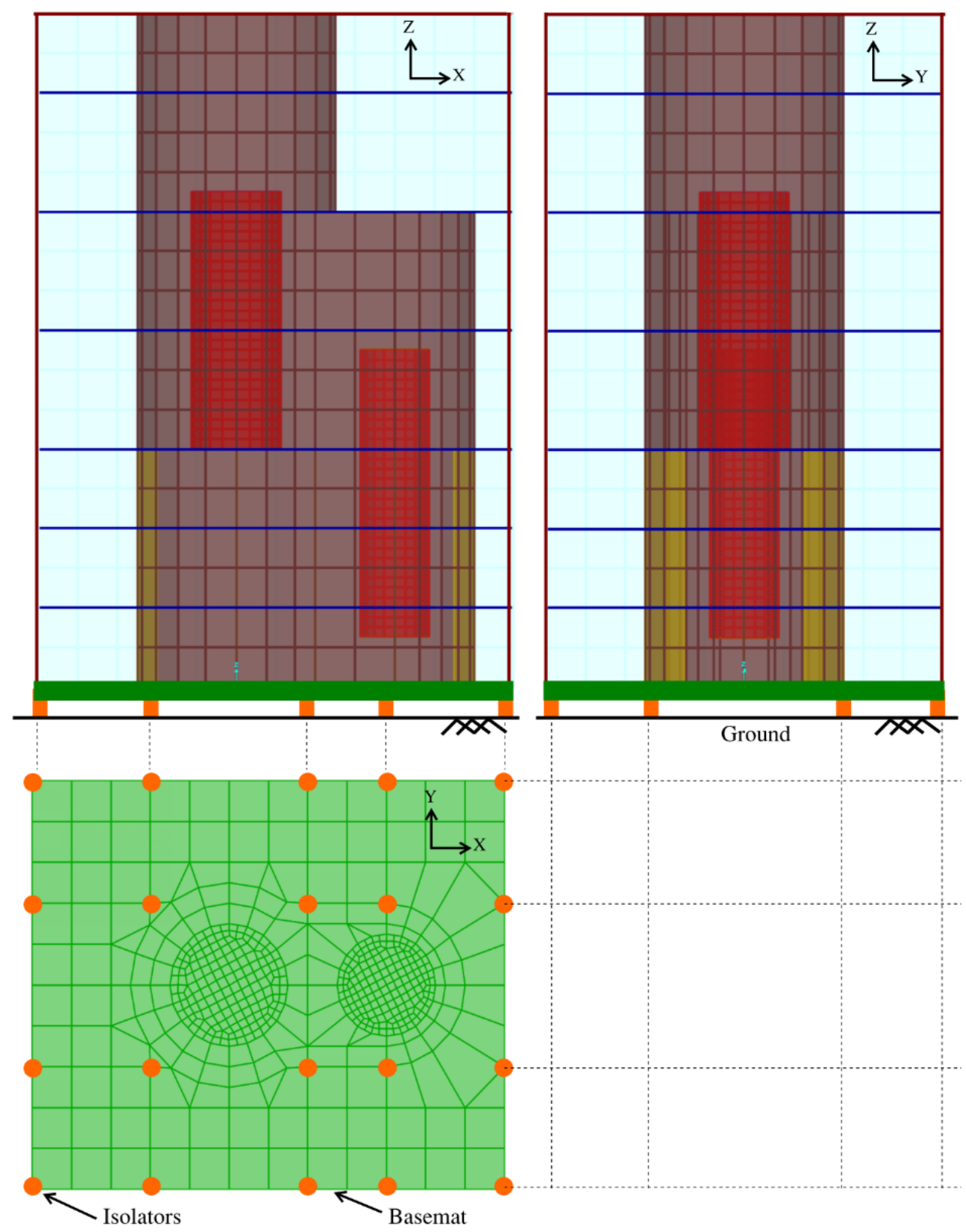

Figure 2-17: Elevation view and layout of the isolation system for building \#2

\subsubsection{Response-history analysis}

\subsubsection{Analysis and reporting of results}

Identical to building \#1, the fixed-base and isolated (option 3) variants of building \#2 were analyzed for the INL motions amplitude scaled to a PGA of $0.1 \mathrm{~g}, 0.2 \mathrm{~g}, 0.3 \mathrm{~g}$, and $0.5 \mathrm{~g}$. For building \#2, the first 150 Ritz modes recovered $99 \%$ and $90 \%$ of the mass in the horizontal and vertical directions, respectively. The damping in the fixed-base and the isolated buildings was assigned identical to building \#1 (see discussion on damping in Section 2.6.4). The products of the response-history analyses, for incremented intensities of earthquake shaking, were: 
1. Stresses in the walls of the vessels (RV and SG).

2. Horizontal accelerations at the points marked using solid green circles in Figure 2-18a. Points $\# \mathrm{a} 7, \# \mathrm{a} 9$, and \#a10 are the selected representative locations for the internals of the vessels.

- \#a6 - point of attachment of the reactor vessel and steam generator

- \#a7 - top of the reactor vessel (point of attachment of the CRDM housing)

- \#a8 - top of the CRDM housing

- $\quad \#$ a9 - top of the steam generator

- \#a10 - bottom of the steam generator

3. Horizontal displacements between points of interest, as identified in Figure 2-18b.

- \#d4 - displacement at the top of the RV with respect to its point of attachment

- \#d5 - displacement at the top of the CRDM housing with respect to the top of the RV

- \#d6 - displacement at the top of the SG with respect to its points of attachment

- \#d7 - displacement at the bottom of the SG with respect to its points of attachment

4. Displacement across the isolation interface (\#id2), as shown in Figure 2-18b.

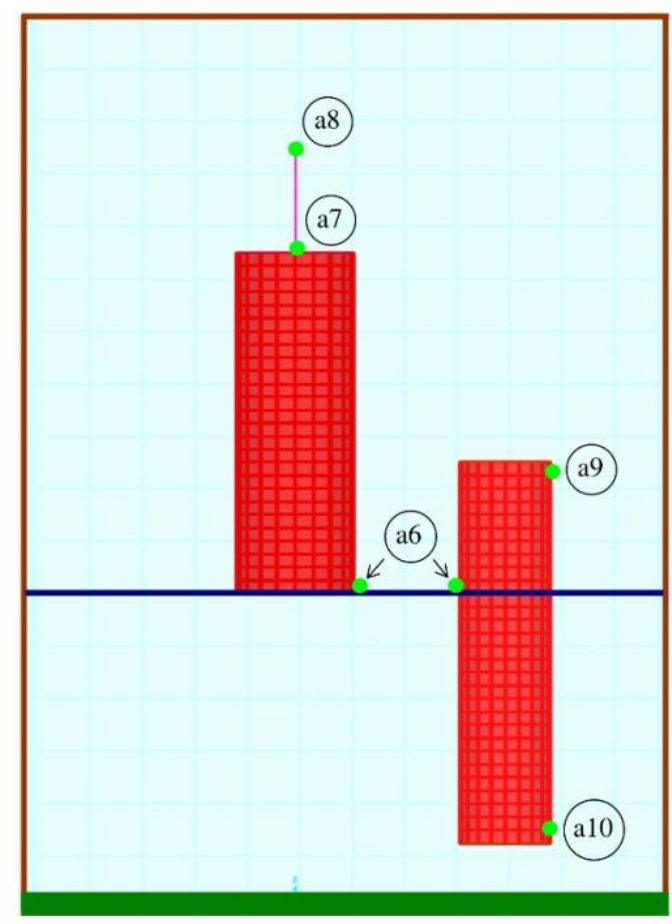

a) horizontal accelerations

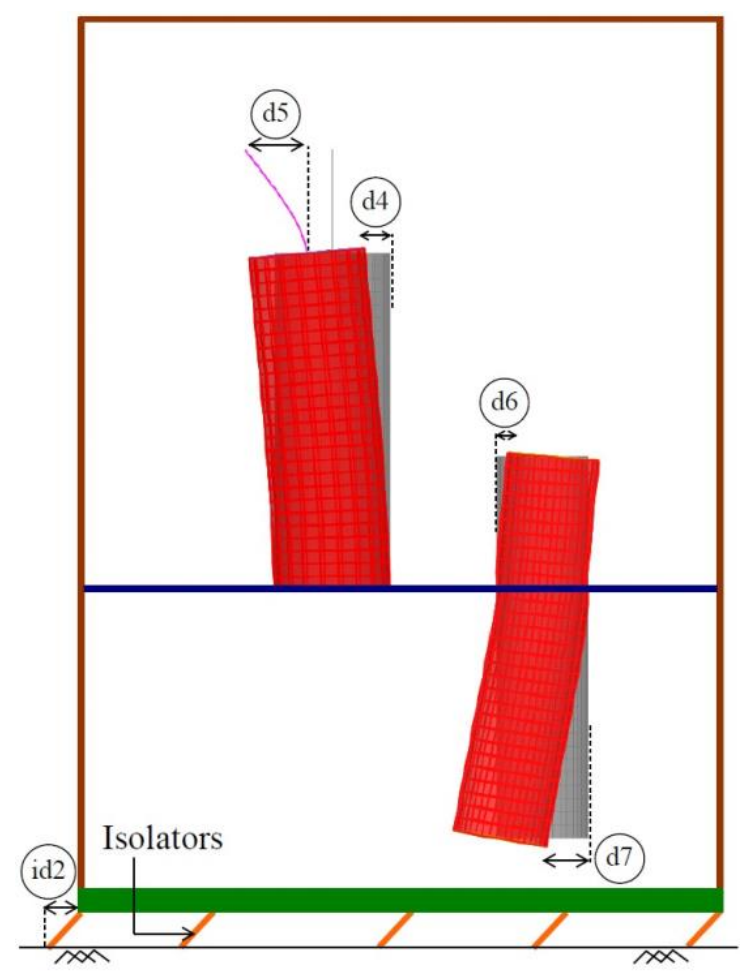

b) horizontal relative displacements

Figure 2-18: Response quantities of interest reported in building \#2

Quantities \#a6 through and \#a10, and \#d4 through \#d7 are reported for both the fixed-base and the isolated buildings. Quantity \#id2 is reported only for the isolated building. The earthquake-induced stresses in the vessels were calculated at the $80^{\text {th }}$ percentile and then increased by $25 \%$ similar to building \#1 to adjust for $2 \%$ (or less) damping. The horizontal accelerations at representative locations for the internals (\#a7, \#a9, \#a10) and at the upper end of the CRDM housing (\#a8) were calculated at $80^{\text {th }}$ percentile and increased by $25 \%$ to account for their 2\% (or less) damping. The relative horizontal displacements \#d4 through \#d7 were also increased by $25 \%$ to account for their $2 \%$ (or less) damping. 


\subsubsection{Interpretation of results}

\subsection{Vessel wall thickness and height}

For the fixed-base building, earthquake shaking at the base of the building with a PGA of 0.1 $(0.5) \mathrm{g}$ results in a 10\% (60\%) and 5\% (20\%) increase in the weights of the reactor vessel and steam generator, respectively, from that required for operational performance only (see Table $2-8$ ). For the base-isolated building, an increase in weights of the reactor vessel and steam generator vessels by $5 \%$ from the operational design would provide sufficient seismic capacity for sites up to a PGA of $0.5 \mathrm{~g}$.

Table 2-8: Normalized vessel weights in building \#2

\begin{tabular}{|c|c|c|c|c|}
\hline \multirow{2}{*}{ PGA } & \multicolumn{2}{|c|}{ Reactor vessel } & \multicolumn{2}{c|}{ Steam generator } \\
\cline { 2 - 5 } & FB & BI & FB & BI \\
\hline $0.0 \mathrm{~g}$ & 100 & 100 & 100 & 10 \\
\hline $0.1 \mathrm{~g}$ & 110 & 105 & 105 & 105 \\
\hline $0.2 \mathrm{~g}$ & 120 & 105 & 105 & 105 \\
\hline $0.3 \mathrm{~g}$ & 135 & 105 & 110 & 105 \\
\hline $0.5 \mathrm{~g}$ & 160 & 105 & 120 & 105 \\
\hline
\end{tabular}

\subsection{Horizontal accelerations}

The $80^{\text {th }}$ percentile geomean horizontal accelerations at points \#a6 through \#a10 are reported in Table 2-9. For a seismic input to the building of PGA $=0.5 \mathrm{~g}$, the amplification of ground motion in the fixed-base (and isolated) buildings are by a factor of: 10 (0.6) at point \#a7; 25 (2) at point \#a8; $6(0.8)$ at point \#a10. The accelerations in the isolated building are small and substantially less than in its fixed-base counterpart. The acceleration response spectra at points \#a6 through \#a10 are presented in Figure 2-19a through Figure 2-19j, for an input PGA to the building of $0.3 \mathrm{~g}$. The $x$ - and $y$-directions correspond to the $24 \mathrm{~m}$ and the $20 \mathrm{~m}$ dimensions of the building (see Figure 2-7), respectively.

Table 2-9: 80th percentile geomean horizontal accelerations (g) in building \#2

\begin{tabular}{|c|c|c|c|c|c|c|c|c|}
\hline \multirow{3}{*}{$\begin{array}{l}\text { Response } \\
\text { parameter }\end{array}$} & \multicolumn{8}{|c|}{ Input horizontal ground acceleration } \\
\hline & \multicolumn{2}{|c|}{$0.1 \mathrm{~g}$} & \multicolumn{2}{|c|}{$0.2 \mathrm{~g}$} & \multicolumn{2}{|c|}{$0.3 \mathrm{~g}$} & \multicolumn{2}{|c|}{$0.5 \mathrm{~g}$} \\
\hline & FB & BI & FB & BI & FB & BI & FB & BI \\
\hline$\#$ a6 & 0.23 & 0.08 & 0.45 & 0.09 & 0.67 & 0.10 & 1.12 & 0.13 \\
\hline \#a7 & 1.07 & 0.20 & 2.13 & 0.27 & 3.20 & 0.29 & 5.33 & 0.33 \\
\hline$\# \mathrm{a} 8$ & 2.57 & 0.54 & 5.14 & 0.70 & $7.70^{1}$ & 0.85 & 12.85 & 1.02 \\
\hline$\# \mathrm{a} 9$ & 0.41 & 0.14 & 0.81 & 0.19 & 1.21 & 0.20 & 2.01 & 0.25 \\
\hline$\#$ a10 & 0.61 & 0.21 & 1.21 & 0.29 & 1.81 & 0.32 & 3.01 & 0.40 \\
\hline
\end{tabular}

1. Geomean horizontal accelerations are reported in this table. See Figure 2-19e and f for example. For the fixedbase building, the peak horizontal accelerations at the top of the CRDM housing (\#a8) in the $\mathrm{x}$ and $\mathrm{y}$ directions are $9 \mathrm{~g}$ and $6.6 \mathrm{~g}$, respectively. The geomean horizontal acceleration is $\sqrt{9 \times 6.6}=7.7 \mathrm{~g}$. 
Fixed-base - - Base-isolated Option 3

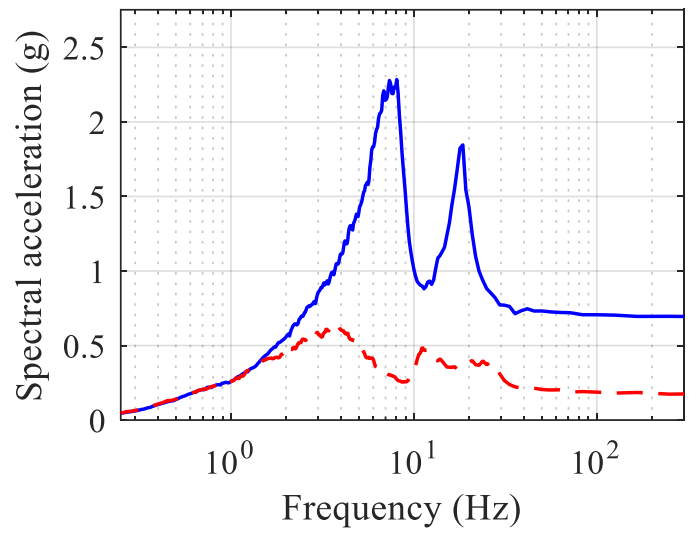

a) $x$-direction, \#a6

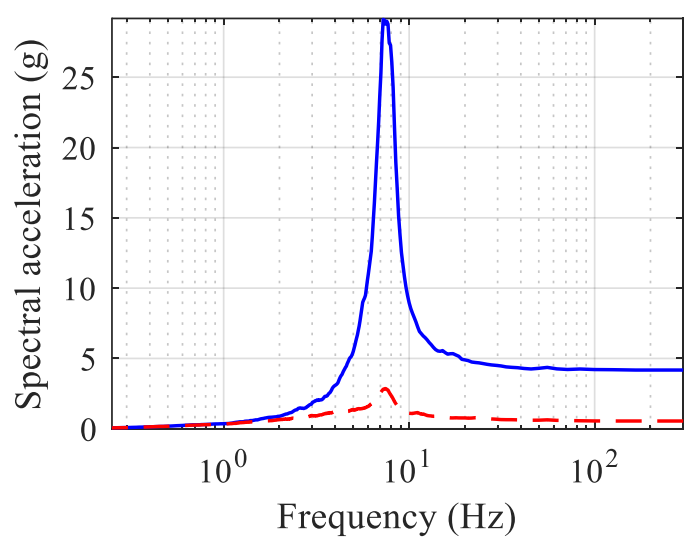

c) $x$-direction, \#a7

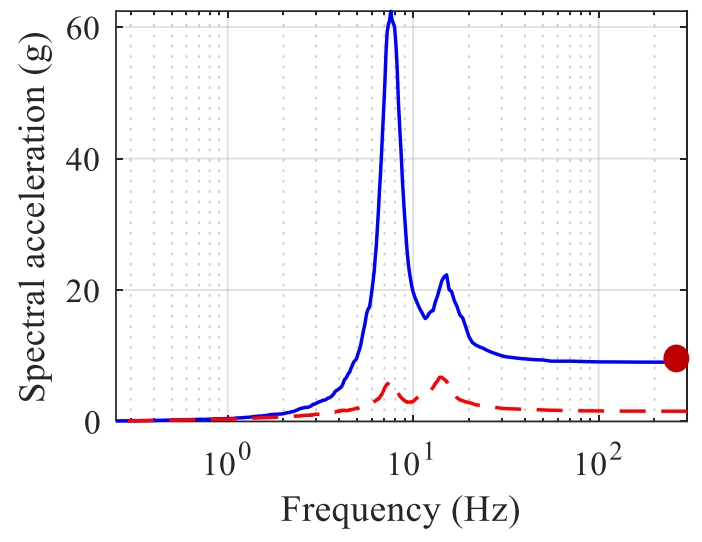

e) $x$-direction, \#a8

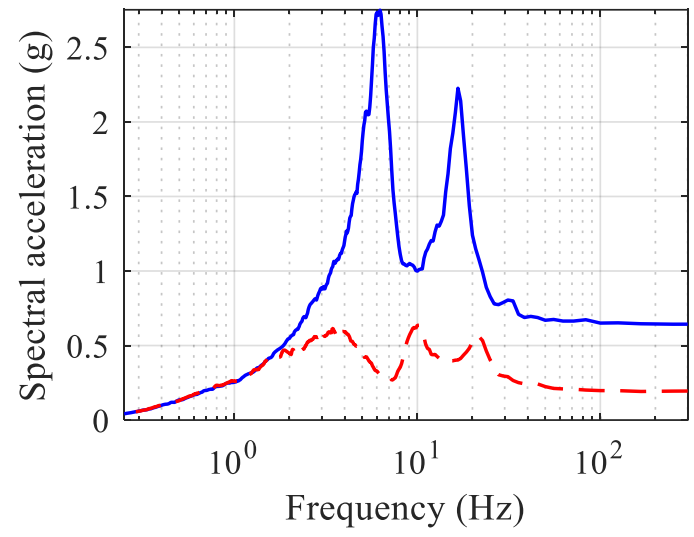

b) $y$-direction, \#a6

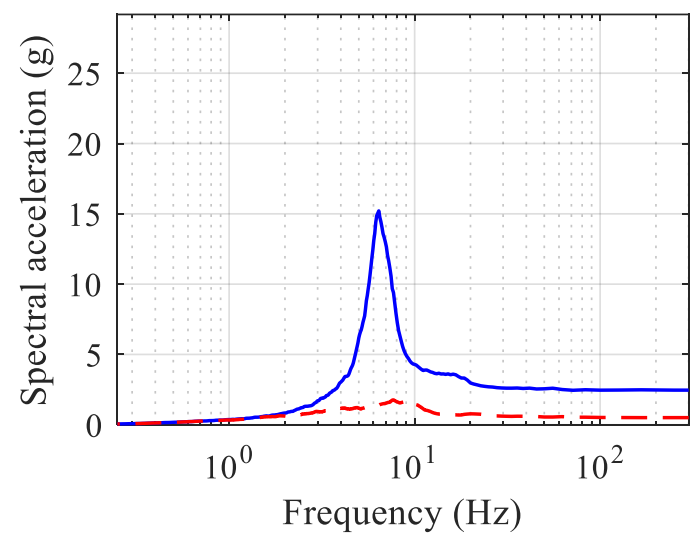

d) $y$-direction, \#a7

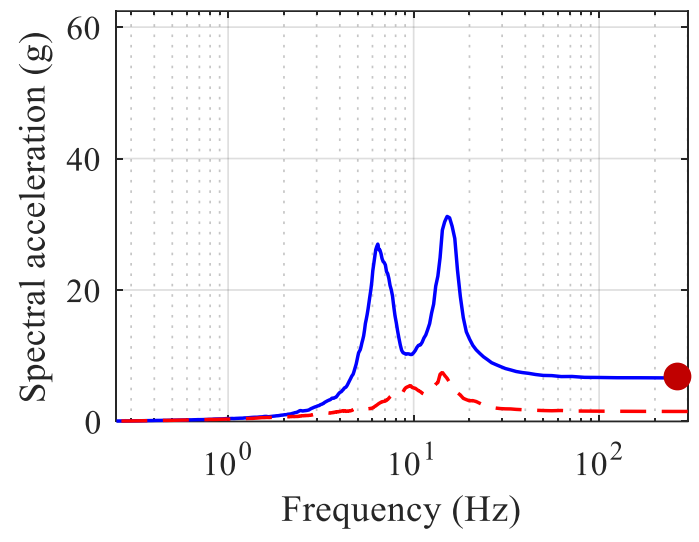

f) $y$-direction, $\# \mathrm{a} 8$

Figure 2-19: $80^{\text {th }}$ percentile horizontal acceleration spectra in building \#2, input PGA $=0.3 \mathrm{~g}$ 


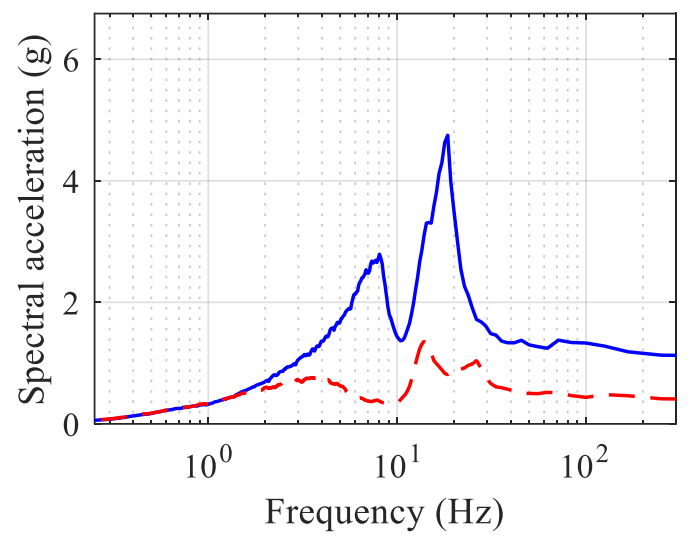

g) $x$-direction, \#a9

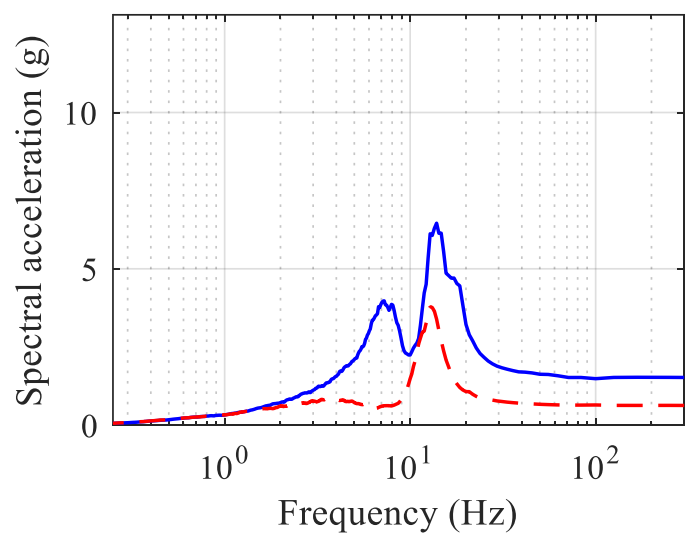

i) $x$-direction, \#a10

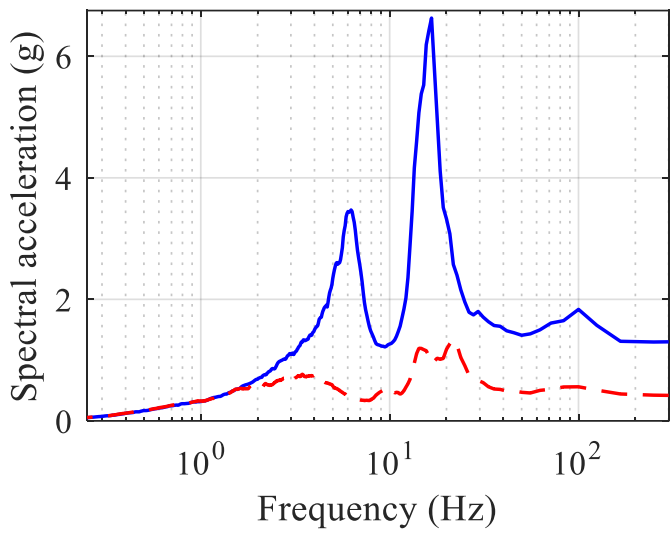

h) $y$-direction, \#a9

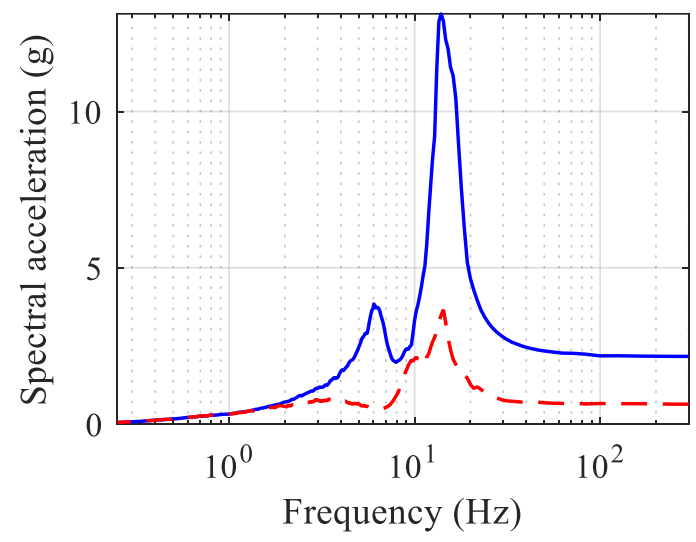

j) $y$-direction, \#a10

Figure 2-19: $80^{\text {th }}$ percentile horizontal acceleration spectra in building \#2, input PGA $=0.3 \mathrm{~g}$ (cont'd)

\subsection{Horizontal displacements}

The $80^{\text {th }}$ percentile relative horizontal displacements, \#d4 through \#d7, are presented in Table 2-10. Displacement \#d4 is approximately $38 \mathrm{~mm}$ in the fixed-base building and $2 \mathrm{~mm}$ in the isolated building, for an input PGA to the building of $0.5 \mathrm{~g}$. A similar reduction was observed for $\# \mathrm{~d} 5$. The $80^{\text {th }}$ percentile SRSS isolator displacements in building \#2 are: $13 \mathrm{~mm}$ at $0.1 \mathrm{~g}$ site; 41 $\mathrm{mm}$ at $0.2 \mathrm{~g}$ site; $76 \mathrm{~mm}$ at $0.3 \mathrm{~g}$ site; and $165 \mathrm{~mm}$ at $0.5 \mathrm{~g}$ site. 
Table 2-10: 80th percentile SRSS horizontal relative displacements $(\mathrm{mm})$ in building \#2

\begin{tabular}{|c|c|c|c|c|c|c|c|c|}
\hline \multirow{2}{*}{$\begin{array}{c}\text { Response } \\
\text { parameter }\end{array}$} & \multicolumn{9}{c|}{ Input horizontal ground acceleration } \\
\cline { 2 - 10 } & \multicolumn{2}{|c|}{$\mathbf{0 . 1} \mathbf{g}$} & \multicolumn{2}{c|}{$\mathbf{0 . 2} \mathbf{g}$} & \multicolumn{2}{c|}{$\mathbf{0 . 3} \mathbf{g}$} & \multicolumn{2}{c|}{$\mathbf{0 . 5} \mathbf{~}$} \\
\hline & FB & BI & FB & BI & FB & BI & FB & BI \\
\hline \#d4 & 8 & 1 & 15 & 2 & 23 & 2 & 38 & 2 \\
\hline \#d5 & 9 & 2 & 17 & 2 & 26 & 3 & 43 & 3 \\
\hline \#d6 & 1 & 1 & 1 & 1 & 1 & 1 & 2 & 1 \\
\hline \#d7 & 1 & 1 & 3 & 1 & 4 & 1 & 7 & 1 \\
\hline
\end{tabular}

\subsection{Summary and conclusions}

The two goals of this chapter were to: (1) quantify the impact of the seismic load case (or seismic penalty) on the design of conventionally constructed advanced reactor buildings and their safety-class equipment, and (2) quantify the reductions in seismic demands enabled by seismic base isolation. Generic designs were developed for the two reactor buildings each housing a fundamentally different reactor type based on information in the open literature, including geometries, materials, boundary conditions, internals, and operating conditions, so the results presented herein are not indicative of reactors specific to one nuclear steam system supplier. Accordingly, analysis results presented in this report are considered generic and indicative of the possible seismic penalties in advanced reactors.

The buildings were analyzed for incremented intensities of earthquake shaking and the seismic penalty was then quantified in terms of required increase in wall thickness of the vessels, horizontal accelerations and displacements at the points of attachment of, and the internals in, the safety-class equipment, as a function of increasing earthquake shaking to the building. The following key conclusions are drawn from this chapter:

1. The seismic penalty on the weights (and thus cost) of the reactors and the steam generators installed in the conventional (fixed-base) buildings can be significant. To increase the seismic capacity of the vessels from an input PGA to the building of $0.0 \mathrm{~g}$ (operational loads only) to $0.5 \mathrm{~g}$, the weights of the reactor vessel (steam generator) must be increased from 100 (100) to 165 (190) units in building \#1 and 100 (100) to 160 (120) units in building \#2. If the buildings are base isolated, a $10 \%$ increase in the vessel wall thickness from that required for operational loadings would provide sufficient seismic capacity to resist earthquake shaking of up to PGA of $0.5 \mathrm{~g}$. The seismic penalty on safety-class equipment is greatly reduced if isolation is implemented.

2. The horizontal accelerations in the vessel internals and the CRDM housings in the fixedbase buildings are very high. For example, the acceleration at the top of the CRDM housing in building \#2 is approximately $13 \mathrm{~g}$ for an input PGA of $0.5 \mathrm{~g}$ to the building. The design and qualification of the housings to accommodate such high accelerations might be impossible. For an input PGA to the building of $0.5 \mathrm{~g}$, base isolation enables a reduction in these horizontal accelerations by a factor of between 7 and 20 for the vessel internals, and by a factor of 13 at the top of the CRDM housings. 
3. Base isolation of the reactor buildings would enable standardization of equipment designs for the four safety-class vessels (RV and SG in each building) considered herein.

Equipment in the building certified for a seismic hazard of PGA of $0.1 \mathrm{~g}$, assuming conventional construction, could be used at sites of much higher seismic hazard, if the buildings are isolated. (The effects of incremented vertical shaking would have to be addressed in the seismic qualification, but the effects of horizontal shaking are much more detrimental on the equipment considered here than vertical shaking.) Only the isolation system would have to be designed at each site to limit the demands (stresses, accelerations, and displacements) in the equipment to their rated capacities. This should eliminate the need for site-specific seismic qualification, licensing and regulatory review of equipment designs and provide a pathway for NoaK construction of advanced reactors. Site-specific qualification and testing, per ASCE/SEI Standard 43 will be required for the isolators that comprise the isolation system. 


\section{RISK- AND COST-BASED DESIGN OPTIMIZATION OF A GENERIC SAFETY SYSTEM}

\subsection{Introduction}

Design optimization is a routine goal of all branches of engineering. For example, the designs of some buildings, commercial airliners, fighter jets, automobiles, etc., are optimized to reduce the cost of fabricating or constructing each product, within the constraints of safety, regulations, and manufacturability. Because of the disciplines involved, the design optimization of a nuclear power plant (NPP) can be considerably more complex, given the stringent regulations in the nuclear industry and the disparate collection of a large number of systems, structures and components (SSCs), including structural elements, and mechanical and electrical equipment, that comprise each NPP.

Advanced reactors are designed with newer, safer reactor technologies like passive and 'walk-away' safe systems. However, the design procedures for the balance of plant (BoP) of advanced reactors are similar to those used in existing nuclear power plants. Without swift and aggressive innovation in design procedures and construction technologies aimed towards reducing capital costs, advanced reactors are at a risk of running into cost overruns. The risk reduction from advanced reactor technologies, apart from increasing safety, provides a unique opportunity to reduce capital costs, especially in the BoP. The risk-based design paradigm aims to use this opportunity to translate the risk reductions into cost reductions by designing the various SSCs based on their relative risk contributions. Nuclear power plants in the past have been designed using essentially deterministic, non-iterative methods that result in highly conservative and expensive designs (Figure 3-1). This study proposes a more iterative risk- and cost-based design process where the seismic design is optimized to both meet safety performance goals, as well as minimize the total capital cost. This design process is termed as risk- and costbased design optimization.

This chapter demonstrates the risk- and cost-based seismic design optimization of an idealized, but representative, safety system in a nuclear facility, hereafter referred to as the generic nuclear facility (GNF). The GNF is assumed to be sited in the Idaho National Laboratory (INL) site, which has a low to moderate seismic hazard. The design of the safety system in GNF is defined by seismic fragilities of the SSCs of the safety system. Seismic fragility is a measure of the seismic capacity of the SSC and is represented as a double lognormal distribution defined by a median and two lognormal standard deviations for epistemic and aleatory uncertainties (Huang et $a l ., 2008$ a). For a higher median fragility, the seismic integrity of the SSC is higher, and seismic risk is smaller. A higher seismic fragility also requires more upfront capital investment to make the SSC stronger, and therefore has a higher capital cost. The goal of the design optimization process presented in this chapter is to minimize the total capital cost of the GNF while meeting performance goals, which are to remain below a user-specified seismic risk limit. This is an optimization problem involving capital cost and risk calculation. The seismic risk is calculated through seismic probabilistic risk assessment (SPRA) performed using MASTODON (Veeraraghavan et al., 2020), which is an open-source seismic analysis and risk assessment software being developed at Idaho National Laboratory. The optimization is performed using Dakota (Adams et al., 2014), which is another open-source software for optimization and uncertainty quantification developed at Sandia National Laboratory. Section 3.2 describes the 
SPRA process in MASTODON and Section 3.3 describes the formulation of the design optimization problem to be solved by Dakota. Section 3.4 presents the development of a representative probabilistic risk assessment (PRA) model for the GNF and the capital cost calculation process for GNF. Section 3.5 describes the design optimization of GNF using MASTODON and Dakota along with the results. In this section, design optimization is first performed without including component seismic isolation, and the optimal seismic fragilities are calculated that result in a minimum capital cost. The optimization is performed again while including component seismic isolation. In this case the in addition to calculating the optimal seismic fragilities, the design optimization process also results in the optimal set of SSCs that need to be isolated to result in the minimum capital cost. Section 3.6 presents a summary and the conclusions of this chapter.

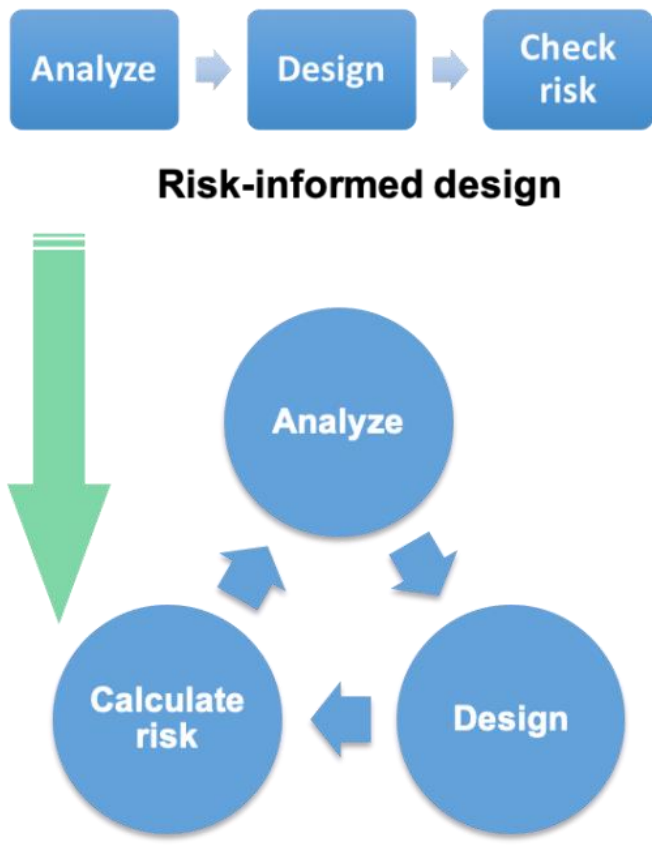

\section{Risk-based design}

Figure 3-1: Illustration of non-iterative and iterative design processes

\subsection{Seismic probabilistic risk assessment using MASTODON}

MASTODON performs SPRA calculations using the time-based methodology proposed by Huang et al. (2008a) and Huang et al. (2011b). This methodology (hereafter referred to as the Huang methodology) accommodates nonlinear response in the soil-structure system, unlike the traditional SPRA approach (EPRI, 2013), which assumes linear behavior throughout the model. The Huang methodology is therefore suitable for problems that include nonlinear soil-structure interaction (SSI), nonlinear site response, seismic isolation, and nonlinear structural response (which may occur in NPPs during beyond design basis shaking). A primary improvement in this methodology from the traditional SPRA is the usage of fragility curves for systems, structures and components (SSCs) that are functions of a local demand parameter such as, spectral 
acceleration at the point of attachment of an equipment. In a traditional SPRA approach, the SSC fragility curves are typically expressed as functions of peak ground acceleration (PGA).

The Huang SPRA methodology involves five steps, as illustrated in Figure 3-2. The first step is plant system analysis, which involves the development of event trees and fault trees that lead to an accident or an unacceptable event (such as core damage). Fault trees describe the logic leading to the occurrence of a top event from one or more basic events, which typically correspond to the damage or failure of an SSC, such as a pipe burst or a shear wall failure. For each of these basic events, a fragility curve is calculated, which describes the probability of the occurrence of the basic event conditioned upon a local demand parameter such as the story drift of a shear wall. An event tree describes the logic between several such top events leading to an accident or an unacceptable event. The second step involves a probabilistic seismic hazard analysis and the calculation of seismic hazard curves, which describe the mean annual frequency of exceedance (MAFE) of a particular ground motion parameter, such as PGA or the spectral acceleration at $0.1 \mathrm{sec}$. In the Huang methodology, the seismic hazard curve is divided into several intervals (or bins) spanning through the range of interest of the seismic hazard. Ground motions are selected and scaled for each of these bins such that they represent the seismic hazard of the bin as well as the uncertainty in the ground motion characteristics, such as frequency content. The third step involves probabilistic simulations of the structure using the ground motions selected in the previous step. These probabilistic simulations involve random sampling (using sampling procedures like Monte Carlo or Latin Hypercube) of the ground motions and properties of the soil-structure system and performing several (tens to hundreds) simulations. The results of these simulations are used to calculate the probabilistic demands (expressed as lognormal distributions) at the locations of SSCs corresponding to the basic events. In the Huang methodology, the demands from the tens or hundreds of simulations are expanded to hundreds of thousands of demands using the Yang et al. (2009) procedure, which conserves the statistical correlations between the various SSC demand distributions while expanding the demand datasets. The fourth step involves using these demands, along with the fragility curves calculated in the first step, to calculate the probability of failure of the SSCs conditioned upon the seismic demands. In the fifth step, these conditional probabilities of failure, along with the event trees and fault trees developed in the first step, are used to calculate the probability of occurrence of the accident or unacceptable event for each hazard bin. Such a calculation is referred to as fault tree analysis (FTA) and can be performed either using a closed-form solution, or through Monte Carlo simulations using the expanded demand datasets calculated in the previous step. While the closed-form solutions are computationally inexpensive, they also assume that the demands from various SSCs are statistically independent. However, the Monte-Carlo simulations proposed by the Huang methodology do not require this assumption. Yu et al. (2018) compared the results calculated using the closed form solutions and Monte Carlo simulations for a simple fault tree and found that the results are similar for the problem considered in their study. The FTA is repeated for all the hazard bins of step 2 and the probability of each bin is multiplied with the corresponding mean annual frequency of shaking (from the hazard curve) to calculate the risk contribution from each bin. The total risk of accident or unacceptable performance is then calculated as the sum of the risk contributions. 


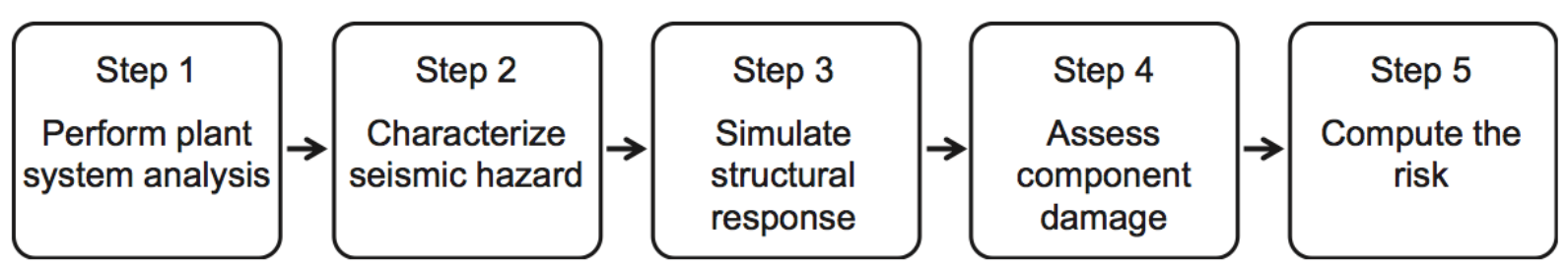

Figure 3-2: The SPRA methodology (Huang et al., 2008a; Huang et al., 2011b)

The Huang SPRA methodology is implemented in MASTODON, both as a Python module and as a part of the source code (written in $\mathrm{C}++$ ). While the inclusion in the source code provides a continuous integration between the finite-element simulations and SPRA, the Python module provides the flexibility to perform standalone SPRA in a more interactive environment. Both the Python module and the source code offer the capability to perform steps 3, 4, and 5 of the Huang SPRA methodology illustrated in Figure 3-2. The integration of SPRA in MASTODON and a description of the capabilities is presented in Figure 3-3.

MASTODON inputs the ground motions selected and scaled in step 2 and uses the stochastic tools module of the MOOSE framework to sample the properties of the finite element model along with the ground motions and run probabilistic simulations. Currently, it includes the Latin Hypercube and Monte Carlo samplers and is capable of efficiently parallelizing the probabilistic simulations amongst hundreds or thousands of processors. MASTODON also inputs the number of bins in the hazard curve, and postprocesses the probabilistic demands at SSC locations for each of these bins. Using the fragility curves (or capacity distributions, i.e., the probability of failure of the SSC given a local demand parameter) for each SSC provided by the user, MASTODON then calculates a probability of failure conditioned upon seismic shaking for each bin. A lognormal distribution is fit into these probabilities of failure to calculate an 'enhanced fragility', which describes the probability of failure of the SSC conditioned upon the seismic input to the plant. These enhanced fragilities are then used in the FTA to calculate the system fragility. The system fragility is then convolved with the seismic hazard according to step 5 of the Huang SPRA methodology (and consistent with traditional approaches) to calculate the system risk.

Fault tree analysis and quantification in MASTODON can be performed both using closedform solutions as well as Monte Carlo simulations. Currently, MASTODON is limited to the quantification of one fault tree at a time and does not analyze event trees. The closed-form solutions for FTA in MASTODON are calculated using the same approach used by the industrystandard probabilistic risk assessment (PRA) code, Saphire (USNRC, 2011) developed by INL for the United States Nuclear Regulatory Commission (USNRC). Saphire uses the MOCUS (Method for Obtaining Cut Sets) algorithm (Fussel and Vesely, 1972; Smith and Wood, 2011) to perform FTA and calculate the minimal cut sets for each fault tree. A minimal cut set is a combination of basic events, which, when occur together, will lead to occurrence of the top event of the fault tree. Generation of cut sets using MOCUS is a recursive calculation involving various Boolean operations and application of set theory. A detailed description of this cut set generation procedure is provided in the Saphire technical manual (Smith and Wood, 2011). Each fault tree can result in several minimal cut sets and the probabilities associated with these cut sets are calculated using the probabilities of basic events. This calculation is referred to as fault tree quantification. MASTODON, like Saphire, offers three methods of fault tree quantification: (1) rare event approximation, which involves the summation of the probabilities of all the minimal 
cut sets and is suitable for cut sets that have very small probabilities, (2) minimal cut set upper bound, which is an approximation of the probability of the union of all cut sets that provides a conservative estimate to the top event probability, and (3) min-max approach, which is an exact quantification of the fault tree and calculates the exact probability of the union of all the cut sets.

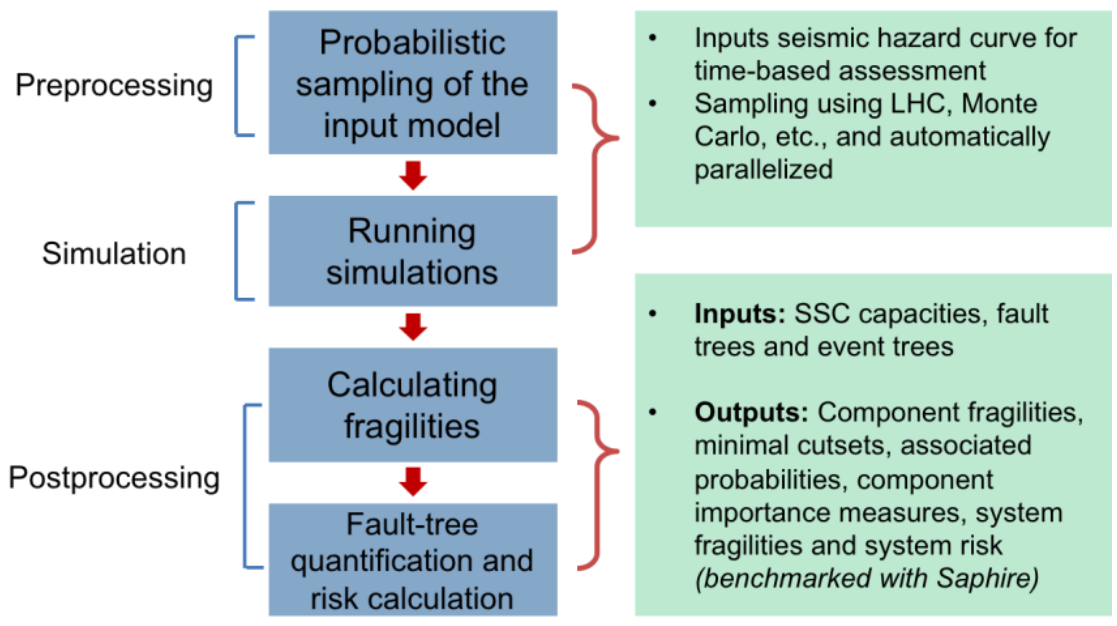

Figure 3-3: SPRA in MASTODON (Bolisetti et al., 2019)

\subsection{Formulation of the risk- and cost-based design optimization problem}

Mathematical optimization problems typically strive to minimize an objective function that depends on various design variables and subject to one or more constraints. The result of the optimization process is a set of design variables that result in the 'best' or minimum objective function while satisfying the constraints. In engineering practice, design optimization is typically used to calculate the set of design variables (e.g., geometry of the wing of an airplane) that maximizes the safety or efficiency of an engineering system while minimizing resources (e.g., amount of material).

The objective of the design optimization described in this study is to minimize the total capital cost of a representative advanced reactor safety system, while keeping the risk of unacceptable performance below a user-specified threshold. The safety system is assumed to include several SSCs that are vulnerable to earthquake shaking, and each of these SSCs has a fragility curve that is assumed to be representative of its seismic capacity. For this study, the cost of each SSC is assumed to be a function of its median fragility. The total cost of the safety system is then calculated as the sum of the costs of the SSCs. The risk of failure of the safety system is calculated using SPRA as described in Section 3.2, using the seismic hazard curve, fragilities of the SSCs, and the fault tree of the safety system. For simplicity, it is assumed that the SSCs are only designed to meet the performance goal of the system, i.e., not exceeding a risk threshold. It is also assumed that, in the set of feasible designs, the median fragilities have a lower bound and an upper bound that are determined by practical constraints specific to the SSC. The optimization problem is described mathematically by equations 3-1 and 3-2 below. 


$$
\begin{gathered}
C\left(a_{1}, a_{2}, \ldots a_{n}\right)=\sum_{i=1}^{n} c_{i}\left(a_{i}\right) \\
\text { minimize } C\left(a_{1}, a_{2}, . . a_{n}\right) \\
\text { subject to the constraints: }\left\{\begin{array}{c}
R\left(\operatorname{LN}\left(a_{1}, \beta_{1}\right), L N\left(a_{2}, \beta_{2}\right), \ldots L N\left(a_{n}, \beta_{n}\right)\right) \leq \mathrm{R}_{\mathrm{U}} \\
l_{1} \leq a_{1} \leq u_{1} \\
l_{2} \leq a_{2} \leq u_{2} \\
. . \\
l_{n} \leq a_{n} \leq u_{n}
\end{array}\right.
\end{gathered}
$$

In these equations, $a_{1}, a_{2}, \ldots a_{n}$ are the median seismic fragilities (or capacities) of $n$ SSCs of the safety system and are also the design variables of the optimization problem. The objective function, $C$, is total capital cost of the safety system expressed as the sum of individual SSC costs, $c_{i}\left(a_{i}\right)$. Each of the functions, $c_{i}(a)$, is a cost function, which is the capital cost of the SSC as a function of its median seismic fragility, $a$. The constraints of the optimization problem are described by equation 3-2. The first constraint describes the performance goal, where $L N\left(a_{i}, \beta_{i}\right)$ are the lognormal fragility functions with $a_{i}$ and $\beta_{i}$ are the median and lognormal standard deviation, respectively, $R$ is the risk of the unacceptable performance of the safety system and $R_{U}$ is the user-specified risk threshold. The rest of the constraints describe the upper and lower bounds on the design variables, i.e., the median fragilities of the SSCs. As the fragilities of the SSCs are reduced, the total cost of the system decreases, but the risk of an unacceptable performance of the system increases, and beyond a certain point, will exceed the threshold. The optimization algorithm will result in an optimal set of SSC fragilities that result in minimum total cost, while maintaining the risk below the threshold.

Although the optimization problem described here is idealized, it can be easily extended to more practical scenarios by adding more design variables, more complex cost functions, or additional design constraints. For example, component seismic isolation can be considered by changing the cost and risk functions by accounting for the additional capital cost due to isolation, and the corresponding reduction in risk due to the reduction in seismic demands. This is described in Section 3.5.4. The simplicity of the problem chosen here enables a clearer interpretation of the initial and optimized design, and the behavior of the optimization algorithm. A generalized form of the algorithm is illustrated in Figure 3-4 below. 


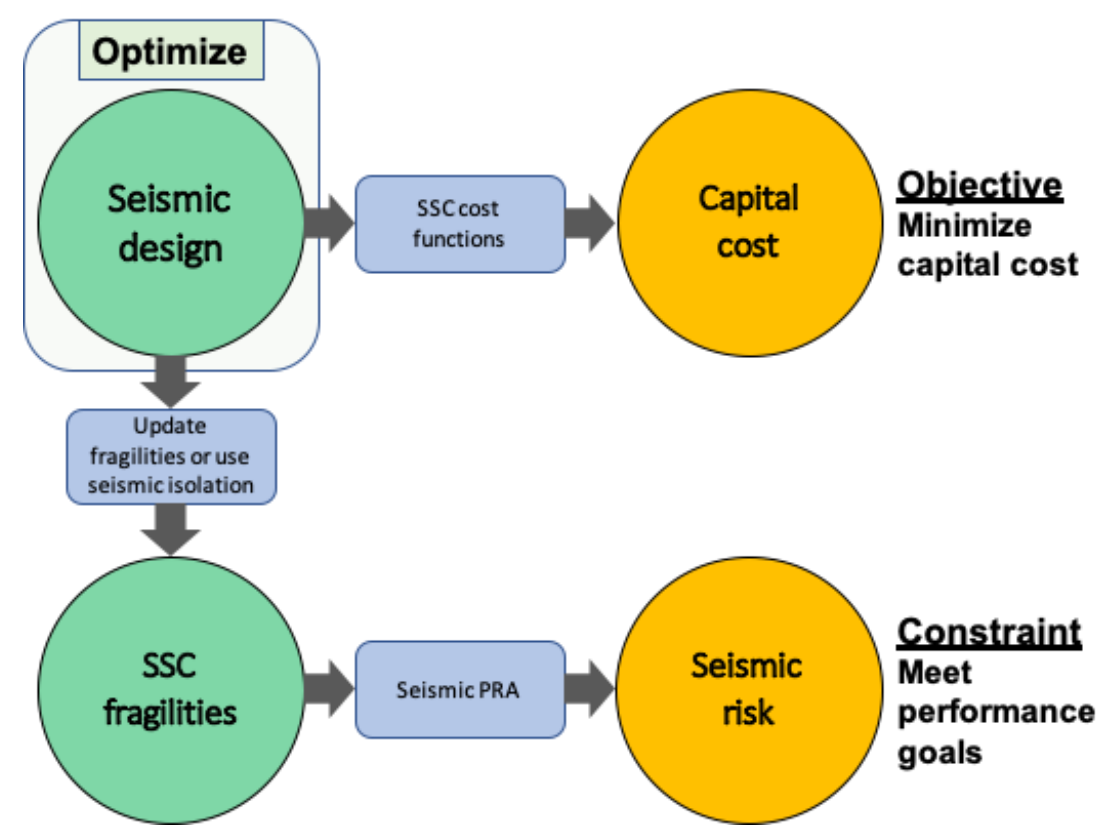

Figure 3-4: Illustration of the optimization problem of this study

Optimization algorithms can be broadly classified into gradient-based algorithms (e.g., gradient descent), which search for a local or global minimum of an objective function by moving along the gradient of the function, and non-gradient-based algorithms, which typically involve a logical and iterative search of the variable space, based on the value of the objective function and the adherence to the constraints of the optimization problem. Although gradientbased algorithms are fast, and often assure the best solution to a problem, they also require the objective functions to be continuous and differentiable. Engineering problems are often complex with a large number of design variables and constraints, and objective functions and constraints that are non-convex, not continuous or differentiable, or even expressible as mathematical functions. Moreover, design optimization problems often encounter discrete variables (e.g., thickness of a pressure vessel, which can only take discrete values, based on the thickness of steel plates that are manufactured) or characteristic variables (e.g., a safety component being seismically isolated or not) and the problem can involve a combination of continuous and discrete variables, making it almost impossible to solve with traditional, gradient-based algorithms. Therefore, in the recent years, non-gradient-based approaches (sometimes labeled as nontraditional methods) have been increasingly employed for engineering problems. Nongradient-based algorithms deploy numerically based, brute force type approaches that are slower than gradient-based counterparts and often search for the global optimum in a given design space. Although their use may not result in the mathematically optimal solution, they almost always converge to an engineering solution that is better than the initial solution, which by itself, is quite advantageous in engineering design optimization. Many non-gradient-based optimization algorithms are inspired by natural phenomena such as the behavior of biological or molecular systems. Examples include evolutionary or genetic algorithms, which are based on Darwin's theory of natural selection, and particle swarm optimization, which are based on the behavior of flocks or birds or schools of fish. Given their versatility and the widespread use, a genetic algorithm implementation in Dakota is used for this study.

Genetic algorithms are inspired from genetics and natural selection and are based on the principle of 'survival of the fittest'. Genetic algorithms start with a population of candidate 
designs in the design space (i.e., trial design vectors) on which a series of 'genetic' operations are performed to calculate the next 'generation' of the population. The members of each generation are evaluated based on a 'fitness' function, which is a combination of the objective function and the adherence of the design to the required constraints. The designs with the highest fitness are reproduced in future generations, whereas the ones with the lowest fitness are eliminated. Each design variable is first converted to a string of binary variables, which are analogous to chromosomes in genetics. Each design vector is then represented by joining these strings and creating a larger string analogous to a gene. Each set of strings, or the population undergoes operations called reproduction (termed as replacement in Dakota), crossover, and mutation, before their fitness is evaluated. Each cycle of these operations and fitness evaluation is referred to as a generation. Reproduction is the first operation and involves rewarding the designs with high fitness by making copies of them for the next generation using a probabilistic procedure to form a mating pool. Reproduction is followed by crossover, which involves creating new strings (i.e., design vectors) by exchanging information amongst 'parent' strings of the mating pool, resulting in 'child' strings that are expected to have better fitness than the parents. While the crossover is the main operation that creates new strings, a small percentage of the new strings are created using the mutation operation. The mutation operation involves randomly changing a few digits of the string from 0 to 1 or vice versa. Mutation ensures that a local search is performed around the current solution and that the algorithm is not 'stuck' at a local minimum. After several such generations, the population converges towards a single point, which is the global optimum. Convergence criteria of genetic algorithms typically involve an upper limit in the generational change in the optimum value (candidate with the best fitness in a population) or simply, a maximum number of generations. Further information on genetic or evolutionary algorithms can be found in the Dakota manual Adams et al. (2014), or various other sources such as Eddy and Lewis (2001), Rao (2009), etc.

\subsection{Development of a generic PRA model for design optimization}

\subsubsection{Generic safety system}

A safety system for a generic nuclear facility (GNF) that is adopted from Yu et al. (2018) and modified is used for this study. The GNF and the safety system are assumed to be representative of a nuclear reactor that involves a nuclear steam supply components including a reactor vessel, control rod drive mechanism (CRDM; or other reactor control mechanisms), steam generator, coolant pump, and piping, electrical components including a motor control center (MCC) and a battery, and containment components including the containment structure, air handler and a duct. It is assumed that the failure of any of these component groups will lead to a failure of the safety system as described in the fault tree of Figure 3-5. The symbols, $\square$ and $\triangle$ in this figure represent AND and OR gates, respectively, and the circles denote basic events corresponding to the ten steam supply, electrical and containment components. The failure of the safety system in the GNF is assumed to cause unwanted release of radioactive material into the environment, as shown in the event tree presented in Figure 3-6. The SSCs considered here are representative of both existing and advanced nuclear reactor facilities and are taken from the EPRI SPRA Guide (EPRI, 2013).

The seismic PRA of this safety system is performed in MASTODON. Since the event tree only comprises a single event corresponding to the fault tree of the generic safety system, the 
success or failure of the fault tree also determines the success or failure in the event tree.

Therefore, the system risk is calculated only using the fault tree quantification and not event tree quantification is performed. The GNF is assumed to be located within the boundary of the Idaho National Laboratory (INL) and the corresponding seismic hazard curve at a period of $0.1 \mathrm{sec}$, calculated by Yu et al. (2018) from United States Geological Survey (USGS) data, is used for this study. This seismic hazard curve is presented in Figure 3-7.

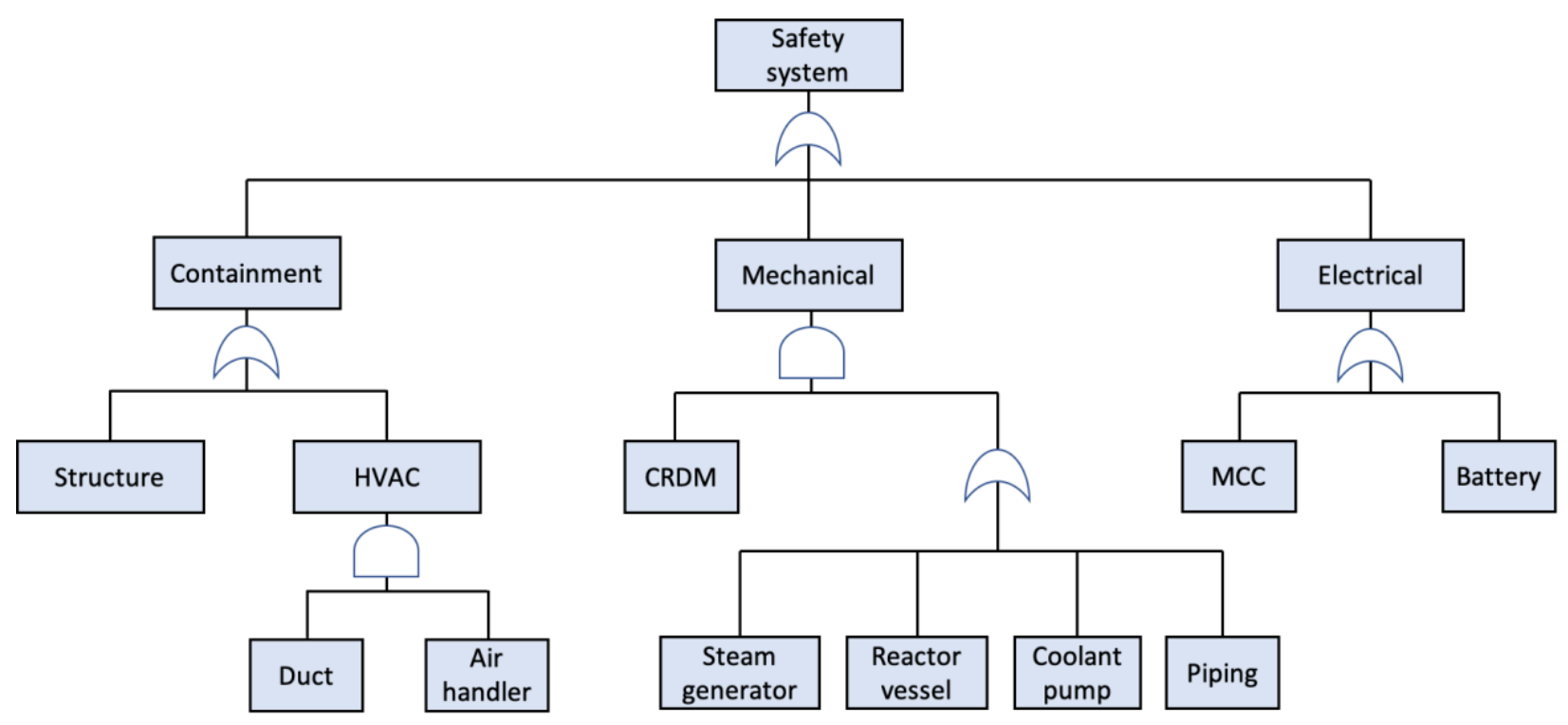

Figure 3-5: Fault tree

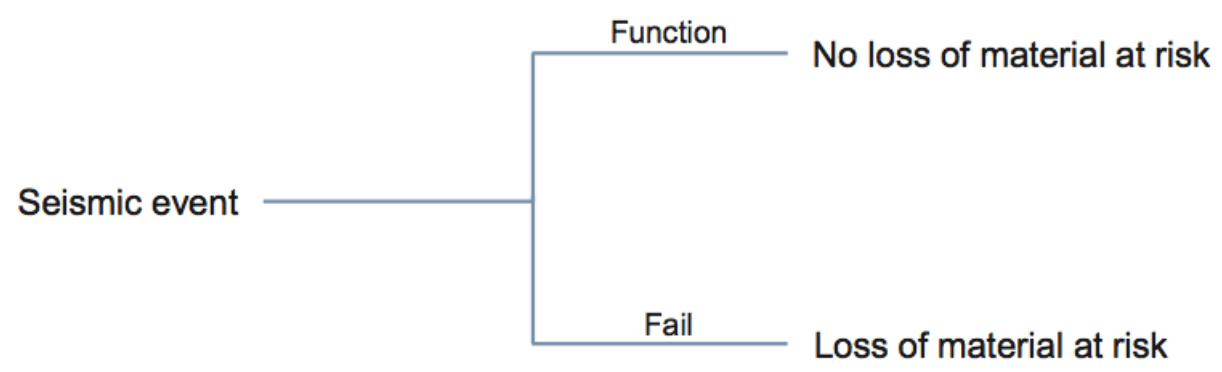

Figure 3-6: Event tree 


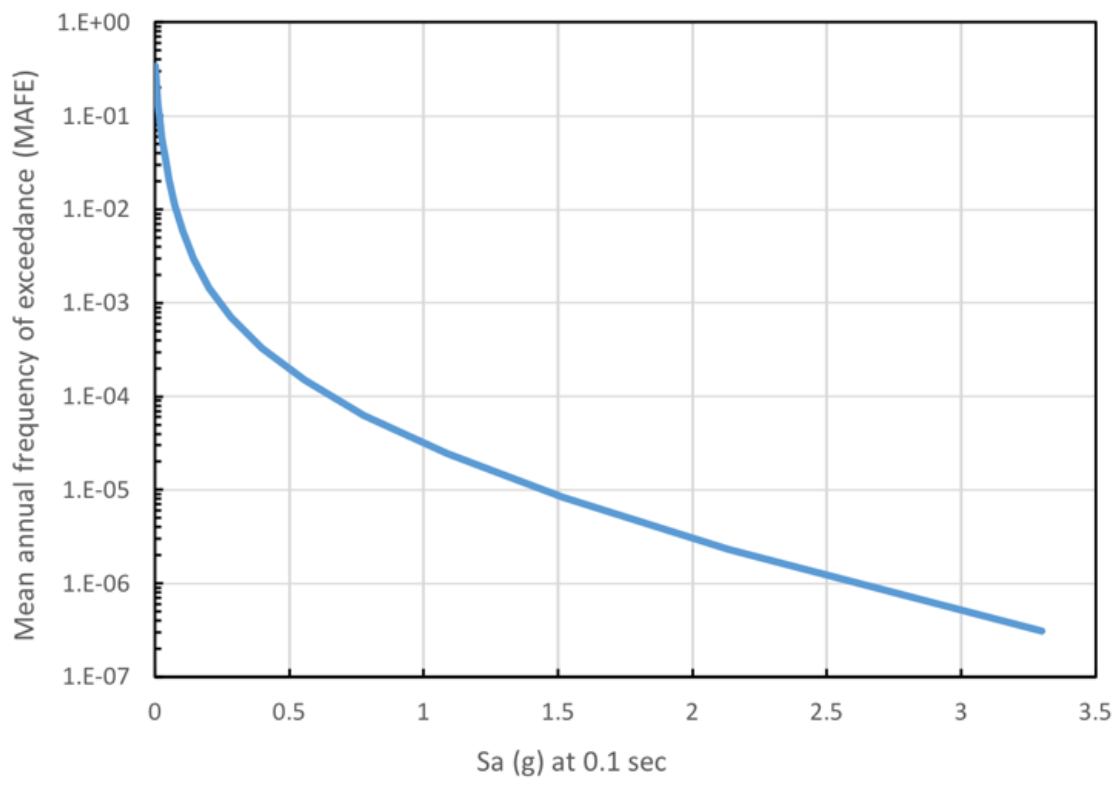

Figure 3-7: Seismic hazard curve for the peak ground acceleration at the INL site (Yu et al., 2018)

\subsubsection{Development of fragility and cost functions}

The seismic design of the safety system is taken as the set of fragilities for the selected SSCs. Generic fragilities of the SSCs (median, $A_{m}$, and lognormal standard deviations due to uncertainty and randomness, $\beta_{u}$ and $\beta_{r}$, respectively) are chosen from the fragilities recommended by the EPRI SPRA guide (EPRI, 2013). The composite lognormal standard deviation, $\beta_{c}$, is calculated as the square root of the sum of the squares of $\beta_{u}$ and $\beta_{r}$. These fragilities are assumed to be the 'enhanced fragilities' in the MASTODON implementation of the Huang SPRA methodology, and represent the probability of failure of the SSCs, given an intensity of shaking in the hazard curve. The optimization algorithm also requires a range of fragilities (or the design space) as an input. The fragility ranges provided in the EPRI SPRA guide are used for this purpose and are assumed to be sufficient for the purpose of this study. The initial fragilities and design spaces for all SSCs in the GNF are listed in Table 3-1.

Optimization of the seismic design of the safety system also requires estimates of costs of the SSCs as well as estimates of the increase of their costs with an increase in the seismic fragilities (i.e., the cost penalty for seismic design). A previous review of available literature by Bolisetti et al. (2016) and Yu et al. (2018) found that information regarding the seismic design costs in NPPs is scarce. The only available information is through surveys conducted by Stevenson (1981) in the 1980s, and anecdotal information from experienced professionals in the nuclear industry. Lal et al. (2019), (Lal et al., 2020), and (EPRI, 2020) present generated data on the seismic design cost penalty for the SSCs listed in Chapter 2 for incremental levels of ground shaking. Due to the lack of modern data for the SSCs in GNF, generic SSC costs and cost functions (variation of SSC costs with median fragilities) are assumed for this study. The SSC costs are adjusted such that the total capital cost of the initial design amounts to almost $\$ 100$ million. To ensure that the optimization process works for a diverse set of cost function types, including linear, step, quadratic and square root functions, are assumed for the different SSCs. These cost functions are plotted in the design spaces of the SSCs and are presented in Figure 3-8. Step functions are 
assumed to describe the cost increases with median fragility of the motor control center (MCC), batteries, and the coolant pump. A linear function is assumed for the air handler, reactor vessel, steam generator and CRDM. Quadratic functions are assumed for the structure and the pressure vessel. The cost of the distribution systems, piping and ducts, is assumed to be directly proportional to the square root of the median fragilities, as suggested by Stevenson (1981). The cost increases (ratio of the maximum to minimum costs for a specific SSC presented in Figure 3-8) for the reactor vessel, steam generator, and the CRDM are chosen to be roughly the same as those presented in (Lal et al., 2020). The total capital cost and seismic risk of the initial design are calculated and presented in Section 3.4.3.

Table 3-1: List of SSCs in the GNF along with their initial median fragilities, composite lognormal standard deviations and design spaces

\begin{tabular}{|l|c|c|c|c|}
\hline SSC name & $\begin{array}{c}\text { Median fragility } \\
(\mathbf{g})\end{array}$ & $\begin{array}{c}\text { Lower bound } \\
(\mathbf{g})\end{array}$ & $\begin{array}{c}\text { Upper bound } \\
(\mathbf{g})\end{array}$ & $\boldsymbol{\beta}_{\boldsymbol{c}}$ \\
\hline MCC & 2.0 & 1.0 & 2.9 & 0.46 \\
\hline Battery & 1.5 & 1.0 & 2.0 & 0.46 \\
\hline Coolant pump & 2.5 & 1.8 & 3.2 & 0.50 \\
\hline Air handler & 2.5 & 2.0 & 4.0 & 0.50 \\
\hline Duct & 2.0 & 1.0 & 3.0 & 0.61 \\
\hline Structure & 2.0 & 1.6 & 2.4 & 0.46 \\
\hline Reactor vessel & 2.0 & 1.0 & 3.0 & 0.46 \\
\hline Steam generator & 2.5 & 1.5 & 4.0 & 0.58 \\
\hline CRDM & 2.0 & 1.0 & 6.0 & 0.58 \\
\hline Piping & 2.5 & 1.5 & 4.0 & 0.58 \\
\hline
\end{tabular}




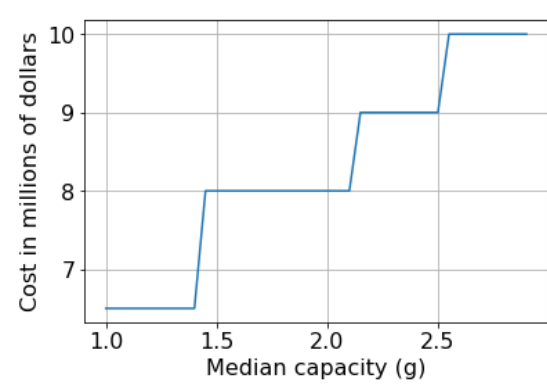

a. MCC

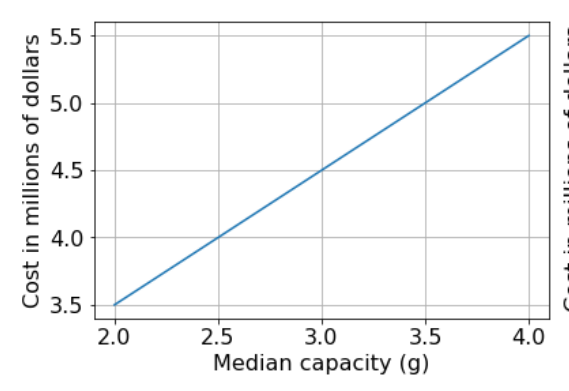

d. Air handler

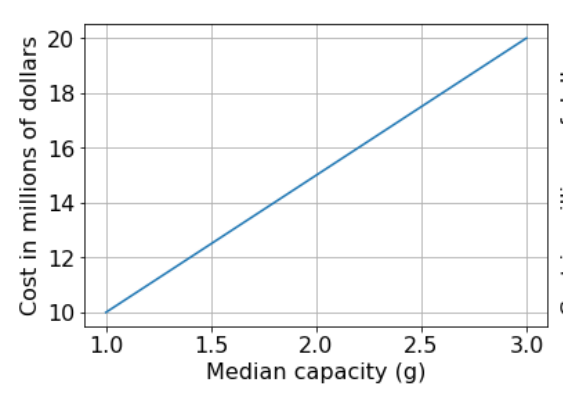

g. Reactor vessel

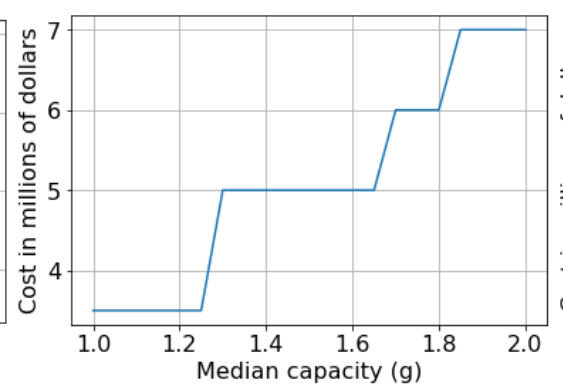

b. Battery

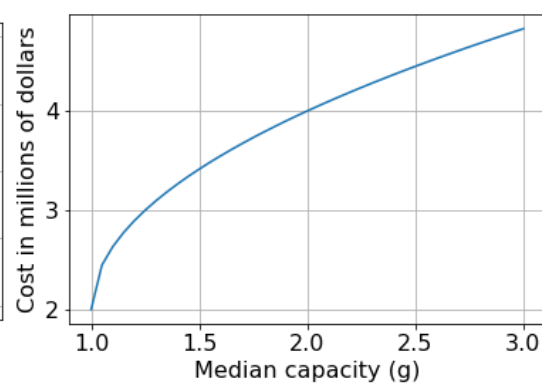

e. Duct

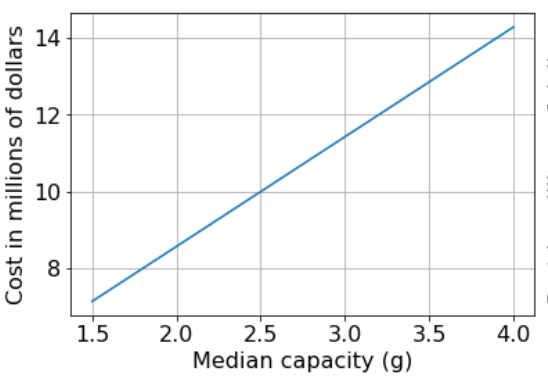

h. Steam generator

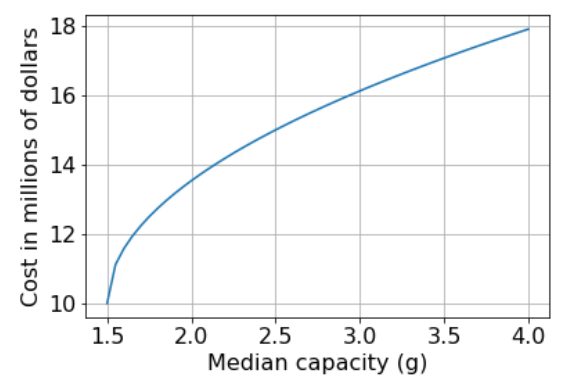

j. Piping

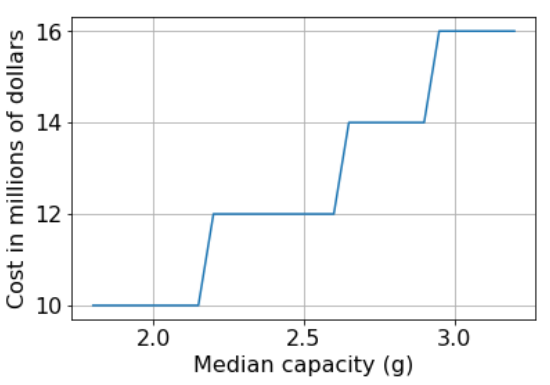

c. Coolant pump

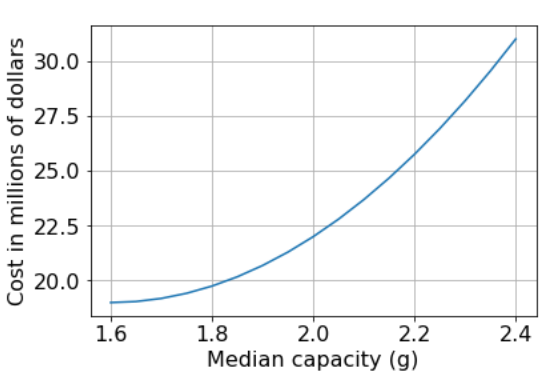

f. Structure

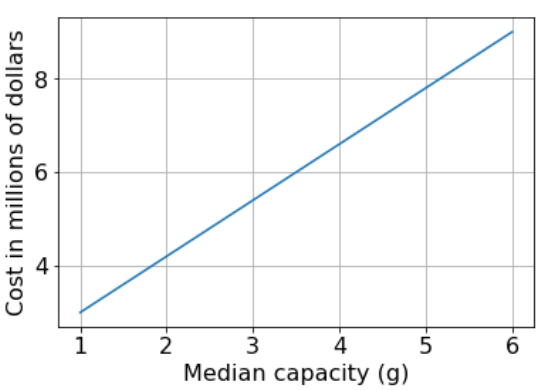

i. CRDM

Figure 3-8: Capital costs of individual SSCs as a function of their median seismic fragility 


\subsubsection{Capital cost and seismic risk of the initial design of the generic safety system}

The initial capital cost of GNF calculated using the median fragilities in Table 3-1 and the cost functions in the Figure 3-8 is $\$ 99.2$ million. For simplicity, the risk calculation in the optimization of this study only involves steps 4 and 5 of the Huang methodology. Since the SSC fragilities are assumed to be functions of the shaking intensity in the hazard curve (PGA in this case), structural response simulations are not performed. Nevertheless, given the modular implementation of the PRA process in MASTODON, this procedure can be easily extended to include the structural simulations and perform a more comprehensive optimization. The hazard curve is split into ten bins, and the fault tree analysis and quantification are performed using the MOCUS method. For each bin, the probability of system failure is calculated and multiplied by the corresponding mean annual frequency to calculate the risk. The total system risk is then calculated as the sum of the risk in each of the ten bins. It is assumed that the performance goal of the GNF safety system is to stay under a risk limit of $5.0 \times 10^{-5}$. The system risk of the initial, unoptimized design of GNF calculated using MASTODON is $5.16 \times 10^{-5}$, roughly meeting the performance goal. This upper limit on the seismic risk of $5.0 \times 10^{-5}$ is provided as a constraint to Dakota $\left(\mathrm{R}_{\mathrm{U}}\right.$ in equation 3-2). SPRA in MASTODON also results in the minimal cutsets and the corresponding risk contributions in the final risk. The minimal cutsets, corresponding risks and relative risk contributions are presented in Table 3-2. The abbreviations listed in the table are used to denote the minimal cutsets in the results presented in Section 3.5.

Table 3-2: Minimal cutsets of the GNF safety system and their corresponding risks and risk contributions calculated for the initial design and the seismic hazard curve described in the previous sections

\begin{tabular}{|c|c|c|c|}
\hline Minimal cutset & Abbreviation & Risk & Risk contribution (\%) \\
\hline Structure & 'struct' & $9.28 \times 10^{-6}$ & 18.00 \\
\hline $\mathrm{MCC}$ & 'mcc' & $9.28 \times 10^{-6}$ & 18.00 \\
\hline Battery & 'batt' & $2.29 \times 10^{-5}$ & 44.37 \\
\hline Air handler AND Duct & 'airhand \& duct' & $1.74 \times 10^{-6}$ & 3.37 \\
\hline Steam generator AND CRDM & 'sgen \& crdm' & $2.00 \times 10^{-6}$ & 3.87 \\
\hline Reactor vessel AND CRDM & 'pvess \& crdm' & $2.70 \times 10^{-6}$ & 5.22 \\
\hline Coolant pump AND CRDM & 'cpump \& crdm' & $1.71 \times 10^{-6}$ & 3.32 \\
\hline Piping AND CRDM & 'piping \& crdm' & $2.00 \times 10^{-6}$ & 3.87 \\
\hline Total risk & & $5.16 \times 10^{-5}$ & 100.00 \\
\hline
\end{tabular}




\subsection{Design optimization of the generic safety system}

\subsubsection{Coupling MASTODON and DAKOTA}

Dakota offers optimization capabilities using genetic algorithms through the 'JEGA' package implemented by Eddy and Lewis (2001). This package includes the single-objective genetic algorithm (SOGA) and multi-objective genetic algorithm (MOGA), which are offered in Dakota as separate algorithms. The SOGA method is used for the design optimization of this study. This method can optimize both constrained and unconstrained problems, and can accommodate continuous, discrete, and characteristic design variables. Dakota provides interfaces to couple with external software, which can compute and provide objective functions, constraint functions, gradient matrices or the Hessian matrices. For this study Dakota and MASTODON are coupled through Dakota's Python 'fork' interface. This interface is a Python file that transfers iterated design variables from Dakota to MASTODON (which calculates the risk constraint in equation 3-2 using fault tree and event tree analysis) and the calculated constraint value (i.e., seismic risk) back to Dakota. The objective function, which is the total cost, is evaluated by a separate Python file, which is also connected to Dakota through the Python 'fork' interface.

\subsubsection{Sensitivity of the results to the genetic algorithm parameters}

The Dakota input file includes the design space (ranges of median fragilities of all SSCs, Boolean values for seismic isolation, etc.), specification of the objective function and the risk constraint, and as well as the SOGA optimization parameters including population size, number of iterations, seed value for randomization, and crossover, mutation, and replacement types. While Dakota offers choices for the crossover, mutation, and replacement types, the default types are chosen for this study as recommended by the Dakota manual (Adams et al., 2014). Prior to performing the design optimization of the safety system of GNF, the sensitivity of the results (i.e., the final objective function and the constraint, which are the capital cost and the seismic risk of the optimized design) to the seed value and population size is examined in this section. Additionally, the convergence of the solution with number of iterations is also examined. The sensitivity analysis is performed for the safety system of GNF, with the seismic hazard, event tree and fault tree, median fragility ranges and cost functions provided in Section 3.4. Seismic isolation is not considered for the sensitivity analyses.

Any stochastic study involving randomization involves a seed value that is used for random number generation. In SOGA, for example, the initial population is generated by randomly sampling the design space. The seed value ensures that the randomization, and therefore, the optimization is repeatable, i.e., the same result is calculated when the optimization is repeated. However, when different seed values are used the algorithm is likely to produce different results and to ensure stability, these differences must be small. Table 3-3 presents the total capital cost and seismic risk of the optimized design with four different seed values. The table shows that the results are almost the same for all four seed values. The seismic risk of the optimized design is slightly smaller than the constraint, which is $5.00 \mathrm{e}-05$, for all seed values, and the total capital cost of the optimized design is consistently around $\$ 83$ million USD, which is about $16 \%$ smaller than that of the initial, unoptimized design. These results demonstrate the stability of SOGA with changing seed value. The optimization results are discussed in more detail in Section 3.5.3. 
Another important parameter in SOGA is the population size. A population size that is too small may not adequately cover the design space and may result in a suboptimal solution. A very large population size will lead to solution that is a theoretical optimum but will require more function evaluations and longer computation time. To choose a reasonable population size five optimization analyses are performed with increasing population sizes. Table 3-4 presents the total capital cost and the seismic risk of the optimized design for the different population sizes, along with. The total number of function evaluations required to reach an optimum. The table shows that for a small population size (10) the total capital cost of the optimized design is around $\$ 89$ million, which reduces to around $\$ 83$ million for a population size of 50. The results show that the optimized solution converges with increasing population size.

The optimization analyses performed so far involved 40 iterations, i.e., 40 generations of the SOGA populations. Figure 3-9 presents a scatter of the capital cost (objective function) and seismic risk (constraint) of SOGA population at various stages of the optimization process when a seed of 30 and a population size of 50 is chosen. The blue triangle in the figure corresponds to the initial, unoptimized design and the orange circles correspond to the various designs in the population. The figure presents these values for iterations 1, 10, 25, and 40 and illustrates the convergence of the population to one single point, which is the optimal solution. The figure therefore shows that the algorithm converges to an optimal solution with repeated iterations and that 40 iterations is adequate for the current problem.

Although the algorithm is stable and convergent for the parameters calculated in this section, these parameters are specific to the problem presented here. The sensitivity analysis presented in this section should be repeated for each new problem and the appropriate genetic algorithm parameters should be calculated in order to achieve the best results.

Table 3-3: Sensitivity of the optimization results to the randomization seed for SOGA

\begin{tabular}{|c|c|c|}
\hline Seed & Seismic risk from optimized design & $\begin{array}{c}\text { Capital cost of optimized design } \\
\text { (USD millions) }\end{array}$ \\
\hline 10 & $4.96 \times 10^{-5}$ & 83.33 \\
\hline 20 & $4.94 \times 10^{-5}$ & 84.15 \\
\hline 30 & $4.96 \times 10^{-5}$ & 83.21 \\
\hline 40 & $5.00 \times 10^{-5}$ & 83.90 \\
\hline
\end{tabular}

Table 3-4: Sensitivity of the optimization results to the population size

\begin{tabular}{|c|c|c|c|}
\hline $\begin{array}{c}\text { Population } \\
\text { size }\end{array}$ & $\begin{array}{c}\text { Seismic risk from } \\
\text { optimized design }\end{array}$ & $\begin{array}{c}\text { Capital cost of } \\
\text { optimized design } \\
\text { (USD millions) }\end{array}$ & $\begin{array}{c}\text { Total number of function } \\
\text { evaluations }\end{array}$ \\
\hline 10 & $4.96 \times 10^{-5}$ & 88.78 & 136 \\
\hline 20 & $4.95 \times 10^{-5}$ & 83.85 & 632 \\
\hline 30 & $4.79 \times 10^{-5}$ & 83.91 & 772 \\
\hline 40 & $4.96 \times 10^{-5}$ & 83.61 & 1326 \\
\hline 50 & $4.96 \times 10^{-5}$ & 83.21 & 1395 \\
\hline
\end{tabular}



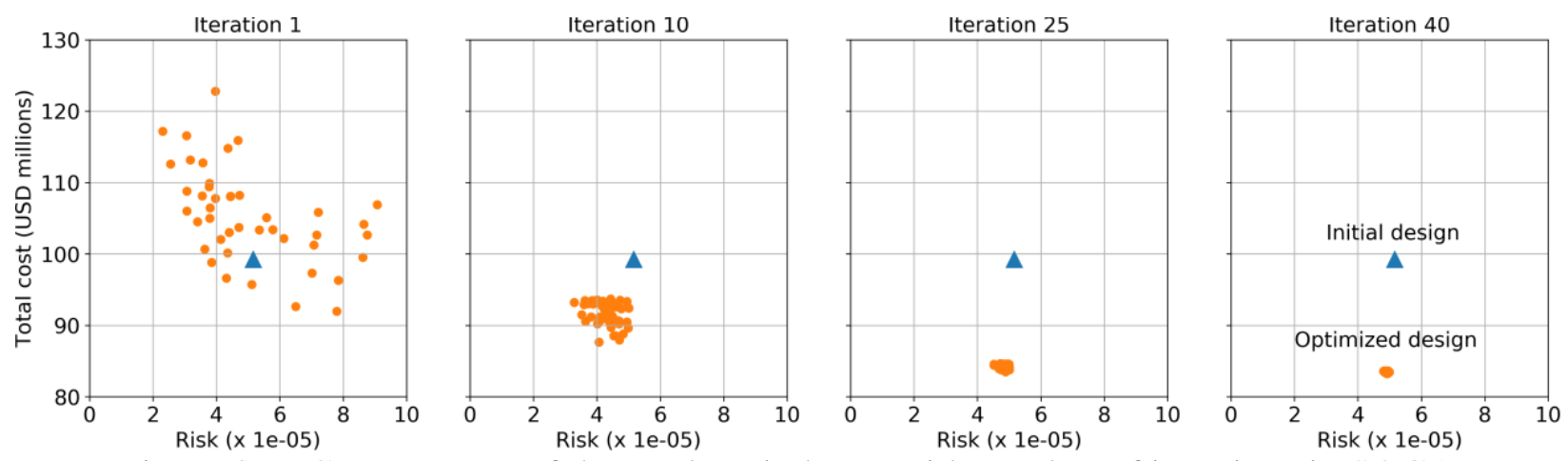

Figure 3-9: Convergence of the total capital cost with number of iterations in SOGA

\subsubsection{Design optimization of the safety system without considering seismic isolation}

Results of the design optimization are presented in this section, including the median fragilities of the SSCs that result in the minimal capital cost while staying below the risk margin of $5.0 \times 10^{-5}$. Component isolation is not included as an option in the optimization process here and is considered in Section 3.5.4. The MASTODON Python PRA module is available on the MASTODON GitHub repository ${ }^{b}$ for users to download and use freely. Detailed instructions for running the optimization problem including the input files, post processing files, and results are reproduced as a MASTODON example, which is available on the MASTODON documentation website $^{c}$. As shown in the Dakota input file, a population size of 50, seed value of 30, and a maximum number of iterations (generations) of 40 are chosen for design optimization of the GNF safety system based on the sensitivity analyses presented in Section 3.5.2. Additionally, default parameters are used for the replacement, crossover, and mutation parameters, including the crossover and mutation rates of 0.8 and 0.08 , respectively. The design space (i.e., the range of median fragility of each SSC) listed in Table 3-1 are also provided in the Dakota input file. For each design fitness evaluation, the objective function (total cost) and the constraint (risk) are calculated in the Python interface file by calling the cost function file and the MASTODON PRA module, respectively. Apart from the median fragilities, which are the design variables, the seismic hazard shown in Figure 3-7, lognormal standard deviations shown in Table 3-1 and the fault tree and event tree shown in Figure 3-5 and Figure 3-6 are used as inputs in the risk calculation.

Table 3-5 and Figure 3-10 present the results of the optimization carried out using Dakota. Table 3-5 presents the capital cost and risk of the safety system before and after the design optimization. The table shows that the optimal design has a capital cost of around $\$ 83$ million, which is about a $\$ 16$ million reduction from the capital cost of the initial, unoptimized design of the GNF safety system. The design optimization resulted in a $16 \%$ reduction in the capital cost of the GNF, while meeting the safety goals of the GNF.

Panels a and b of Figure 3-10 present the median fragilities and capital costs, respectively, of individual SSCs. These panels show that most of the cost reductions in the optimized design are from the nuclear and steam supply system (NSSS) components - steam generator, reactor vessel, coolant pump, and piping - as their corresponding median fragilities are reduced in the

\footnotetext{
${ }^{\mathrm{b}}$ https://github.com/idaholab/mastodon

${ }^{\mathrm{c}}$ https://mooseframework.inl.gov/mastodon
} 
optimization process. Panel $\mathrm{c}$ of the figure presents the risk contributions of individual minimal cutsets (i.e., possible accident sequences) of the safety system. Panel c shows that, in spite of a reduction in their median fragilities, the risk contributions from the cutsets corresponding to the NSSS components (the four cutsets from the right) are reduced in the optimized design. This is because the CRDM, which accompanies all the other NSSS components in their minimal cutsets, is strengthened significantly in the optimized design (see panel a). Since the occurrence of these minimal cutsets requires both the CRDM and an NSSS component to fail, the strengthening of $\mathrm{CRDM}$ and the consequent reduction in its failure probability results in a net reduction in the risk contribution of the corresponding cutsets. Note that the steam generator, reactor vessel, coolant pump, and piping are all relatively expensive components compared to the CRDM. Therefore, instead of strengthening all of these expensive components the design optimization algorithm automatically prioritizes strengthening the CRDM (which provides a redundancy to the rest of the NSSS components) for a lower cost, resulting in a lower overall capital cost.

Figure 3-10 also shows that another source of cost reduction is the structure, which is the most expensive SSC in the safety system. However, this is a smaller reduction than that seen in the NSSS components and is achieved by reducing the median fragility, which consequently increases the structure's risk contribution by more than $50 \%$. Unlike the structure, the battery, which is much less expensive than the structure, is strengthened in the optimized design and consequently, its risk contribution decreases by $30 \%$. There are two takeaways from this observation. First, the risk contributions of the structure and the battery are much more sensitive to changes in fragility than that of the NSSS components. This is because of the added redundancy in the NSSS components provided by the CRDM, which acts as another layer of defense for the NSSS systems. Unlike these components, the structure and the battery do not have any redundancy, i.e., the failure of the structure or the battery will inevitably lead to the failure of the safety system ${ }^{\mathrm{d}}$. Second, due to the sensitivity of the change in fragilities in the structure and the battery, their fragilities and costs are adjusted only marginally by the optimization algorithm, when compared to the reactor vessel, coolant pump, and piping. This shows that the optimization process rewards redundancies and 'defense in depth' and leverages them to reduce the total capital cost of the system.

Table 3-5: Capital cost and risk of the safety system before and after design optimization

\begin{tabular}{|l|c|c|}
\cline { 2 - 3 } \multicolumn{1}{c|}{} & $\begin{array}{c}\text { Capital cost } \\
\text { (USD millions) }\end{array}$ & Seismic risk \\
\hline Initial & 99.20 & $5.16 \times 10^{-5}$ \\
\hline Optimized & 83.22 & $4.92 \times 10^{-5}$ \\
\hline
\end{tabular}

\footnotetext{
d It must be noted that in practice, nuclear systems have a range of redundancies and are designed with 'defense in depth' and typically do not have single points of failure such as the idealized safety system here. Such a fault tree is chosen here to demonstrate the importance of redundancies on the capital cost.
} 


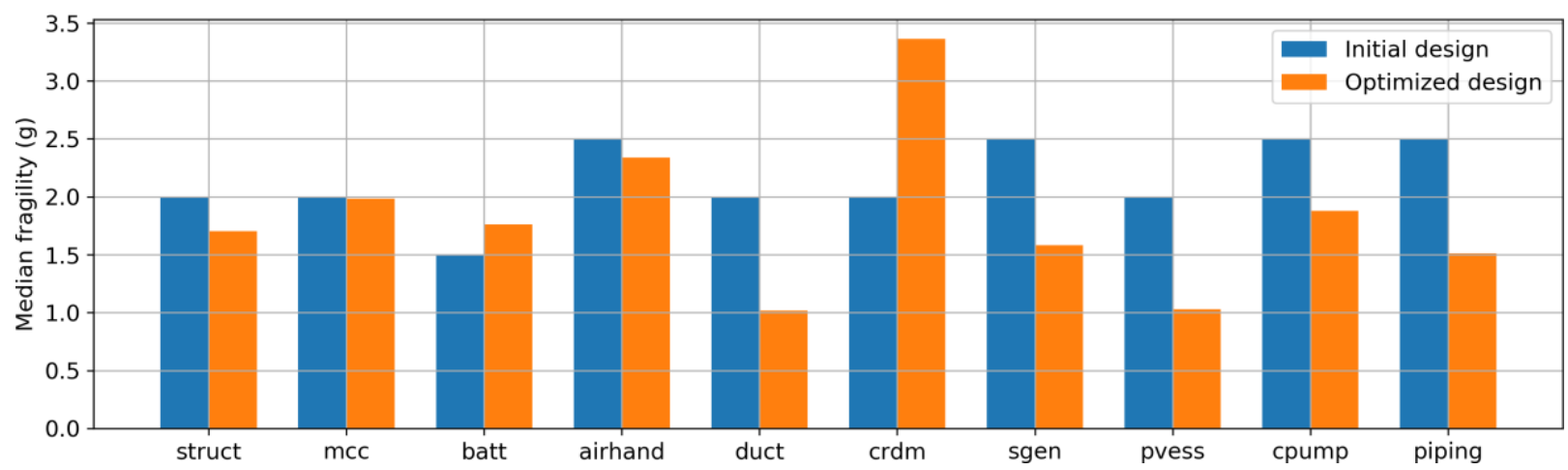

a. Median fragilities

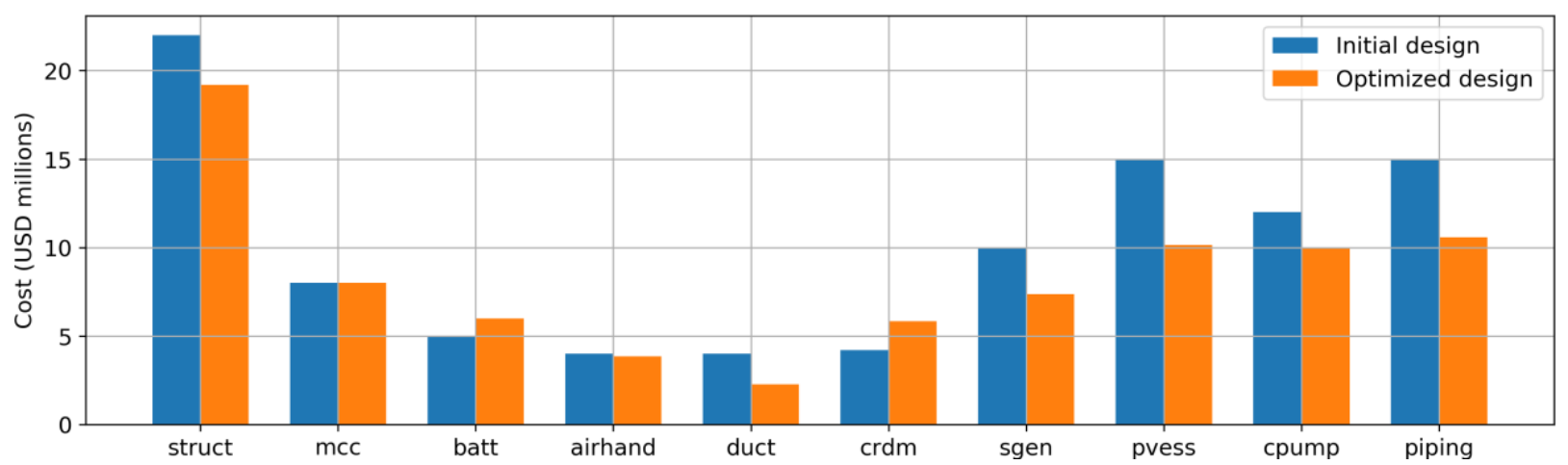

b. Capital cost of individual SSCs

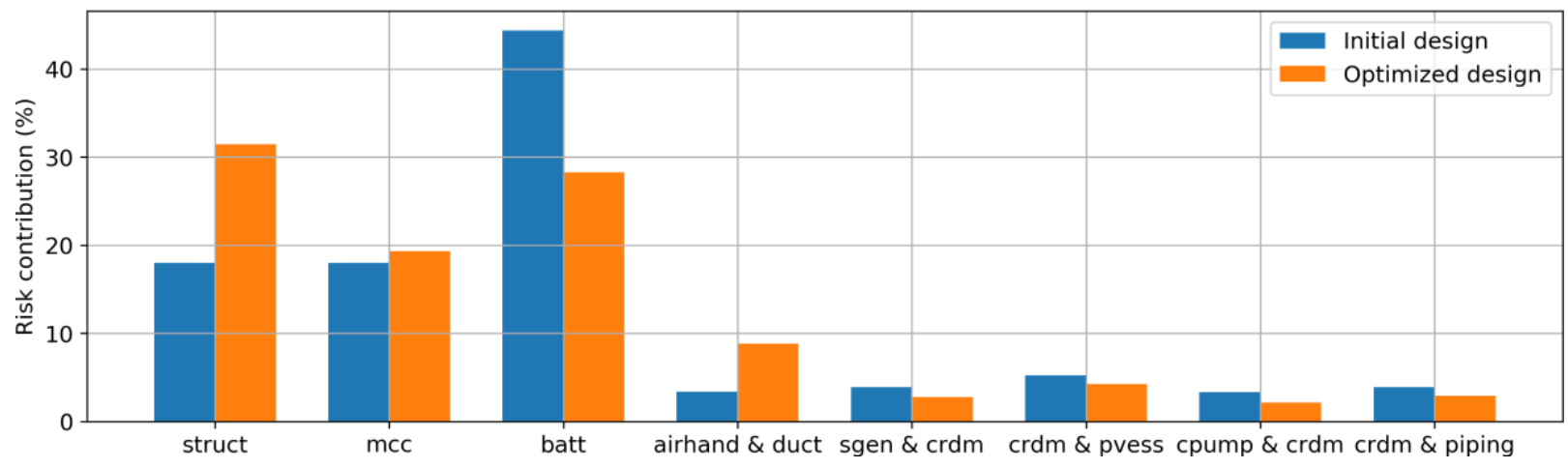

c. Risk contribution from the minimal cutsets

Figure 3-10: Comparison between initial and optimized design of the GNF safety system

\subsubsection{Effect of cost functions on the optimized design}

The data on seismic design penalty is scarce, especially for advanced nuclear reactor components and it can be challenging to build accurate cost functions for any SSC. However, design optimization is typically performed during the preliminary design stage when the design is 'fine-tuned' before being detailed. Therefore, approximate cost functions are usually adequate, as long as the trends of the costs are modeled, especially the rate of increase of seismic design costs with increase in the median fragility (or other measures of seismic integrity), relative rate of increase amongst different SSCs, and the relative cost of individual SSCs. For example, since the structure is the most expensive SSC of the GNF safety system and has a considerable contribution to the total seismic risk, even small changes in the rate of increase might 
considerably affect the total capital cost. On the contrary, since the duct is relatively less expensive and has a small contribution to the risk, the change in the cost function of the duct may not affect the optimized design significantly.

In order to examine the effect of cost functions on the optimized design, a separate design optimization is performed in this section with modified cost functions presented in Figure 3-11. These cost functions are modified such that the total initial capital cost is almost the same, but the rate of increase of the capital cost is modified for all components, except for the duct and air handler. The initial design of the system, i.e., the median fragilities of the SSCs are kept unchanged. A higher rate of capital cost increase indicates a larger seismic design penalty for the component. Figure 3-11 shows that the rates are increased for MCC, battery, and CRDM, while it is reduced for the structure, and the rest of the NSSS components, coolant pump, reactor vessel, steam generator, and piping. These modifications are intended to counter the design changes made by the optimization algorithm in the previous section, where the costs and median fragilities of the NSSS components and the structure are reduced, whereas battery and CRDM are strengthened and their capital costs are increased. With the modified cost functions, a reduction in the median fragilities of the structure and the NSSS components will not reduce the cost as much, and an increase in the median fragility of MCC, battery, and CRDM will result in a larger increase in the cost than those from the original cost functions.

The initial and optimized capital cost and seismic risk with the modified cost functions are presented in Table 3-6 below. The table shows that the seismic risk is unchanged from that calculated using the original cost functions (see Table 3-5) which is expected since the median fragilities are also unchanged. While the initial capital cost is similar to that calculated from the original cost functions, the optimized capital cost is considerably larger. With the modified cost functions, the optimal capital cost is around $\$ 88.5$ million, which is about a $10 \%$ reduction from the initial capital cost. In contrast the design optimization with the original cost functions resulted in a $16 \%$ reduction in the capital cost.

Figure 3-12 presents the median fragilities, costs, and risk contributions, calculated for the initial and optimized design with the modified cost functions. Although the total cost reduction is smaller, note that the trends in the cost reduction (or increase) amongst various SSCs are almost the same as those calculated using the original cost functions. Panels a and b of Figure 3-12 show that the median fragilities and the costs of the structure, and the NSSS components are decreased during the optimization, and those of the battery and CRDM are increased. However, the magnitudes of these increases and decreases are smaller than those calculated using the original cost functions. For example, the median fragility of the CRDM is increased by about $70 \%$ with the original cost functions, but it increases by less than $50 \%$ with the modified cost functions since they have a higher rate of cost increase, which indicates that it is more expensive to strengthen the CRDM. These observations indicate that the relative costs of the SSCs, rate of change of the costs with median capacity, and relative risk contributions of the individual SSCs can have a considerable effect on the results of the design optimization. 


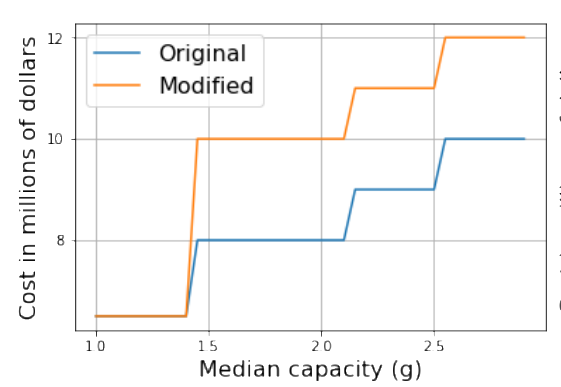

a. MCC

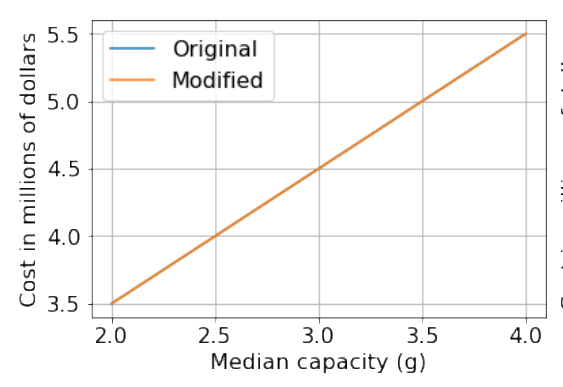

d. Air handler

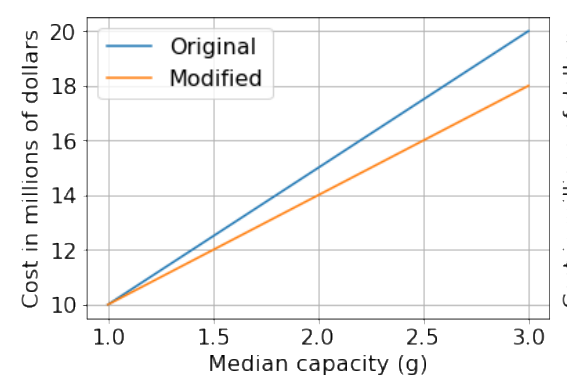

g. Reactor vessel

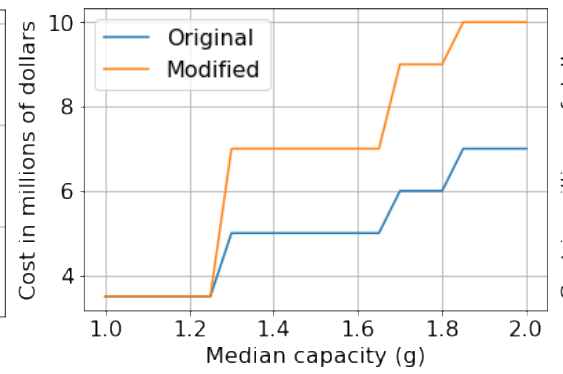

b. Battery

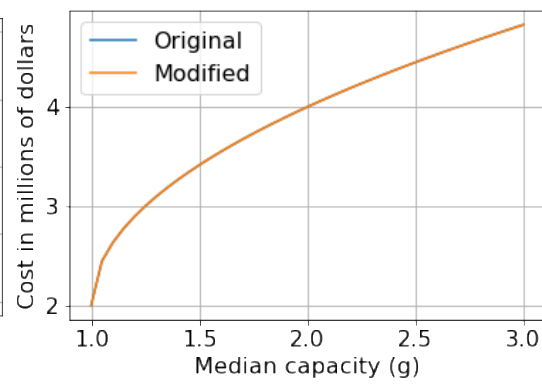

e. Duct

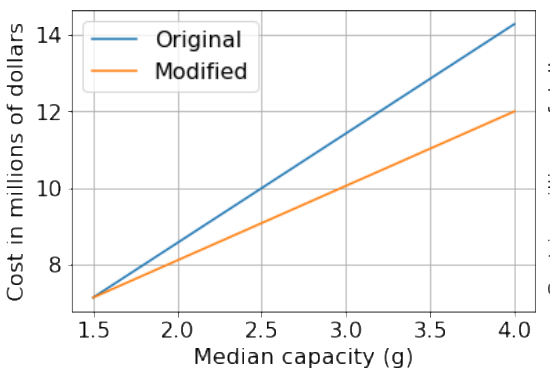

h. Steam generator

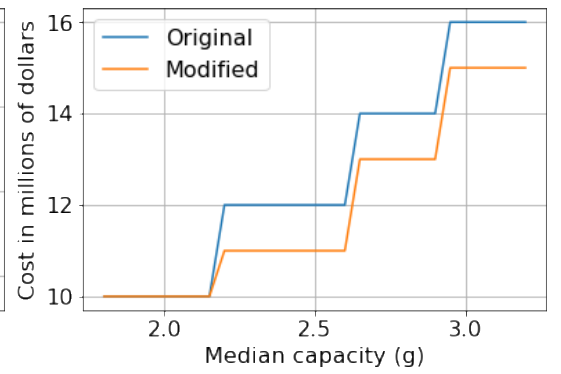

c. Coolant pump

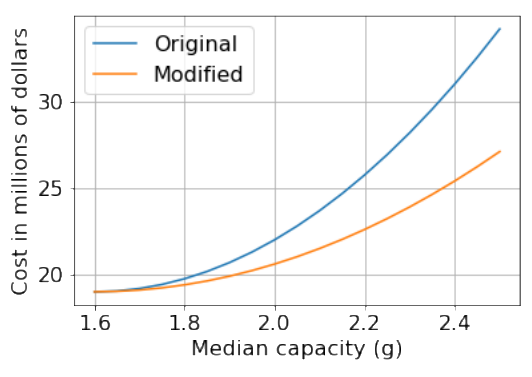

f. Structure

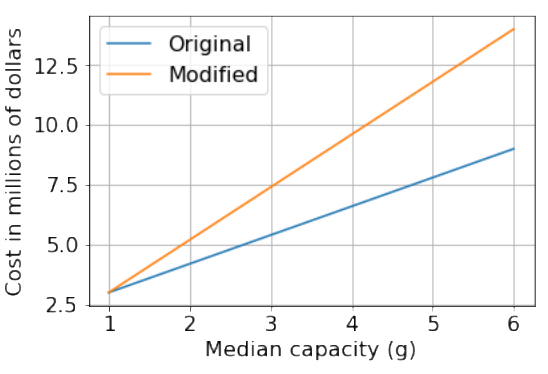

i. CRDM

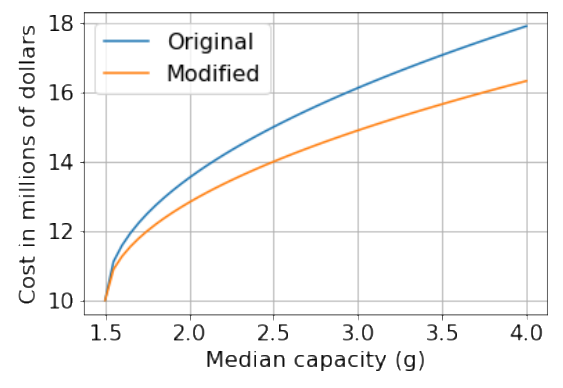

j. Piping

Figure 3-11: Modified cost functions 
Table 3-6: Capital cost and risk of the safety system before and after optimization using the modified cost functions presented in Figure 3-11

\begin{tabular}{|l|c|c|}
\cline { 2 - 3 } \multicolumn{1}{c|}{} & $\begin{array}{c}\text { Capital cost } \\
\text { (USD millions) }\end{array}$ & Seismic risk \\
\hline Initial & 98.58 & $5.16 \times 10^{-5}$ \\
\hline Optimized & 88.51 & $4.99 \times 10^{-5}$ \\
\hline
\end{tabular}

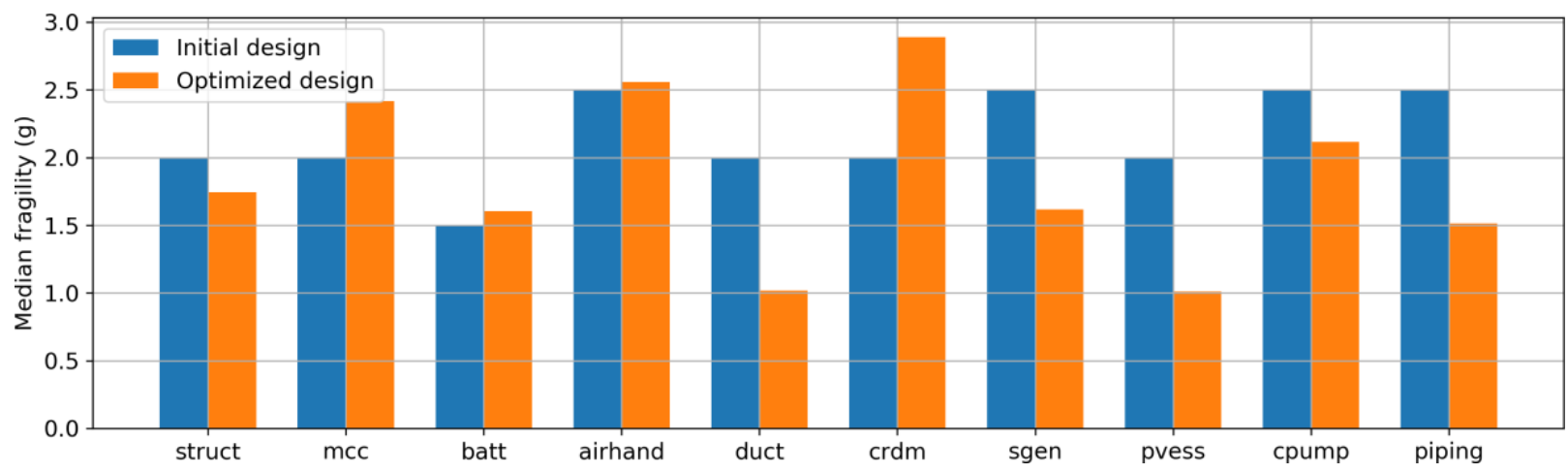

a. Median fragilities

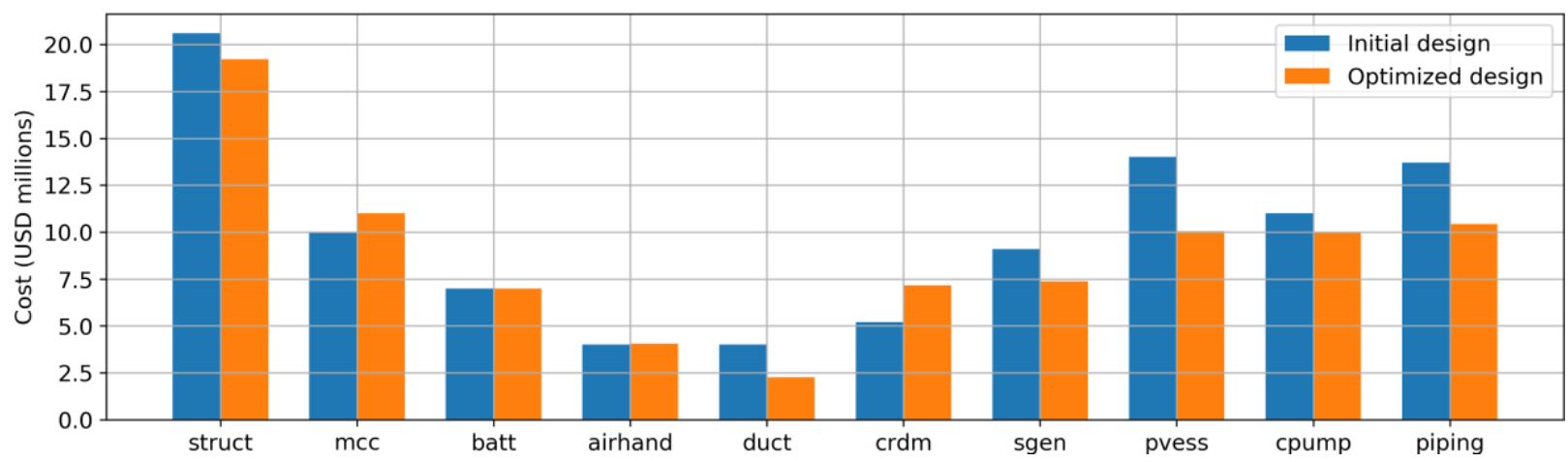

b. Capital cost of individual SSCs

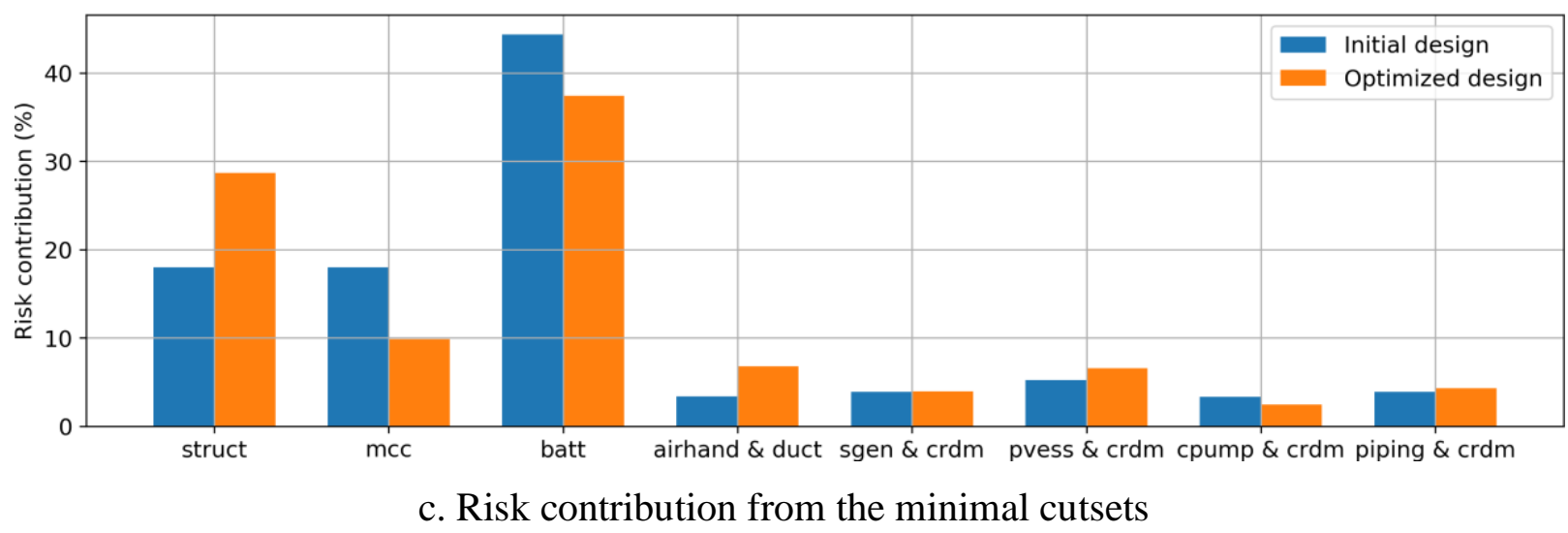

Figure 3-12: Comparison between initial and optimized designs with modified cost functions 


\subsubsection{Design optimization with component seismic isolation}

Similar to seismic base isolation, component seismic isolation involves the use of seismic isolators for individual SSCs to significantly reduce their seismic demands. The choice of selecting the SSCs to seismically isolate in a nuclear power plant depends on various factors including the seismic hazard, cost penalty for their seismic design, cost of seismically isolating the SSC, risk contribution of the SSC, etc. This section demonstrates the use of the design optimization procedure to choose the optimal set of SSCs, which, if seismically isolated, will result in a minimal capital cost. The optimization process developed in the previous sections is extended to include component seismic isolation for this purpose.

Equations 3-3 and 3-4 present the objective function and the constraints, respectively of the optimization problem when component seismic isolation is included. Similar to equation 3-1, the objective function (i.e., the total capital cost), $C^{\prime}$, is a sum of the cost functions, $c^{\prime}{ }_{i}$, evaluated at the values of the design variables. The design variables here include $a_{i}$ and $s i_{i}$, which are the median seismic fragility and a Boolean variable, respectively, corresponding to an SSC, $i$. The Boolean variable takes the value of 0 when the SSC is not seismically isolated, and a value of 1 when it is seismically isolated. The cost functions of the individual SSCs, $c^{\prime}{ }_{i}$, are equal to the original cost functions from Figure 3-8, if the SSC is not seismically isolated. The cost of an isolated SSC is evaluated as a fraction of the nominal capital cost of the SSC (i.e., when it is not designed for seismic loads), which is assumed to be the cost evaluated at the lower bound $\left(l_{i}\right)$ of its design space. This cost is given by $\alpha c_{i}\left(l_{i}\right)$ as shown in equation 3-3, where $\alpha$ is termed as the isolation cost ratio. Seismic isolation typically results in a drastic reduction in seismic demands and the seismic risk (Yu et al., 2018). Therefore, seismically isolated SSCs are assumed to have a negligible contribution to the system seismic risk. In order to ensure that the risk contribution of isolated SSCs is almost zero, their median fragilities are scaled up by a factor of 20 during the evaluation of the system risk, $R^{\prime}$. The rest of the parameters of equations 3-3 and 3-4 are identical to those in equations 3-1 and 3-2 and described in Section 3.3.

$$
\begin{gathered}
C^{\prime}\left(a_{1}, a_{2}, \ldots a_{n}, s i_{1}, s i_{2}, \ldots s i_{n}\right)=\sum_{i=1}^{n}{c^{\prime}}^{\prime}\left(a_{i}, s i_{i}\right) \\
c^{\prime}{ }_{i}\left(a_{i}, s i_{i}\right)=\left\{\begin{array}{c}
\alpha c_{i}\left(l_{i}\right) \text { if } s i_{i}=1 \\
c_{i}\left(a_{i}\right)
\end{array}\right. \\
\text { minimize } C^{\prime}\left(a_{1}, a_{2}, \ldots a_{n}, s i_{1}, s i_{2}, \ldots s i_{n}\right) \\
\text { subject to the constraints }\left\{\begin{array}{c}
R^{\prime}\left(L N\left(a_{1}, \beta_{1}\right), L N\left(a_{2}, \beta_{2}\right), \ldots L N\left(a_{n}, \beta_{n}\right)\right) \leq \mathrm{R}_{\mathrm{U}} \\
l_{1} \leq a_{1} \leq u_{1} \\
l_{2} \leq a_{2} \leq u_{2} \\
. . \\
l_{n} \leq a_{n} \leq u_{n} \\
s i_{i}=0 \text { or } 1
\end{array}\right.
\end{gathered}
$$

The data for seismic isolation cost of specific SSCs is not available in the literature since component isolation is yet to be adopted in nuclear power plants. When available, component seismic isolation cost will likely depend on the component itself, its support structures, and the seismic hazard at the site of the facility. For the study in this section, a value of 0.1 is assumed 
for the isolation cost ratio, $\alpha$, which implies that the isolation cost of the SSC is $10 \%$ of the nominal capital cost of the SSC. This value is likely conservative, since Yu et al. (2018) estimate that when base isolation is used, the capital cost of the SSCs increases by only $1 \%$ of the nominal capital cost for a facility that is similar to that considered in this study and designed for the same seismic hazard. However, a value of 0.1 is still deemed adequate the purpose of the demonstration of the design optimization algorithm in this section. The same value of $\alpha$ is used for all SSCs for simplicity.

Seismic isolation may not be possible for all SSCs. For example, distributed systems like piping cannot be seismically isolated, at least in a traditional sense, using commonly used isolation systems like elastomeric bearings. SSCs like the CRDM may not be independent components but a part of other SSCs like the reactor vessel, based on the design of the reactor. Additionally, isolating the containment structure independently may not be possible for some reactors without compromising its containment function (e.g., light water reactors). In order to replicate these practical limitations in the design optimization of the safety system, it is assumed that the seismic isolation is not admissible for piping, duct, CRDM, and the structure, and only the rest of the SSCs can be isolated. This limitation is enforced in Dakota by setting the Boolean variable, $s i_{i}$, to be 0 (i.e., not seismically isolated) for piping, duct, CRDM, and the structure, and allowing the algorithm to choose between 0 and 1 for the rest of the SSCs.

Table 3-7 presents the capital cost and seismic risk of the initial, unoptimized design (which has no seismic isolation) and the optimized design when component seismic isolation is included in the optimization process. The table shows that design optimization with component seismic isolation results in a capital cost of $\$ 78.61$ million, which is about a $\$ 21$ million smaller than the initial capital cost and about $\$ 5$ million smaller than the optimized capital cost when component seismic isolation is not considered (see Table 3-5). Including component seismic isolation for the GNF safety system therefore results in about a $21 \%$ reduction in capital cost, which is $5 \%$ additional reduction from the optimized design when seismic isolation is not included.

Figure 3-13 presents the median fragilities (panel a), capital costs (panel b) of each SSC, and a breakdown of the risk amongst the various minimal cutsets (panel c) for the initial and optimized designs. In panel a, if an SSC is determined to be seismically isolated in the optimized design, the corresponding median fragility is not presented since it is assumed to be a large number. Therefore, from panel a, it can be inferred that the optimized design requires the MCC, battery, air handler, and reactor vessel to be seismically isolated. (Note that seismic isolation is inadmissible for the piping, duct, CRDM, and the structure.) Panel c shows that the cutsets involving isolated SSCs have almost zero risk contributions, which is expected since the isolated SSCs have are assumed to have a large median fragility and have zero risk. For the other, nonisolated components, the figure shows that the median fragilities are reduced from their corresponding initial values, resulting in a net reduction in the capital cost. Panel c also shows that the seismic risk of the optimized system is distributed amongst the non-isolated systems, thereby increasing their risk contributions. While this is a consequence of using an idealized safety system with only 10 SSCs, concentration of the risk in a small subset of the SSCs may not be a preferred result in practice. Such a risk concentration can be avoided by setting risk constraints on individual SSCs, which is possible when using genetic algorithms. 
Table 3-7: Capital cost and seismic risk of the safety system before and after design optimization when component seismic isolation is included in the optimization process

\begin{tabular}{|l|c|c|}
\cline { 2 - 3 } \multicolumn{1}{c|}{} & $\begin{array}{c}\text { Capital cost } \\
\text { (USD millions) }\end{array}$ & Seismic risk \\
\hline Initial & 99.20 & $5.16 \times 10^{-5}$ \\
\hline Optimized & 78.61 & $4.86 \times 10^{-5}$ \\
\hline
\end{tabular}

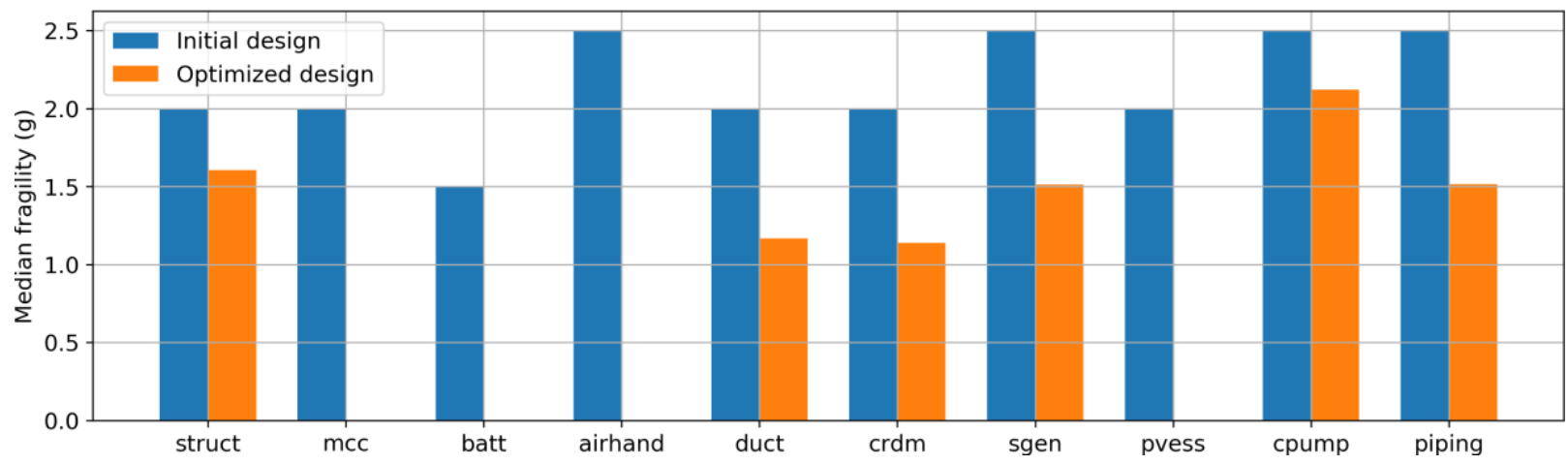

a. Median fragilities

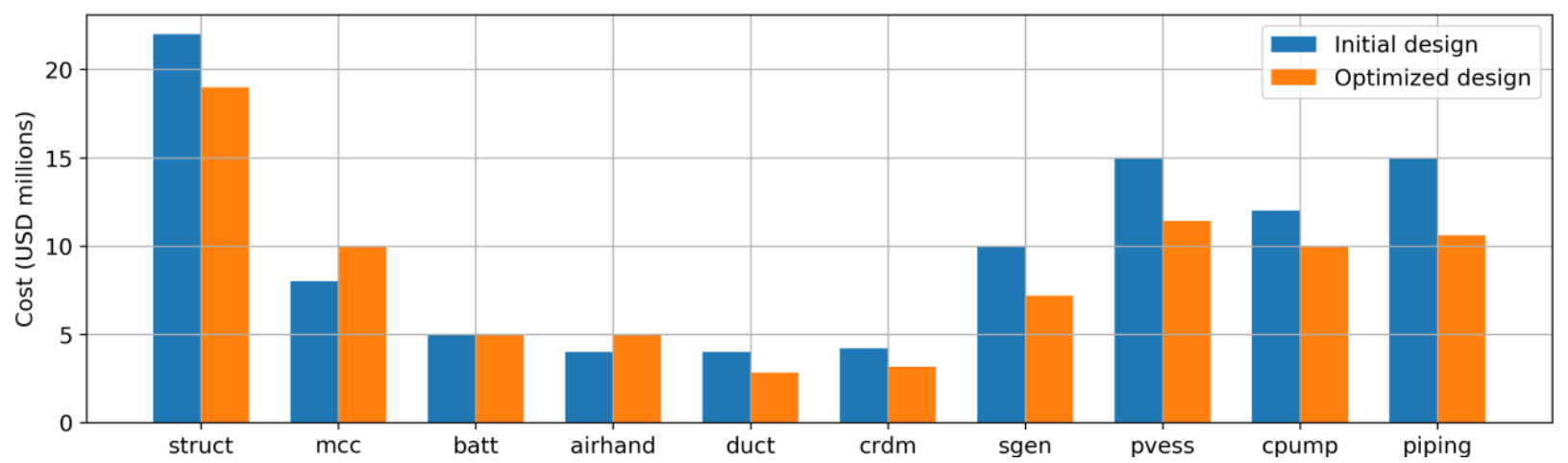

b. Capital cost of individual SSCs

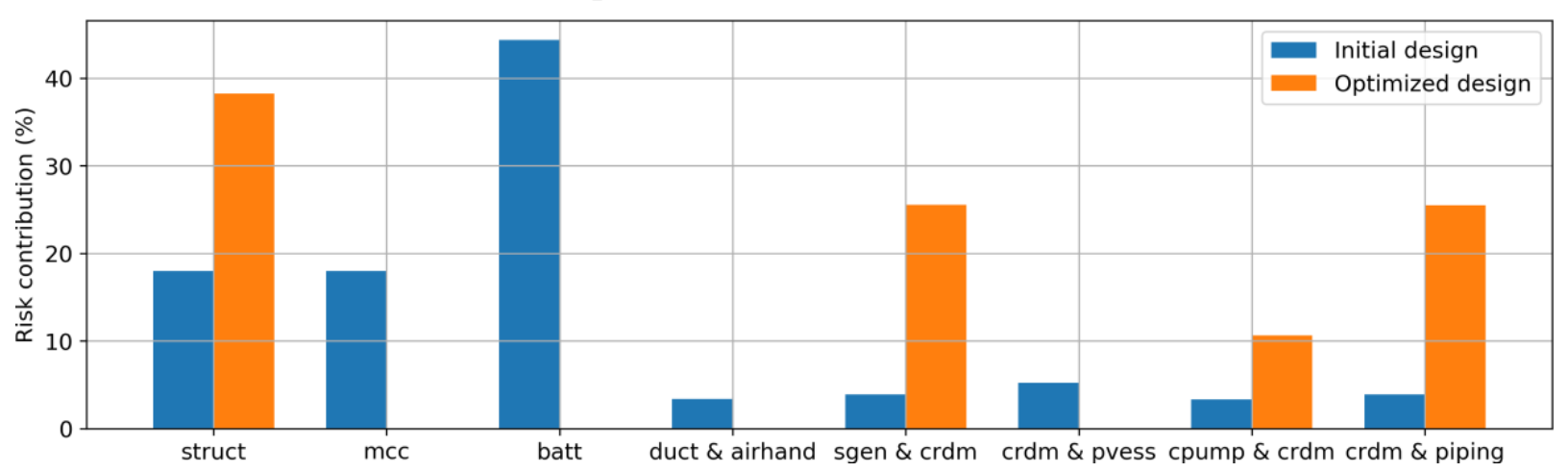

c. Risk contribution from the minimal cutsets

Figure 3-13: Comparison of initial and optimized designs of the GNF safety system while considering component seismic isolation 


\subsubsection{Effect of seismic isolation cost}

The isolation cost ratio, $\alpha$, is a measure of the capital cost of isolating an SSC. Some SSCs might be more expensive to isolate than others depending on the weight and support configuration of the SSC. However, without further data, it is deemed reasonable to assume that the isolation cost is correlated and proportional to the nominal cost of the SSC. Therefore, in this report, the isolation cost is assumed to be a fraction of the nominal cost. Isolation costs comprise the cost of the isolators, cost of the supports for the isolators, qualification costs, engineering and design costs, etc. Several of these costs are expected to reduce considerably, going from a firstof-a-kind (FOAK) to $\mathrm{N}^{\text {th }}$-of-a-kind (NOAK) isolation system for an SSC. This section aims to examine the effect of a reduction in the isolation cost from FOAK to NOAK on the optimized design. This is done by performing another design optimization of the GNF safety system after reducing the isolation cost ratio, $\alpha$, from a value 0.1 from 0.03 .

Table 3-8 presents the capital cost and seismic risk of the safety system with the initial design and the optimized design with original $(\alpha=0.1)$ and reduced $(\alpha=0.03)$ seismic isolation cost. The results for the original seismic isolation cost are taken from Table 3-7. Table 3-8 shows that lowering the isolation cost reduces the optimized solution by about an additional $\$ 2$ million, indicating that the effect of the isolation cost reduction is considerable, but small. Figure 3-14, which presents the median fragilities (panel a) and capital costs (panel b) of the individual SSCs, and also a breakdown of the system risk amongst various cutsets (panel c). The figure shows that the optimized design with reduced seismic isolation cost is quite similar to that calculated using the original seismic isolation cost, except that the steam generator is also isolated. As expected, more SSCs are isolated when the isolation costs are lowered, but the change in the total capital cost is marginal. This indicates that the including seismic isolation in the design optimization process has a stronger impact on the optimized design than fine tuning the seismic isolation cost.

Table 3-8: Capital cost and seismic risk of the safety system of GNF before and after design optimization with reduced seismic isolation cost

\begin{tabular}{|l|c|c|}
\cline { 2 - 3 } \multicolumn{1}{c|}{} & $\begin{array}{c}\text { Capital cost } \\
\text { (USD millions) }\end{array}$ & Seismic risk \\
\hline Initial & 99.20 & $5.16 \times 10^{-5}$ \\
\hline Optimized $(\boldsymbol{\alpha}=\mathbf{0 . 1})$ & 78.61 & $4.86 \times 10^{-5}$ \\
\hline Optimized $(\boldsymbol{\alpha}=\mathbf{0 . 0 3})$ & 76.67 & $3.56 \times 10^{-5}$ \\
\hline
\end{tabular}




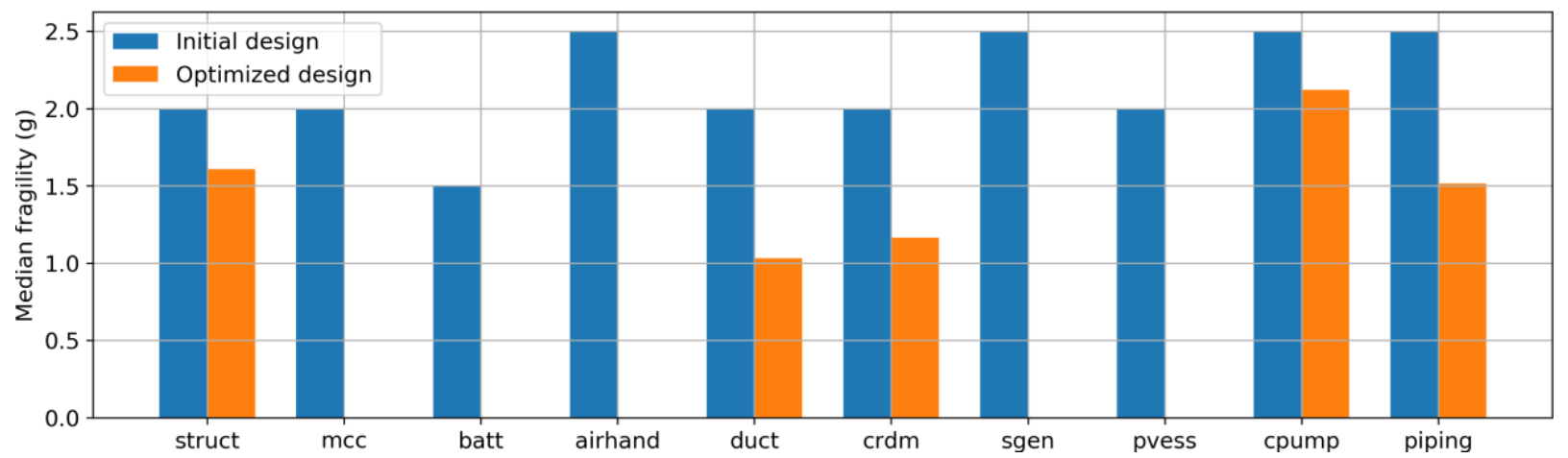

a. Median fragilities

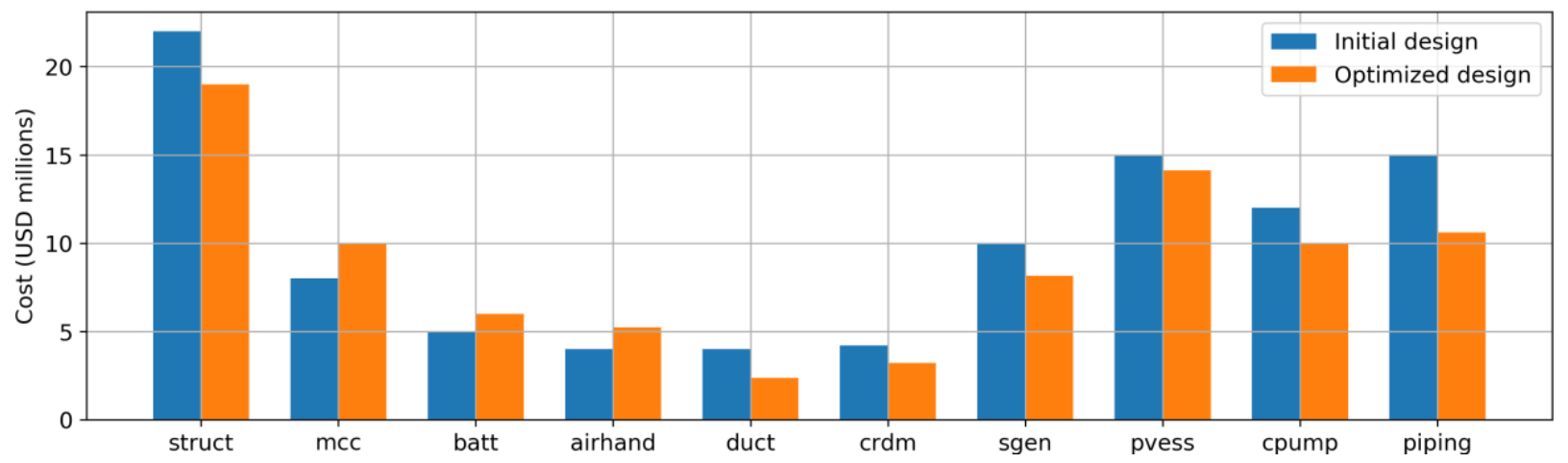

b. Capital cost of individual SSCs

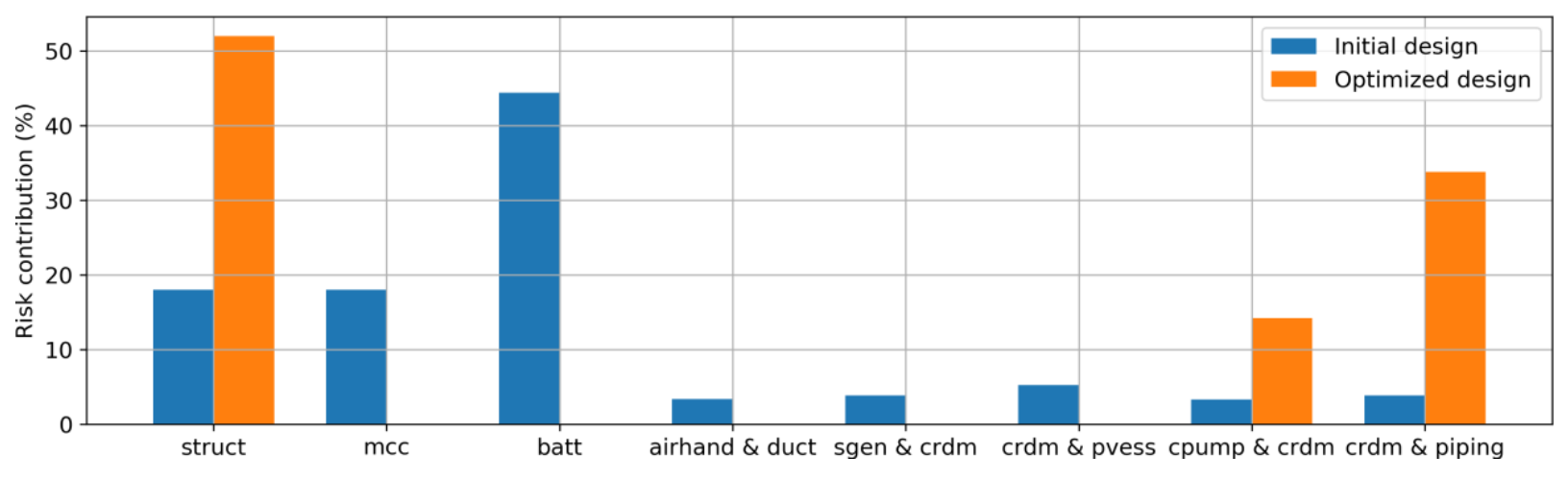

c. Risk contribution from the minimal cutsets

Figure 3-14: Comparison of initial and optimized designs of the GNF safety system with reduced seismic isolation cost

\subsection{Summary and conclusions}

This chapter presents the development and demonstration of a risk- and cost-based seismic design optimization methodology for application to safety-related nuclear structures including nuclear power plants. The methodology is demonstrated on a generic nuclear facility (GNF) that houses a safety system that performs the function of containing radioactive materials within the facility. The safety system is representative of both current and advanced nuclear power plants and comprises three classes of components: (1) electrical components including the motor control center and battery, (2) containment components including the containment structure, air 
handler, and duct, and (3) nuclear and steam supply systems (NSSS) including the reactor vessel, steam generator, coolant pump, and piping. The GNF is assumed to be sited at the Idaho National Laboratory (INL) site, which has a medium seismic hazard. The design of the GNF is characterized by the seismic fragilities of its SSCs that represent their seismic integrity. A representative fault tree and event tree are developed to describe the accident sequences of the GNF. The initial fragility functions (median and lognormal standard deviation) are generic and chosen from the EPRI SPRA guide. The ranges of median fragilities, which serve as the design space for the design optimization, are also taken from this guide. Given the lack of data to relate the capital costs of SSCs to their seismic capacities, generic cost functions are developed for the SSCs. These cost functions represent the seismic design 'penalty' i.e., the additional costs required to strengthen the SSC or its support to achieve the required seismic capacity. With the initial fragilities and cost functions, the total capital cost of the unoptimized design of the GNF is around $\$ 99.2$ million. Risk assessment is performed using MASTODON and the seismic risk from the initial design is calculated to be around $5.16 \times 10^{-5}$. Design optimization is performed using a genetic algorithm in Dakota, with the dual goals of minimizing overnight capital cost and meeting safety performance goals. The performance goal of the GNF is to not exceed a seismic risk of $5.0 \times 10^{-5}$, which is input as a constraint to the genetic algorithm. Design optimization is performed with and without considering seismic isolation of individual SSCs as a design option. Results of the design optimization include the capital cost and seismic risk of the optimized GNF design, and the corresponding design variables, i.e., median seismic fragilities and the set of seismically isolated SSCs. From the optimized design, the final capital cost of each SSC, and the risk contribution of each minimal cut set are also calculated. For each design optimization case, a comparison of these results is presented between the initial (unoptimized) and optimized design.

The following conclusions can be drawn from this chapter:

1. The results of Section 3.5.2 show that, although heuristically based, genetic algorithms exhibit convergence and stability and often provide an optimal solution, even for discontinuous and non-differentiable objective functions. Given this versatility and robustness of genetic algorithms, the optimization framework developed here can be scaled and modified to design optimization in practice, which involve more complex cost functions and variables (e.g., Boolean variables such as those used for component seismic isolation), much larger design spaces, and numerous design constraints. Additionally, while genetic algorithms are not guaranteed to provide a mathematical optimum, they to provide a design solution that is much better than the initial design and satisfies the design constraints. Genetic algorithms are therefore well suited for the large-scale design optimization of nuclear structures.

2. Design optimization of the GNF without including seismic isolation resulted in a $16 \%$ capital cost reduction while meeting the safety goals. This is a significant reduction and demonstrates that 'fine-tuning' the design can result in large capital cost savings. A comparison of the costs and risk contributions corresponding to the initial and optimized design shows that the optimization algorithm automatically rewards redundancy in design and defense in depth. Additionally, the algorithm ensures that the cost profile of the SSCs is in coherence with the risk profile, i.e., the cost investment is prioritized for SSCs that most contribute to the risk and provide the largest benefit-cost ratio. Results from a separate design optimization using modified cost functions shows that moderate changes 
in the cost functions (such as increasing the rate of change of the cost) can affect the total optimized cost, but not significantly.

3. Including component seismic isolation in the design optimization resulted in a 5\% additional cost reduction with a total cost reduction of $21 \%$ and a new optimized capital cost of $\$ 78$ million. This optimization is performed with an assumption that the seismic isolation cost is about $10 \%$ of the nominal cost of the SSC, which is likely overestimated. The results of the optimization showed that the fragility of all the SSCs is either reduced or the SSC is seismically isolated. A separate optimization with the seismic isolation cost reduced to $3 \%$ of the nominal cost resulted in a capital cost of about $\$ 76$ million, which is a small, yet considerable, improvement over the case with higher seismic isolation costs. Additionally, lowering the isolation cost resulted in a larger number of SSCs being isolated in the optimized design.

4. In cases with and without seismic isolation, changing the cost functions (or the isolation cost ratio, when component isolation is considered) resulted in considerable changes in the optimized design. However, the choices of using design optimization or using component seismic isolation themselves are more significant in terms of cost reduction than using accurate cost functions or isolation cost ratios. Although using accurate cost estimates might provide more confidence in the cost of the optimized design, cost functions that reasonably capture the (a) relative costs of the SSCs and (b) rate of change of the cost with median fragility are likely adequate to provide a design that is better than the initial design. The design optimization process presented in this chapter should therefore be viewed as an intelligent alternative to manual 'fine-tuning', which is typically performed for a preliminary design. Given that accurate cost functions or the seismic design penalties for advanced reactor SSCs may not be available for some time, estimates like those calculated by Lal et al. (2019), Lal et al. (2020), and EPRI (2020), are more than adequate to optimize nuclear power plant designs significantly and minimize capital costs.

5. This chapter demonstrates that design optimization of nuclear power plants is possible and can result in significant capital cost reduction without compromising safety. The optimization framework developed here is versatile and scalable and can be extended to real facilities when the required data is available. The framework can be extended to include component seismic isolation, which results in additional cost reductions. In practice, cost reductions due to seismic isolation can be significant, especially since it enables the use of off-the-shelf components eliminates the SSC qualification costs and the corresponding engineering and design costs and potentially accelerates the regulatory process. 


\section{REFERENCES}

1. American Concrete Institute (ACI). (2013). "Code Requirements for Nuclear Safety-Related Concrete Structures and Commentary." ACI 349-13, Farmington Hills, MI.

2. Adams, B. M., Bauman, L. E., Bohnhoff, W. J., Dalbey, K. R., Ebeida, M. S., Eddy, J. P., Eldred, M. S., Hough, P. D., Hu, K. T., Jakeman, J. D., Stephens, J. A., Swiler, L. P., Vigil, D. M., and Wildey, T. M. (2014). "Dakota - A Multilevel Parallel Object-Oriented Framework for Design Optimization, Parameter Estimation, Uncertainty Quantification, and Sensitivity Analysis: Version 6.0 User's Manual." SAND2014-4633, Sandia National Laboratory.

3. American Society of Civil Engineers (ASCE). (2005). "Seismic Design Criteria for Structures, Systems, and Components in Nuclear Facilities." ASCE 43-05, Reston, VA.

4. American Society of Civil Engineers (ASCE). (2010). "Minimum Design Loads for Buildings and Other Structures." ASCE/SEI 7-10, Reston, Virginia.

5. American Society of Civil Engineers (ASCE). (2017). "Seismic Analysis of Safety-Related Nuclear Structures and Commentary." ASCE/SEI Standard 4-16, Reston, Virginia.

6. American Society of Civil Engineers (ASCE). (2019). "Seismic Design Criteria for Structures, Systems, and Components in Nuclear Facilities." ASCE 43-19, Reston, VA.

7. American Society of Mechanical Engineers (ASME). (2017). "ASME Boiler and Pressure Vessel Code." New York, NY.

8. Bolisetti, C., Yu, C., Coleman, J. L., Kosbab, B., and Whittaker, A. S. (2016).

"Characterizing the Benefits of Seismic Isolation for Nuclear Structures: A Framework for Risk-Based Decision Making." INL/EXT-16-40122, Idaho National Laboratory, Idaho Falls, Idaho.

9. Bolisetti, C., Hoffman, W., Parsi, S. S., Kramer, K. J., Kirchman, P., Redd, J., Coleman, J., and Whittaker, A. S. (2019). "Risk- and Cost-Based Seismic Design Optimization of Advanced Nuclear Reactor Systems." 25th International Conference on Structural Mechanics in Reactor Technology (SMiRT25), Charlotte, NC.

10. Buongiorno, J., Parsons, J., Corradini, M., and Petti, D. (2018). "The Future of Nuclear Energy in a Carbon Constrained World - An Interdisciplinary MIT Study." MIT Energy Initiative, Massachusetts Institute of Technology, Cambridge, MA, USA.

11. CSI (2019). Computer Program: SAP2000 (Version 20.1). Computers and Structures Inc, Berkeley, CA.

12. Eddy, J. E., and Lewis, K. (2001). "Effective Generation of Pareto Sets Using Genetic Programming." Proceedings: ASME Design Engineering Technical Conference, American Society of Mechanical Engineers.

13. Electric Power Research Institute (EPRI). (2013). "Seismic Probabilistic Risk Assessment Implementation Guide." 3002000709, Palo Alto, CA. 
14. Electric Power Research Institute (EPRI). (2020). "Cost Basis for Utilizing Seismic Isolation for Nuclear Power Plant Design." 03002018345, Charlotte, NC.

15. Fussel, J. B., and Vesely, W. E. (1972). "A New Methodology for Obtaining Cut Sets for Fault Trees." Transactions of the American Nuclear Society, 15(1).

16. Hancock, J., Watson-Lamprey, J., Abrahamson, N. A., Bommer, J. J., Markatis, A., McCoy, E., and Mendis, R. (2006). "An Improved Method of Matching Response Spectra of Recorded Earthquake Ground Motion Using Wavelets." Journal of Earthquake Engineering, 10:(S1), 67-89.

17. Huang, Y.-N., Whittaker, A. S., and Luco, N. (2008a). "Performance Assessment of Conventional and Base-Isolated Nuclear Power Plants for Earthquake and Blast Loadings." MCEER-08-0019, Multidisciplinary Center for Earthquake Engineering Research, University at Buffalo, The State University of New York, Buffalo, NY.

18. Huang, Y.-N., Whittaker, A. S., and Luco, N. (2008b). "Maximum Spectral Demands in the Near-Fault Region." Earthquake Spectra, 24(1), 319-341.

19. Huang, Y.-N., Whittaker, A. S., Kennedy, R. P., and Mayes, R. L. (2009). "Assessment of Base-Isolated Nuclear Structures for Design and Beyond-Design Basis Earthquake Shaking." Technical Report MCEER-09-0008, Multidisciplinary Center for Earthquake Engineering (MCEER), Buffalo, New York.

20. Huang, Y.-N., Whittaker, A. S., and Luco, N. (2011a). "A Probabilistic Seismic Risk Assessment Procedure for Nuclear Power Plants: (II) Application." Nuclear Engineering and Design, 241, 4004-4011.

21. Huang, Y. N., Whittaker, A. S., and Luco, N. (2011b). "A Probabilistic Seismic Risk Assessment Procedure for Nuclear Power Plants: (I) Methodology." Nuclear Engineering and Design, 241, pp.3996-4003.

22. Kammerer, A. M., Whittaker, A. S., and Constantinou, M. C. (2019). "Technical Considerations for Seismic Isolation in Nuclear Facilities." United States Nuclear Regulatory Commission, Washington, D.C. (ML19050A422).

23. Kumar, M., Whittaker, A. S., and Constantinou, M. C. (2017a). "Extreme Earthquake Response of Nuclear Power Plants Isolated using Sliding Bearings." Nuclear Engineering and Design, 316, 9-25.

24. Kumar, M., Whittaker, A. S., Kennedy, R. P., Johnson, J. J., and Kammerer, A. (2017b). "Seismic Probabilistic Risk Assessment for Seismically Isolated Safety-Related Nuclear Facilities." Nuclear Engineering and Design, 313, 386-400.

25. Kumar, M., Whittaker, A. S., and Constantinou, M. C. (2019a). "Seismic Isolation of Nuclear Power Plants Using Elastomeric Bearings." United States Nuclear Regulatory Commission, Washington, D.C. (ML19063A541).

26. Kumar, M., Whittaker, A. S., and Constantinou, M. C. (2019b). "Seismic Isolation of Nuclear Power Plants Using Sliding Bearings." United States Nuclear Regulatory Commission, Washington, D.C. (ML19158A513).

27. Lal, K., Parsi, S. S., Scott, D., Shirvan, K., Cohen, M., Kirchman, P., Kosbab, B., and Whittaker, A. (2019). "Cost Basis for Utilizing Seismic Isolation in Nuclear Power Plants." 
Structural Mechanics in Reactor Technology (SMiRT 25), August, 2019, Charlotte, NC, USA.

28. Lal, K., Parsi, S. S., Charkas, H., Shirvan, K., Cohen, M., Kirchman, P., Kosbab, B., and Whittaker, A. (2020). "Reducing the Capital Cost of Nuclear Power Plants Using Seismic Isolation." Proceedings: Proceedings of the International Congress on Advances in Nuclear Power Plants (ICAPP), August, 2019, Abu Dhabi, UAE.

29. Rao, S. S. (2009). "Engineering Optimization - Theory and Practice (4th Edition)." John Wiley \& Sons.

30. Smith, C. L., and Wood, T. L. (2011). "Systems Analysis Programs for Hands-on Integrated Reliability Evaluations (SAPHIRE) Version 8." Volume 2: Technical Reference, NUREG/CR-7039, U.S. Nuclear Regulatory Commission, Idaho Falls, ID, USA.

31. Stevenson, J. D. (1981). "Evaluation of the Cost Effects on Nuclear Power Plant Construction Resulting from the Increase in Seismic Design Level." NUREG/CR-1508, U. S. Nuclear Regulatory Commission, Washington, D. C.

32. Stevenson, J. D. (2003). "Historical Development of the Seismic Requirements for Construction of Nuclear Power Plants in the U.S. and Worldwide and their Current Impact on Cost and Safety." Structural Mechanics and Reactor Technology (SMiRT 17), August 17-22, Prague, Czech Republic.

33. USGS (2008). "Unified Hazard Tool - 2008 Interactive Deaggregations." https://earthquake.usgs.gov/hazards/interactive/.

34. United States Nuclear Regulatory Commission (USNRC). (2011). "Systems Analysis Programs for Hands-on Integrated Reliability Evaluations (SAPHIRE)." NUREG/CR-7039, Washington, District of Columbia.

35. United States Nuclear Regulatory Commission (USNRC). (2014). "Design Response Spectra for Seismic Design of Nuclear Power Plants." Regulatory Guide 1.60, Washington, D.C.

36. Veeraraghavan, S., Bolisetti, C., Slaughter, A., Coleman, J., Dhulipala, S., Hoffman, W., Kim, K. T., Kurt, E., Spears, R., and Munday, L. (2020). "MASTODON: An Open-Source Software for Seismic Analysis and Risk Assessment of Critical Infrastructure." Nuclear Technology(Accepted).

37. Whittaker, A. S., Sollogoub, P., and Kim, M. K. (2018). "Seismic Isolation of Nuclear Structures: Past, Present, and Future." Nuclear Engineering and Design, 338, 290-299.

38. Yang, T. Y., Moehle, J. P., Stojadinovic, B., and Der Kiureghian, A. (2009). " Performance Evaluation of Structural Systems: Theory and Implementation." Journal of Structural Engineering, 135(10), 1146-1154.

39. Yu, C.-C., Bolisetti, C., Coleman, J. L., Kosbab, B., and Whittaker, A. S. (2018). "Using Seismic Isolation to Reduce Risk and Capital Costs of Safety-Related Nuclear Facilities." Nuclear Engineering and Design, 326, pp. 268-284. dx.doi.org/10.1016/j.nucengdes.2017.11.016 


\section{APPENDIX A \\ SELECTION OF ISOLATION SYSTEMS}

Buildings \#1 and \#2 were analyzed for the isolation systems of Table 2-2 using the INL ground motions of Yu et al. (2018) for a geomean horizontal PGA of $0.3 \mathrm{~g}$. Two metrics were monitored to judge the effectiveness of an isolation system: 1) reduction in acceleration demand, and 2) increase in isolator displacement. The goal here was to demonstrate that the mechanical properties of an isolation system can be altered to achieve a desired combination of accelerations in the SSCs and displacement across the isolation interface. Table A-1 reports the $80^{\text {th }}$ percentile geomean horizontal accelerations at points \#a1 through \#a5 (see Figure 2-15) and \#a6 through \#a10 (see Figure 2-18) for the fixed-base building and the four isolation systems. Isolator displacements in buildings \#1 and \#2 are reported in Table A-2.

Table A-1: $80^{\text {th }}$ percentile geomean horizontal accelerations $(\mathrm{g})$, all cases

\begin{tabular}{|c|c|c|c|c|c|}
\hline \multirow{2}{*}{ Response parameter } & \multirow{2}{*}{ Fixed base } & \multicolumn{5}{|c|}{ Base isolated } \\
\cline { 3 - 6 } & & Option 1 & Option 2 & Option 3 & Option 4 \\
\hline \multicolumn{5}{|c|}{ Building \#1 } \\
\hline \#a1 & 0.46 & 0.13 & 0.10 & 0.07 & 0.05 \\
\hline$\# \mathrm{a} 2$ & 1.28 & 0.40 & 0.30 & 0.20 & 0.12 \\
\hline$\# \mathrm{a} 3$ & 1.83 & 0.18 & 0.14 & 0.10 & 0.07 \\
\hline$\# \mathrm{a} 4$ & 0.41 & 0.15 & 0.11 & 0.08 & 0.05 \\
\hline$\# \mathrm{a} 5$ & 1.51 & 0.40 & 0.30 & 0.21 & 0.13 \\
\hline & & Building \#2 & & \\
\hline$\# \mathrm{a} 6$ & 0.67 & 0.19 & 0.15 & 0.10 & 0.06 \\
\hline$\# \mathrm{a} 7$ & 3.2 & 0.53 & 0.40 & 0.29 & 0.17 \\
\hline$\# \mathrm{a} 8$ & 7.7 & 1.54 & 1.21 & 0.85 & 0.49 \\
\hline$\# \mathrm{a} 9$ & 1.21 & 0.39 & 0.29 & 0.20 & 0.13 \\
\hline$\# \mathrm{a} 10$ & 1.81 & 0.63 & 0.48 & 0.32 & 0.20 \\
\hline
\end{tabular}

Table A-2: $80^{\text {th }}$ percentile SRSS isolator displacements $(\mathrm{mm})$, all cases

\begin{tabular}{|c|c|c|c|c|}
\hline \multirow{2}{*}{ Response parameter } & \multicolumn{4}{|c|}{ Base isolated } \\
\cline { 2 - 5 } & Option 1 & Option 2 & Option 3 & Option 4 \\
\hline$\#$ id1 & 42 & 58 & 72 & 100 \\
\hline$\#$ id2 & 42 & 59 & 76 & 104 \\
\hline
\end{tabular}

Figure A-1 illustrates the acceleration-displacement trade-off in buildings \#1 and \#2 for the four isolation systems. For example, at point \#a2 (in building \#1), the acceleration is reduced from $0.40 \mathrm{~g}$ to $0.12 \mathrm{~g}$ (by a factor of 3.75 ) as the isolation system is changed from option 1 to option 4 (see Figure A-1a). Similarly, at point \#a8 (in building \#2), acceleration is reduced from

${ }^{\text {e }}$ Corresponding to design basis earthquake (DBE) shaking at the INL site for a return period of 10,000 years (see Figure 2-11). 
$1.54 \mathrm{~g}$ to $0.49 \mathrm{~g}$ (see Figure A-1b). The trade-off is an increase in isolator displacement from 42 $\mathrm{mm}$ to $100 \mathrm{~mm}$ (by a factor of 2.5) in building \#1 and from $42 \mathrm{~mm}$ to $104 \mathrm{~mm}$ in building \#2. Among the four isolation systems considered, Option 3, with low accelerations and isolator displacements for DBE shaking was selected for further analysis.

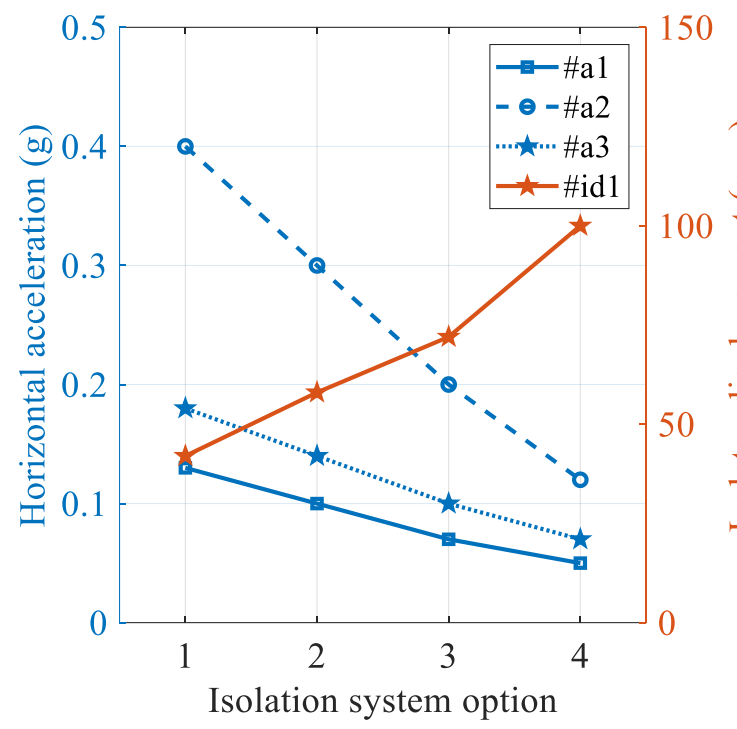

a) building \#1

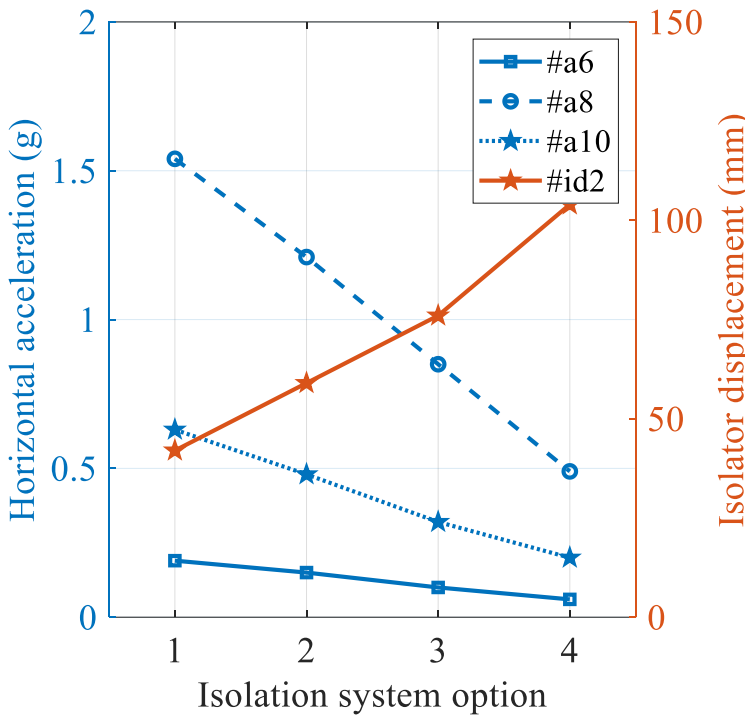

b) building \#2

Figure A-1: Acceleration-isolator displacement trade-off for different isolation systems

Figure A-2 shows the horizontal force-displacement loops of the FP bearing in building \#1 for the scaled Lamont 1059, Duzce, Turkey (1999) ground motion of Table 2-1. The dashed red lines identify the bounding behavior of the simplified model of the FP bearing and are derived assuming the coefficient of sliding friction and radius of the sliding surface per Table 2.2 and a displacement capacity of $200 \mathrm{~mm}$. The $80^{\text {th }}$ percentile acceleration response spectra in buildings \#1 and \#2 are presented in Figure A-3 and A-4, respectively, for the fixed-base condition and the four seismically isolated options. These spectra enable a comparison of equipment accelerations as a function of isolation-system properties.

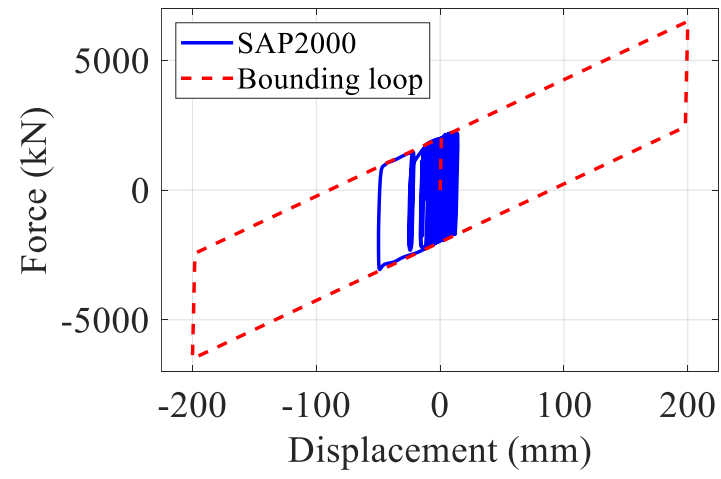

a) Option 1

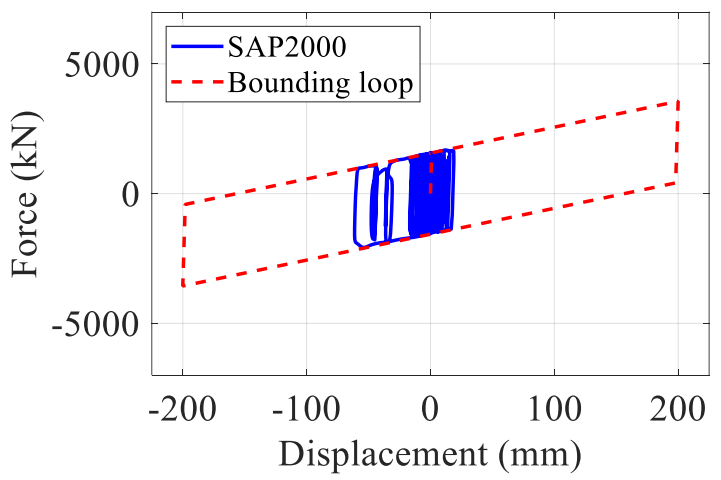

b) Option 2

Figure A-2: Isolator force-displacement loops in building \#1 


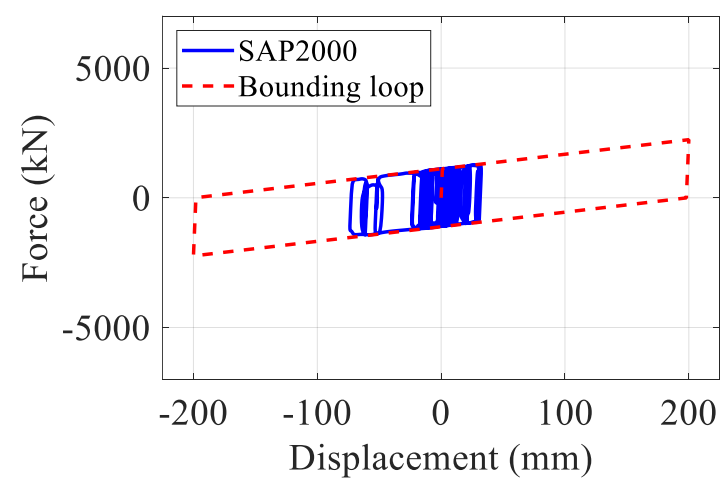

c) Option 3

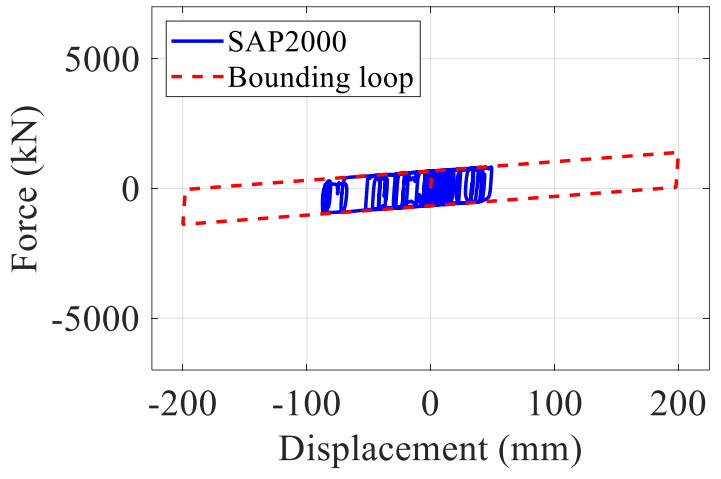

d) Option 4

Figure A-2: Isolator force-displacement loops in building \#1 (cont'd)

- Fixed-base --- Option $1---$ Option $2---$ Option $3---$ Option 4

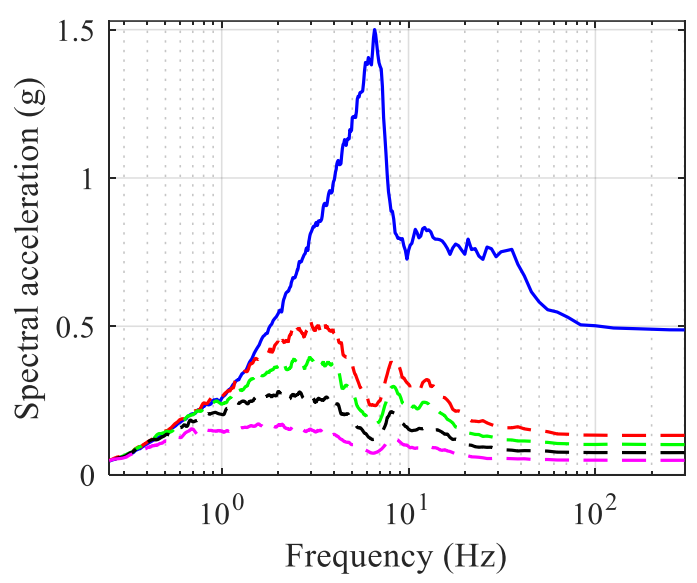

a) $x$-direction, \#a 1

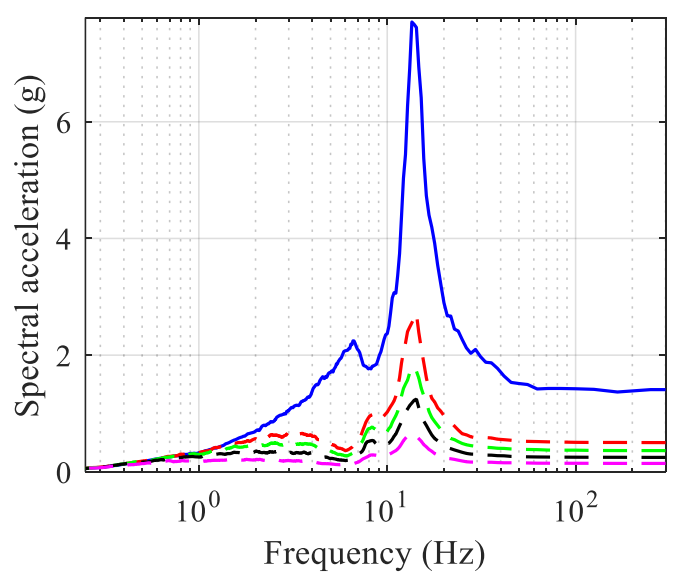

c) $x$-direction, $\# \mathrm{a} 2$

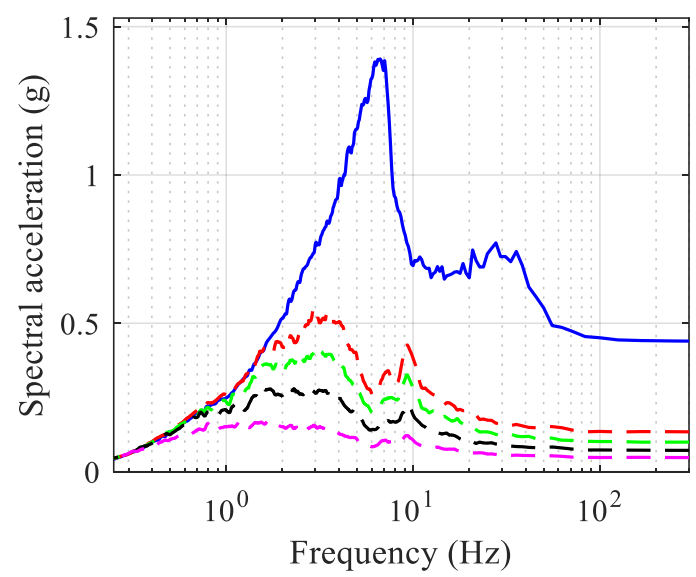

b) $y$-direction, \#a1

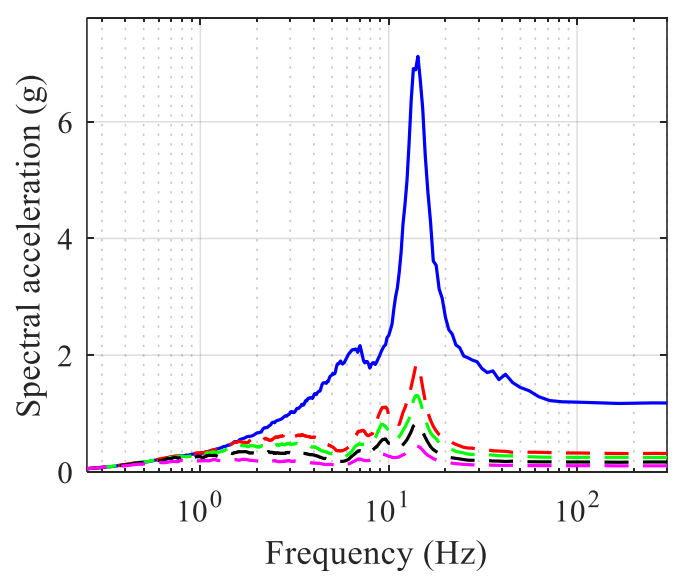

d) $y$-direction, \#a2

Figure A-3: $80^{\text {th }}$ percentile horizontal acceleration spectra in building \#1, PGA $=0.3 \mathrm{~g}$, all cases 


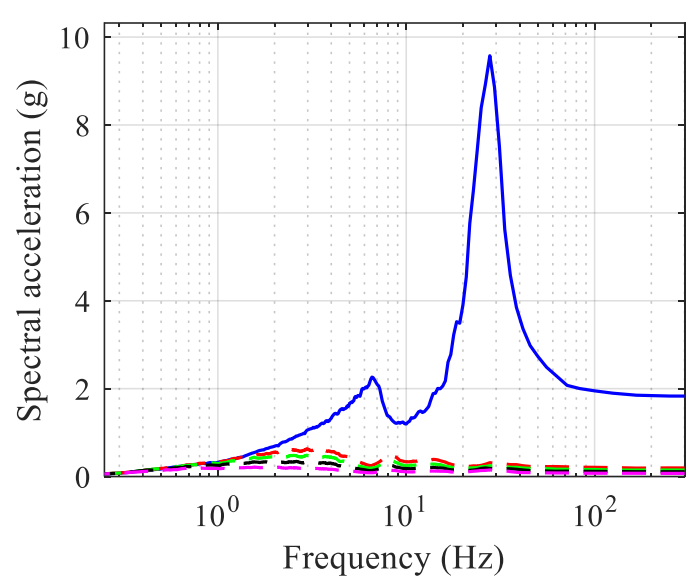

e) $x$-direction, \#a3

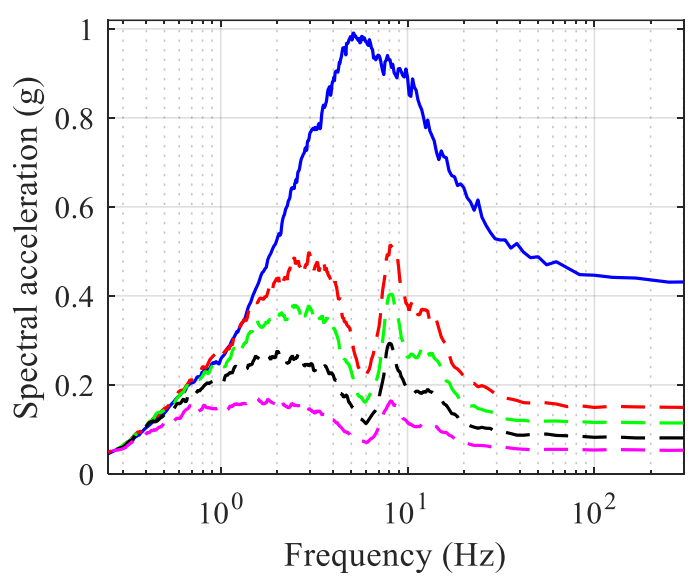

g) $x$-direction, \#a4

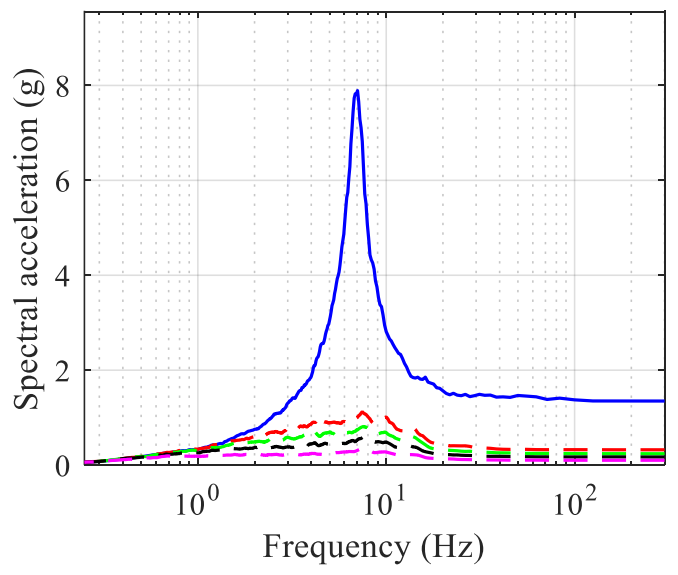

i) $x$-direction, \#a5

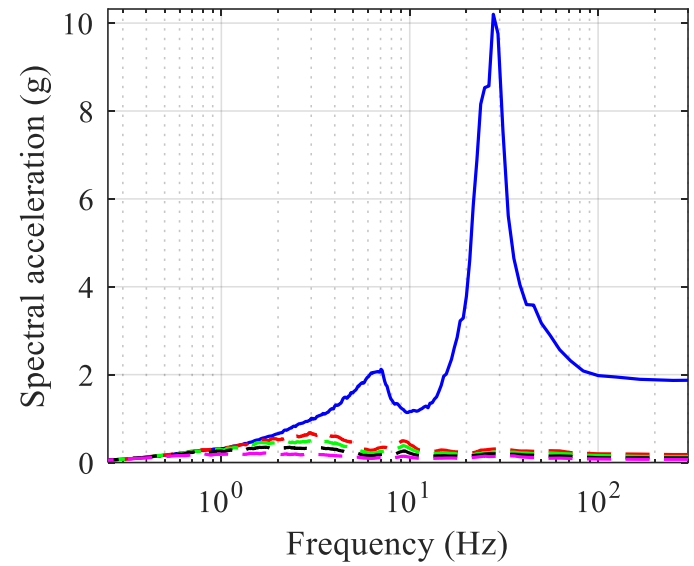

f) $y$-direction, \#a3

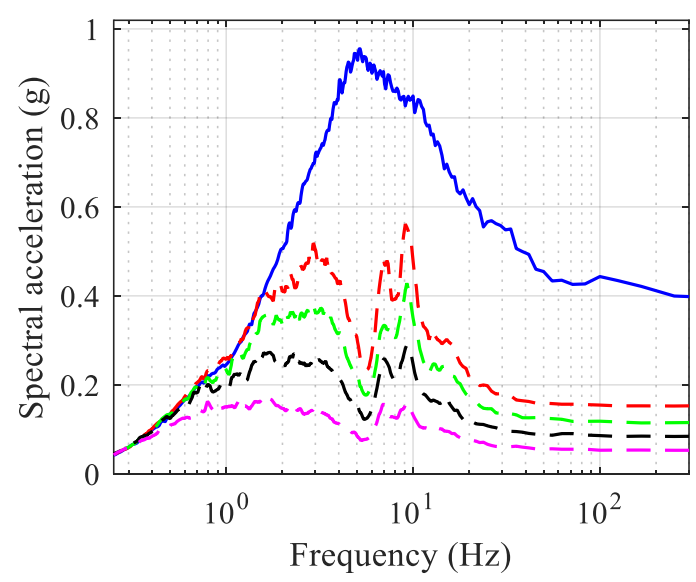

h) $y$-direction, \#a4

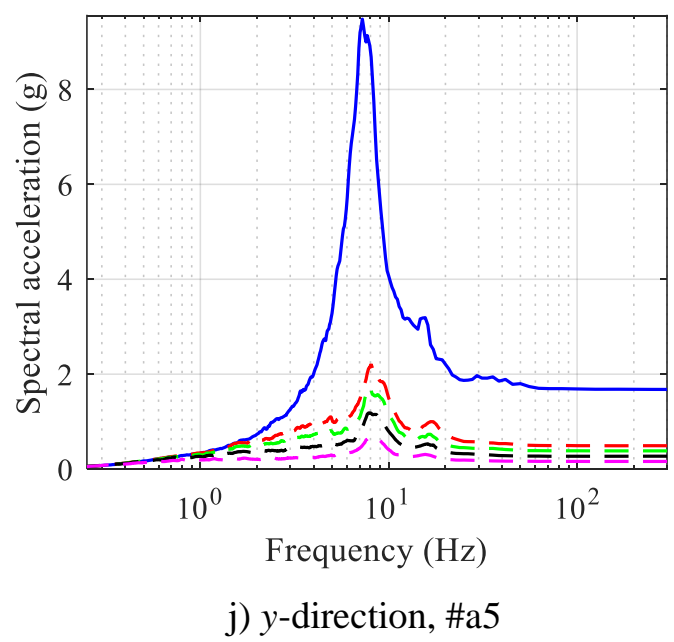

Figure A-3: $80^{\text {th }}$ percentile horizontal acceleration spectra in building \#1, PGA $=0.3 \mathrm{~g}$, all cases (cont'd) 
- Fixed-base --- Option $1---$ Option $2---$ Option $3---$ Option 4

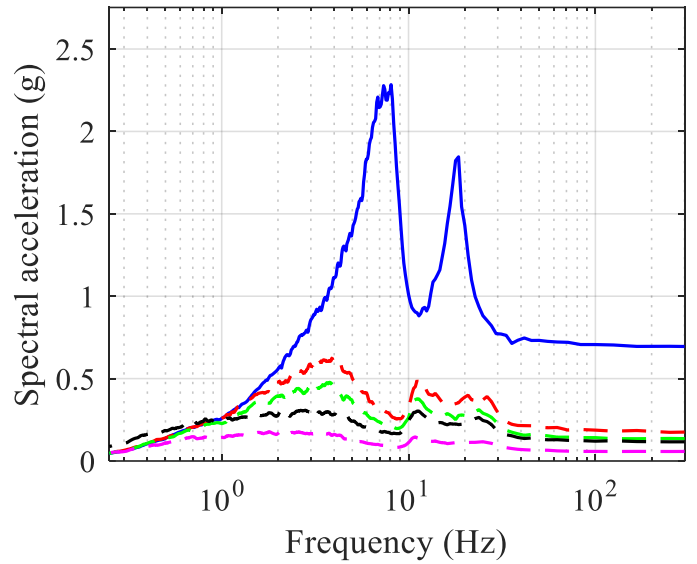

a) $x$-direction, \#a6

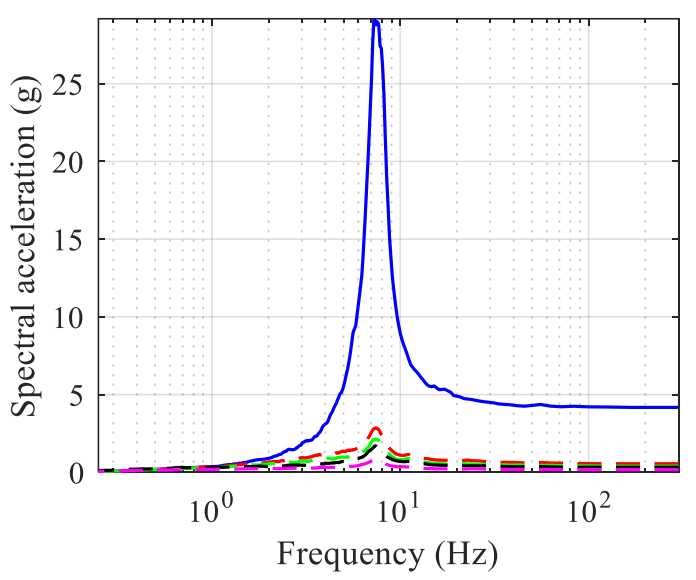

c) $x$-direction, \#a7

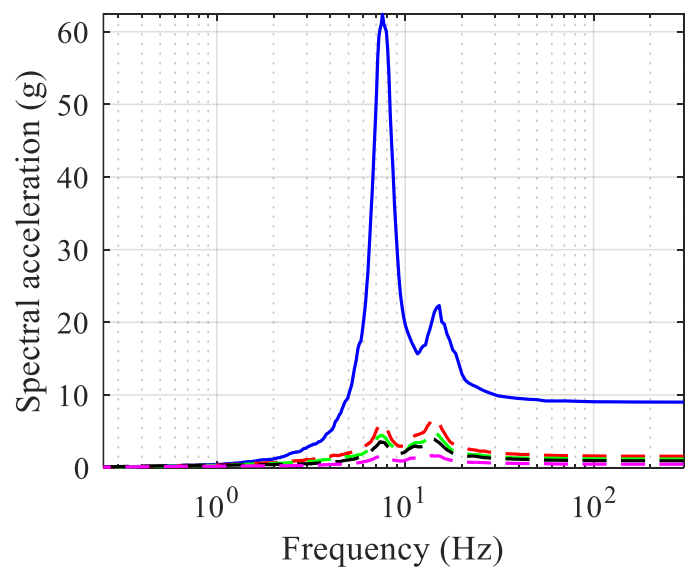

e) $x$-direction, \#a 8

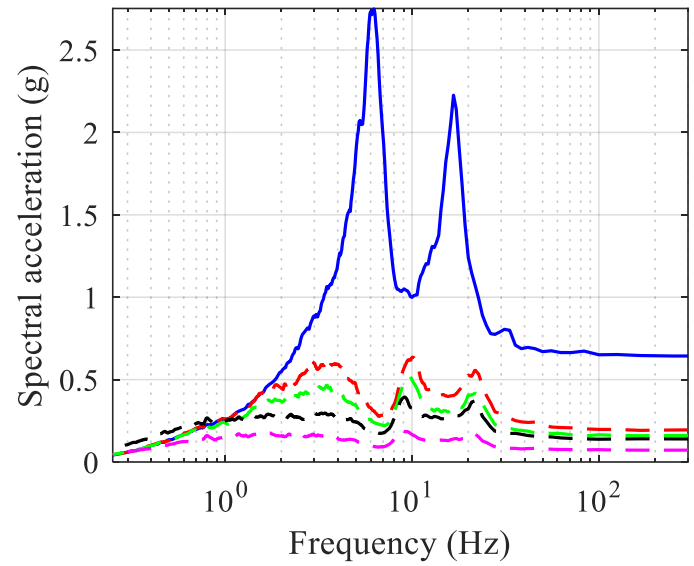

b) $y$-direction, \#a6

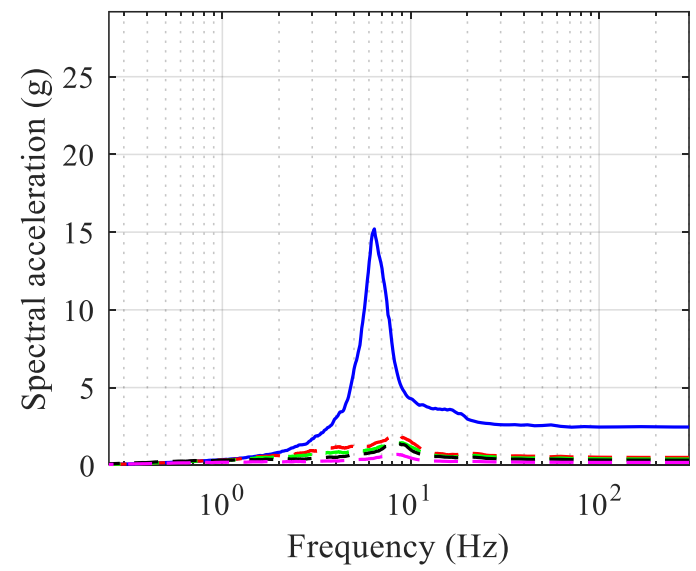

d) $y$-direction, \#a7

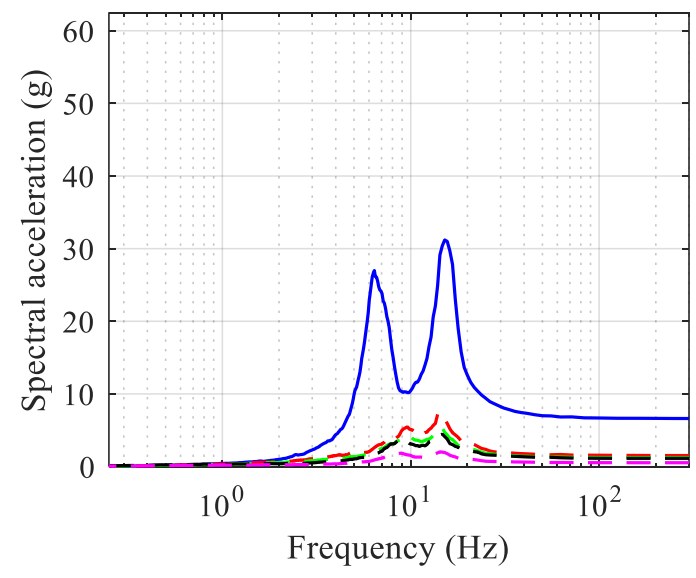

f) $y$-direction, $\# \mathrm{a} 8$

Figure A-4: $80^{\text {th }}$ percentile horizontal acceleration spectra in building $\# 2, \mathrm{PGA}=0.3 \mathrm{~g}$, all cases 


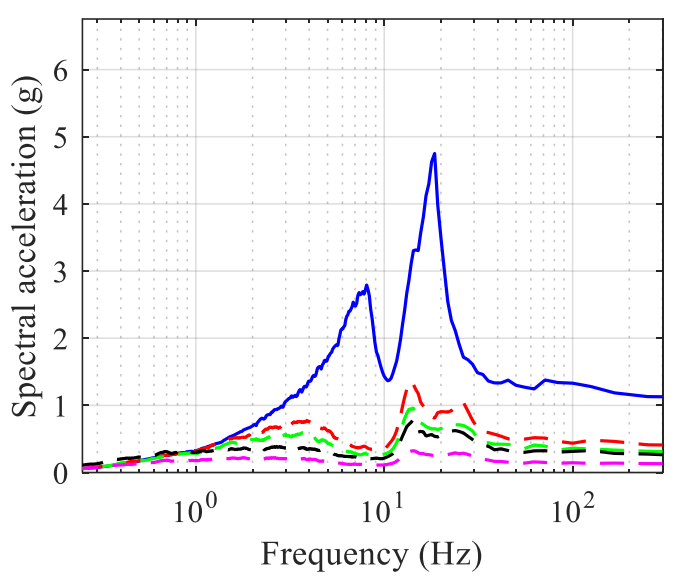

g) $x$-direction, \#a9

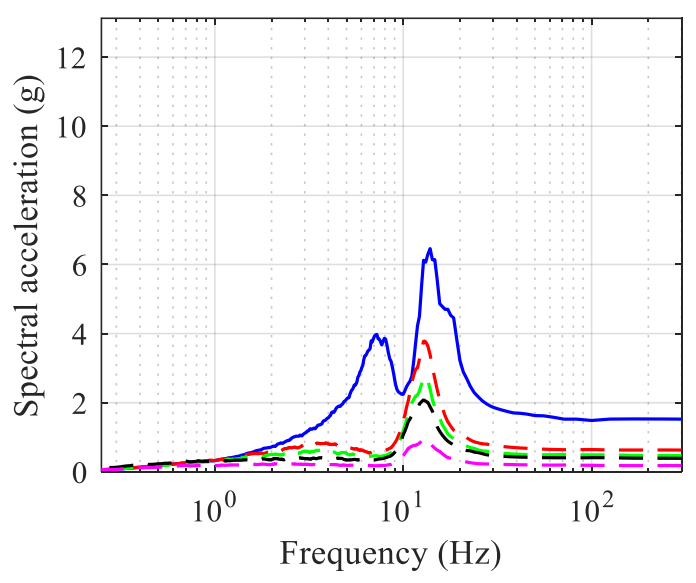

i) $x$-direction, \#a 10

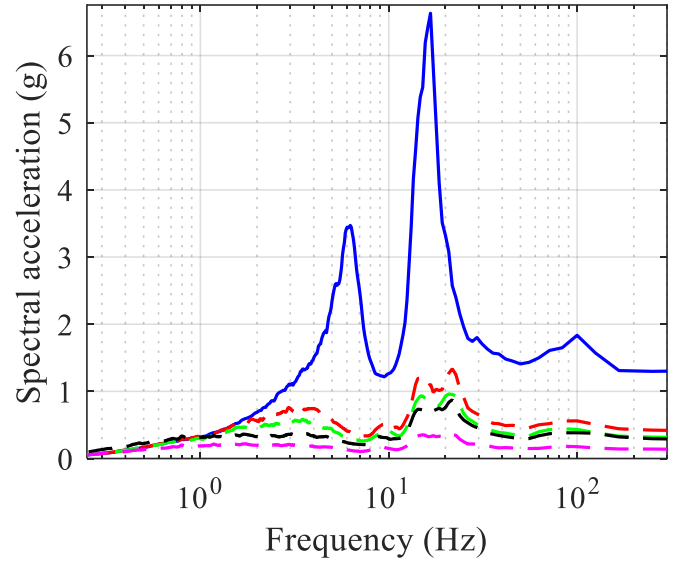

h) $y$-direction, \#a9

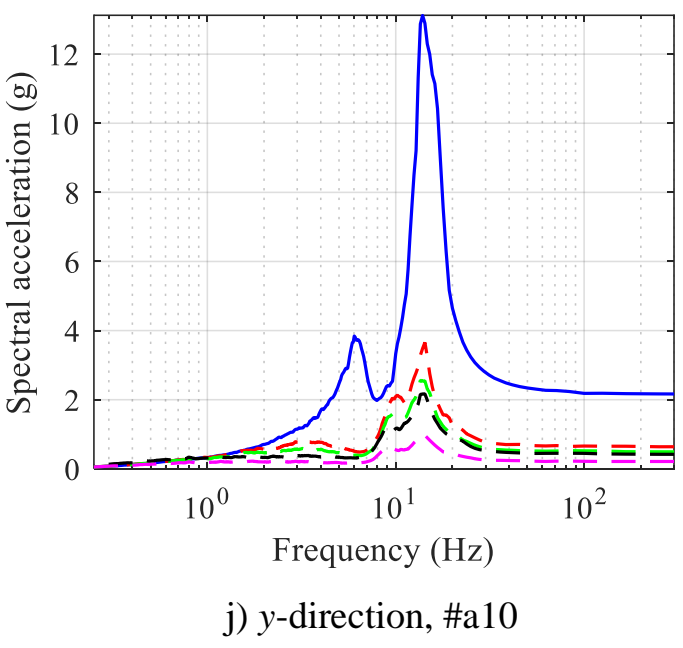

Figure A-4: $80^{\text {th }}$ percentile horizontal acceleration spectra in building \#2, PGA $=0.3 \mathrm{~g}$, all cases (cont'd) 